\title{
Theory of Work Adjustment and Student-Athletes' Transition out of Collegiate Sport
}

Jessica M. Leonard

Follow this and additional works at: https://researchrepository.wvu.edu/etd

\section{Recommended Citation}

Leonard, Jessica M., "Theory of Work Adjustment and Student-Athletes' Transition out of Collegiate Sport" (2015). Graduate Theses, Dissertations, and Problem Reports. 6060.

https://researchrepository.wvu.edu/etd/6060

This Dissertation is protected by copyright and/or related rights. It has been brought to you by the The Research Repository @ WVU with permission from the rights-holder(s). You are free to use this Dissertation in any way that is permitted by the copyright and related rights legislation that applies to your use. For other uses you must obtain permission from the rights-holder(s) directly, unless additional rights are indicated by a Creative Commons license in the record and/ or on the work itself. This Dissertation has been accepted for inclusion in WVU Graduate Theses, Dissertations, and Problem Reports collection by an authorized administrator of The Research Repository @ WVU.

For more information, please contact researchrepository@mail.wvu.edu. 


\title{
Theory of Work Adjustment and Student-Athletes' Transition out of Collegiate Sport
}

\author{
Jessica M. Leonard \\ Dissertation submitted to the \\ College of Education and Human Services \\ at West Virginia University \\ in partial fulfillment of the requirements \\ for the degree of \\ Doctor of Philosophy \\ in \\ Counseling Psychology \\ Christine J. Schimmel, Ed.D., Chair \\ James Bartee, Ph.D. \\ Jeffrey Daniels, Ph.D. \\ Monica Leppma, Ph.D. \\ Vanessa Shannon, Ph.D. \\ Department of Counseling, Rehabilitation Counseling, \\ and Counseling Psychology
}

\section{Morgantown, WV}

2014

Keywords: Theory of Work Adjustment, vocational psychology, career counseling, student-athlete, transition out of sport Copyright 2015 Jessica M. Leonard 


\section{ABSTRACT \\ Theory of Work Adjustment and Student-Athletes' Transition out of Collegiate Sport}

\section{Jessica M. Leonard}

While there are a number of person-environment fit vocational theories, Theory of Work Adjustment (TWA; Lofquist \& Dawis, 1969) distinguishes itself by emphasizing the role of the work environment, not just the individual characteristics, in order to establish "mutual responsiveness" through career transitions. One particular population found both in popular media and peer-reviewed research to have potentially troublesome transitions are student-athletes and their transition out of collegiate sport, despite having the ability to plan for it before graduation. Some researchers have used TWA for those preparing for retirement (Harper \& Shoffner, 2004; Hesketh, Griffen, \& Loh, 2011), but no research to date has examined the use of TWA's elements with student-athletes "retiring" from sport. The purpose of the study was to explore the opinions of those who work with collegiate student-athletes and gain a consensus on the importance, applicability, and potential use of core elements of TWA. A three-round modified online Delphi panel was used and included experts (those with at least 10 years) in the fields of counseling psychology, sport psychology, and academic advising for athletics. The resulting data explored what is currently being discussed and generated a collective expert opinion on the use of TWA with student-athletes indicating the usefulness of TWA with studentathletes as well as indicating responsibilities of professionals who work with student-athletes. 


\section{Acknowledgements}

I am very thankful for everyone's assistance, support, and guidance throughout this entire journey. My desire to conduct research on this topic has propelled me for years and it came true with the help of many individuals.

To my friends and colleagues here - not many people know what this journey entails and I have been blessed with a great support group who has shared in the ups and downs of completing a dissertation. You made this journey not only feasible but also fun.

To my family, you gave me strength and a solid work foundation. To my brothers, who continue to be my inspiration and my aunt, who is my source of endless advice and counsel. To my parents, who have modeled perseverance and commitment. Your never-ending source of love and support has and will continue to give me motivation and confidence to succeed, in and outside of academics.

To the faculty and staff of the Counseling, Rehabilitation Counseling, and Counseling Psychology and Sport and Exercise Psychology Departments, thank you for all of your encouragement and support. To Dr. Shannon, this study would not have taken flight without your introduction and guidance into the Delphi methodology. To Dr. Leppma, thank you for taking time to join my committee. Your impromptu meetings were extremely helpful throughout this process. To Dr. Daniels, from your classroom to our research meetings, your passion for research is contagious and I have learned many things working with you that would not be possible by reading it in a book. To Dr. Bartee, since my first year, you have pushed me to become a better student, researcher, and practitioner. Your encouragement and advice has helped me professionally and personally more than words can say. And last but certainly not least, to my chair, Dr. Schimmel. You bravely took me on as your first "chairee." You have not 
only been a consistent source of advice with my writing, but you were a rock that I could lean on during times of stress. Thank you for believing in me and in this project. 


\section{Table of Contents}

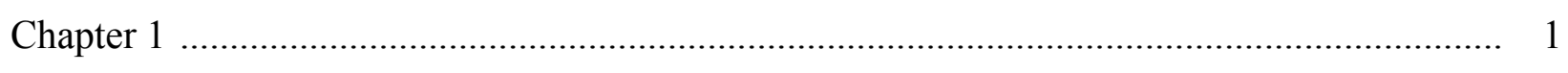

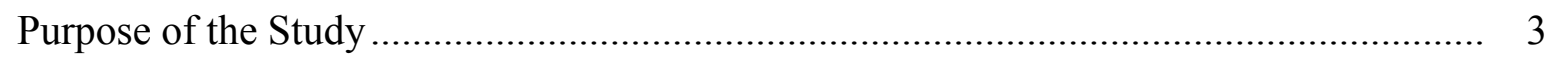

Significance of the Study ................................................................................. 4

Relevance to Counseling Psychology .......................................................................

Research Questions ........................................................................................... 4

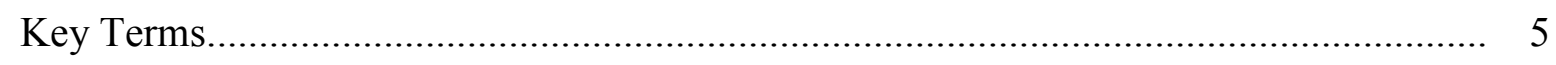

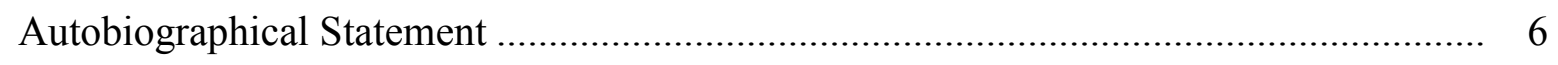

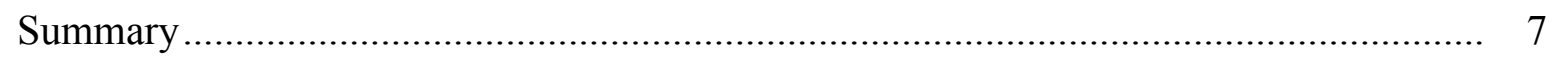

Chapter 2 Literature Review ............................................................................. 9

Vocational/Career Counseling ........................................................................... 9

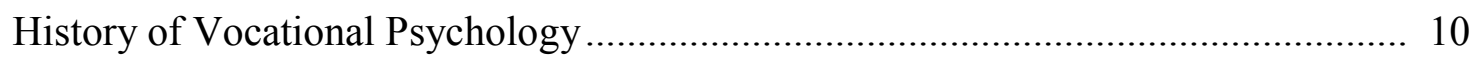

Major Theories of Vocational Psychology …................................................. 13

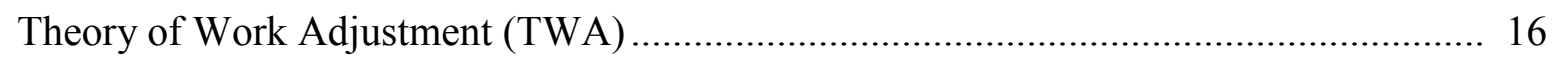

Using TWA in Retirement Counseling .......................................................... 21

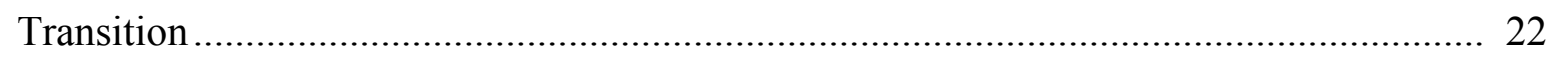

Transitions for Student-athletes ....................................................................... 24

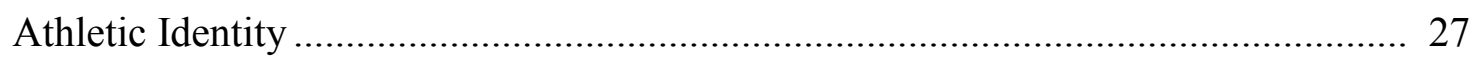

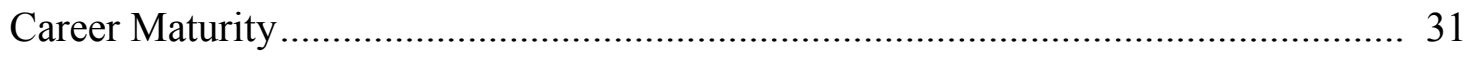

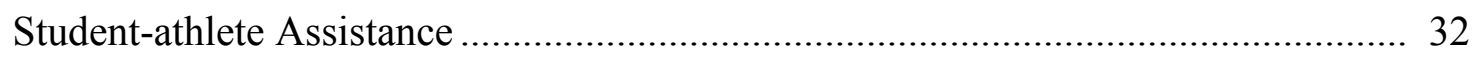

Student-athletes and Career Intervention Models ............................................ 34

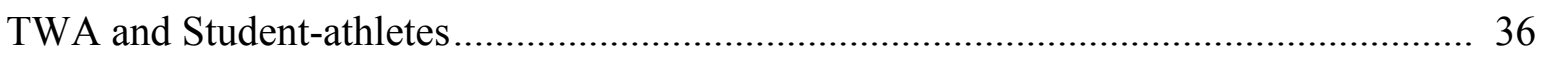

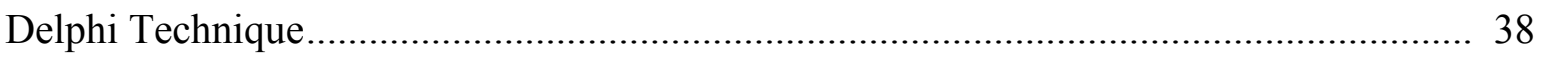


Delphi Technique used in Psychological Research ................................................. 40

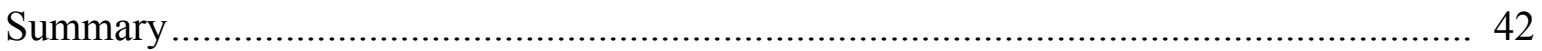

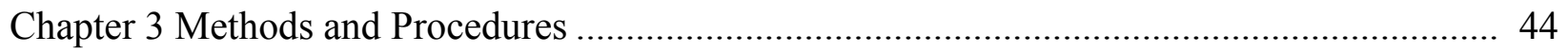

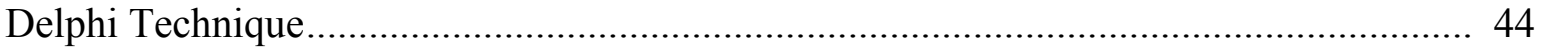

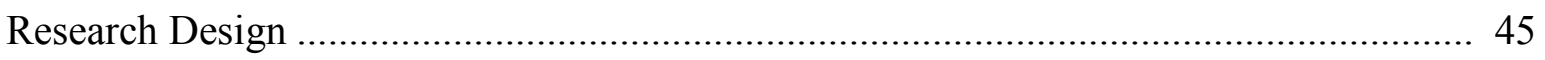

Sample and Identification of Participants .......................................................... 47

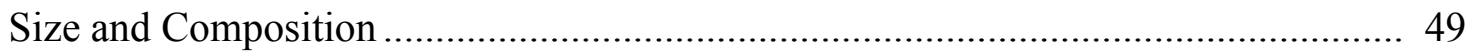

Recruitment of Participants ........................................................................... 49

Participant Demographics......................................................................... 51

Data Collection Procedures ............................................................................. 52

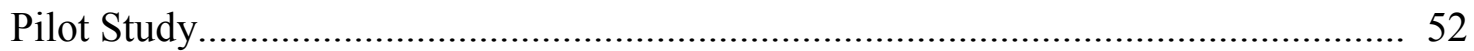

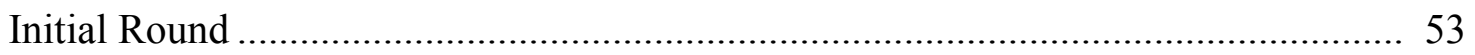

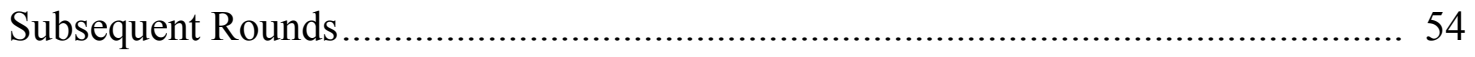

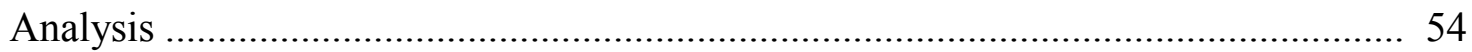

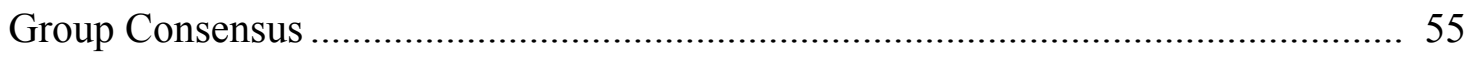

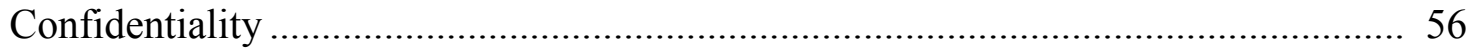

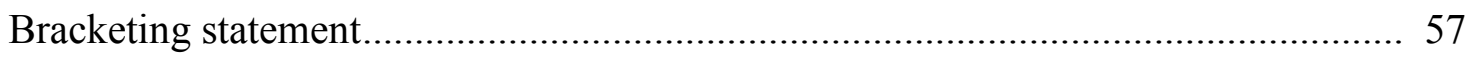

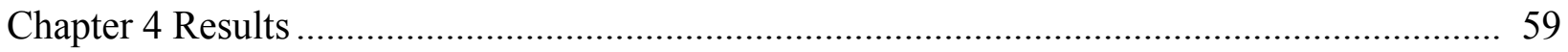

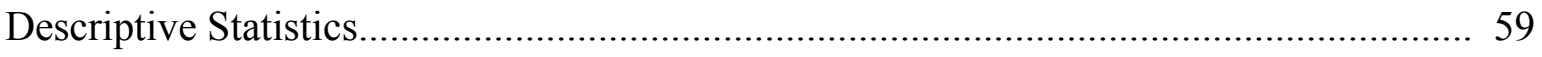

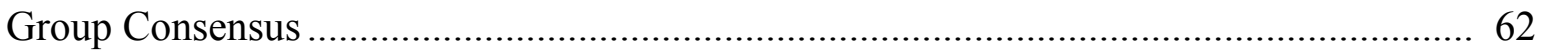

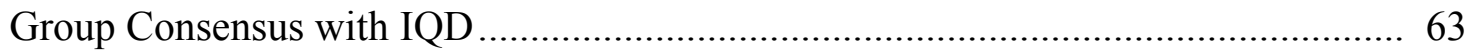

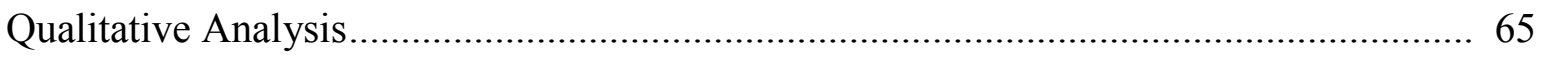

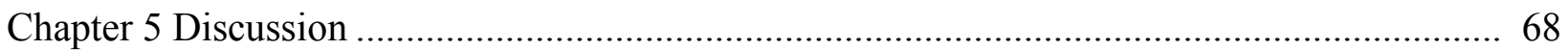


Current Discussions on Transition out of Sport....................................................... 68

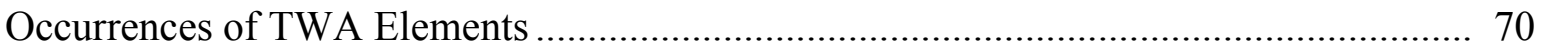

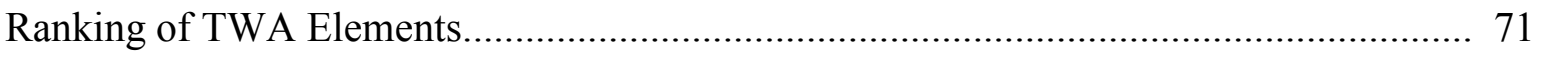

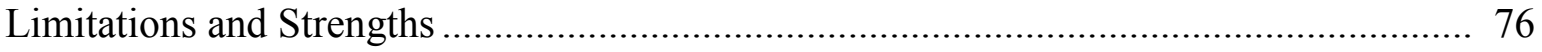

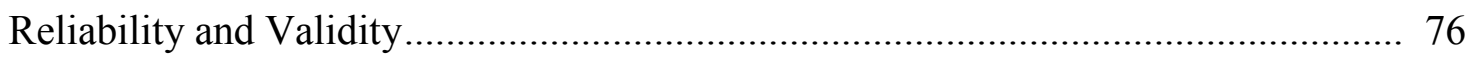

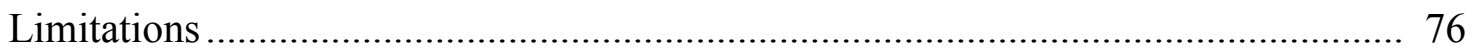

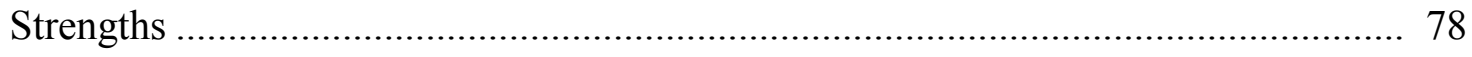

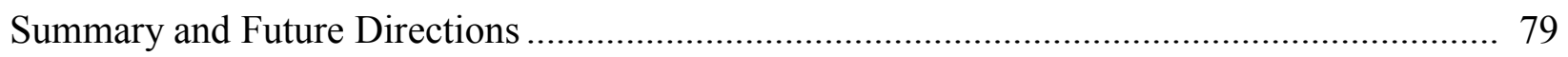

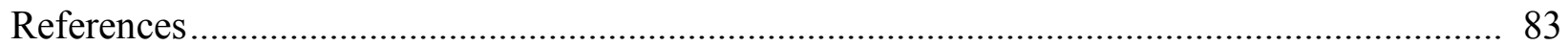

Tables

Table 1. Round 1 Descriptive Statistics................................................................ 60

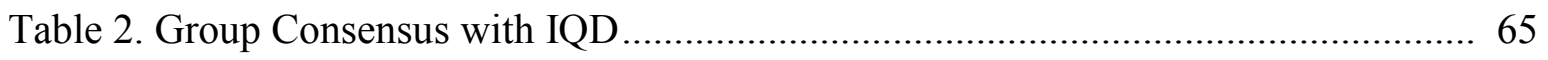

Appendixes

A. Propositions of the Theory of Work Adjustment.............................................. 96

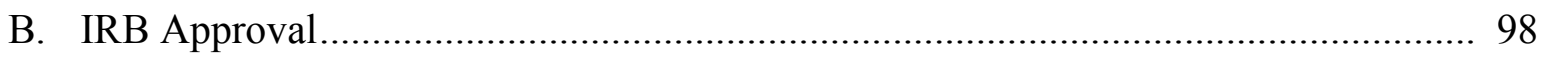

C. Permission for Recruiting Participants through Listservs..................................... 99

D. Participant Recruitment: Introductory E-mail ..................................................100

E. Participant Recruitment: Follow-up E-mail........................................................101

F. Participant Instructions for Round …...................................................... 102

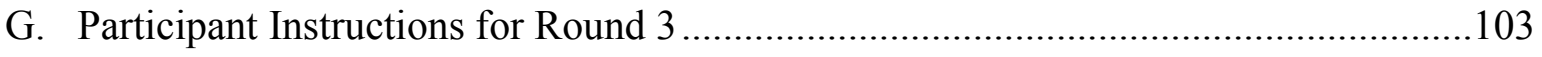

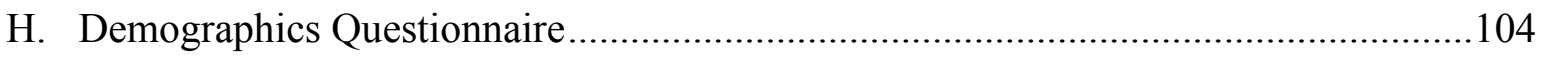

I. Round 1/Subsequent Rounds Questionnaire ..................................................105

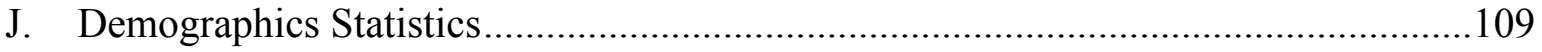




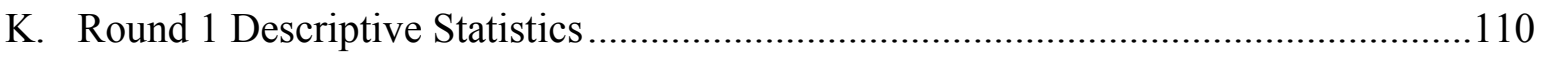

L. Statements and Anonymous Rationales for from Round …...................................112

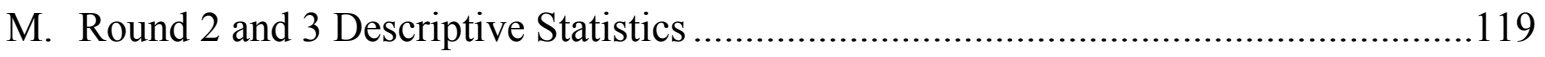

N. Qualitative Analysis of Initial Statement...............................................................121

O. Statements Categorized under TWA Elements ...................................................123 


\section{CHAPTER ONE}

There are many distinct themes that separate counseling psychology from other professional fields. One of these major themes is in the vocational field. Counseling psychologists have a history of helping others initially find a vocation or assisting them through a vocational transition that will effectively fit with their interests. There are many theories in vocational psychology, some of which address how a person can successfully choose and adapt to their vocational choice (Capuzzi \& Stauffer, 2006). Person-environment (P-E) fit theories specifically focus on the characteristics of the individual and the characteristics of the work environment (Fassinger, 2005). One of the most prominent P-E theories is the Theory of Work Adjustment (Lofquist \& Dawis, 1969; Dawis, 2005), which emphasizes the congruence of both characteristics in order to have a successful relationship.

Another theme of counseling psychology is focusing on individual's strengths and assisting them in identifying transitional skills. Transitions are complex constructs that are made up of a variety of factors, that include both inter- and intra-psychosocial factors, as well as situational factors of the event (Schlossberg, 1984). Appropriate responses to a transition occur from the interaction of many different factors. One of the more important factors is the ratio of perceived and actual resources to deficits according to Schlossberg (1984). Transitional research demonstrated that preparing and increasing resources before a transition can be beneficial for individuals to achieve a successful transition (Boerner, 2011; Chow, 2001; Goodman \& Pappas, 2000; Lally, 2006; Schlossberg, Waters, \& Goodman, 1995).

The target population for this study was individuals who work with student-athletes who are about to transition out of playing collegiate sports. Student-athletes put a significant amount of time and effort into their sport throughout their athletic career, even attaining an identity that 
encompasses their athleticism known as athletic identity (Petitipas, Brewer, \& Van Raalte, 2009). However, only a small percentage of student-athletes continue to play at a professional level and those who do, may have relatively short careers (NCAA, 2010). Therefore, student-athletes should be aware of and plan for this inevitable transition out of sport. Burnett (2010) affirmed “essential support needs to be provided to student-athletes in order for him or her to succeed in a role other than that of an active competitor" (p. 201). There has been some research that attempted to identify the patterns of athletic retirement and possible factors that can have an impact on a the nature of transitioning out of collegiate sport including high athletic identity (Brown \& Hartley, 1998; Murphy, Petitpas, \& Brewer, 1996; Webb, Nasco, Riley, \& Hendrick, 1998), career maturity level (Brown \& Hartley, 1998; Linnemeyer \& Brown, 2010; Murphy, et al., 1996), type of sport and sport competition level (Clark, 2008; Carswell, 2009; Harrison \& Lawrence, 2004; Murphy, et al., 1996). Other researchers (Carswell, 2009; Lally, 2006) studied predictors of successful transition out of sport. Lally (2006) found that proactively using coping mechanisms (i.e. awareness, education, and exploration of outside sport identities) might lead to more stable transitions out of sport.

Within a university setting, there are many people involved in assisting student-athletes in both their academic and sporting endeavors. Within most colleges and universities, there are academic support services specifically for student-athletes who are either directly responsible for a specific team or are available for the general student-athlete population. The duties of these professionals assisting the student-athletes with academic support and preparation include: class and major selection (academic advising), homework or study assistance (educational counseling), tutoring, career services, academic and vocational planning and time management (CHAMPS/LIFESKILLS instructor; Career Athlete instructor), alongside goal setting and 
anxiety reduction techniques (sport psychology consultants and counseling psychologists).

These individuals work with student-athletes on a daily basis or are available throughout the student-athletes' years of eligibility and therefore can be considered experts in the area of student-athletes' academics and vocational preparation. According to researchers, "there exists a clear need for the development of a specific methodology to evaluate student-athletes' perceptions of the transitions occurring in their sports career" (Wylleman, Alfermann, \& Lavallee, 2004, p. 17). One such way to evaluate the perceptions of student-athletes is to survey those who assist student-athletes throughout their collegiate career on what techniques they currently use and gain their opinions on the use of certain vocational theories.

\section{Purpose of the Study}

One tool that is not readily available in the literature in assisting student-athletes in transition out of sport within vocational psychology is the Theory of Work Adjustment (TWA). Within TWA, there are two main indicators of a successful work relationship: satisfaction (wellbeing of the individual) and satisfactoriness (adequate performance in the environment; Dawis, 2005). A fundamental element of TWA is the "mutual responsiveness" (Dawis, 1980) of the person and work environment in which the goal is to "achieve and maintain correspondence with each other" (Capuzzi \& Shaufer, 2006, p. 47). TWA that has been used in retirement counseling focused on the balance between the abilities and skills of the retiree and the requirements of the working environment, as well as replacing any values in the post-retirement environment that were lost from the retiree's career transition (Harper \& Shoffner, 2004; Hesketh, et al., 2011). The purpose of this dissertation was to generate a consensus of expert opinion of those who work with collegiate student-athletes with regard to the use of elements of TWA with student-athletes transitioning out of sport. 


\section{Significance of the Study}

The significance of this study was two-fold. First, there is no published research readily available in the literature on the use of TWA with the specific population of student-athletes. Hence, exploratory data from the proposed study was expected to satisfy gaps in research both in the areas of vocational psychology and in the student-athlete community. Secondly, the resulting data were expected to possibly allow further clarification for those already using TWA elements (with or without awareness), or introduce these elements for future use when working with student-athletes transitioning out of sport.

\section{Relevance to Counseling Psychology}

Vocational Psychology is one of the five foundations of counseling psychology (Gelso \& Fritz, 2001). Since the 1940s and 1950s, counseling psychologists have assisted individuals with “providing information about individual's aptitudes, abilities, and interests" and guiding individuals in choosing, adapting to, or transitioning between and out of careers (Gelso \& Fritz, 2001, p. 30). Today, counseling psychologists practice in settings in which vocational psychology can be very valuable for clients: community mental health departments, U.S. Department of Veteran's Affairs (VA), college counseling centers, and university athletic departments. Although the exact number of psychologists who work in university athletic departments is unknown, several athletic departments utilize the services of licensed professional psychologists (Voelker, 2012) who are in the position to assist college student-athletes in their transition out of sport.

\section{Research Questions}

The research questions for the study were: 
1. What is being taught to/discussed with student-athletes who are about transition out of sport?

2. Are elements of TWA being used and how often?

3. If elements of TWA are not currently being used:

a. Are they important to be used with student-athletes transitioning out of sport?

b. Are they applicable to use with student-athletes transitioning out of sport?

c. Do they have the potential to be used with student-athletes transitioning out of sport?

\section{Key Terms}

- Collegiate student-athlete - full-time college student who plays a competitive sport for his/her college/university in the National Collegiate Athletic Association (NCAA; maximum of four competitive playing years)

- NCAA - National Collegiate Athletic Association; governing body for college athletics

- Retirement - "a point of transition from an activity in which there has been a commitment of time, energy, and role identification” (Baille \& Danish, 1992, p. 77)

- $\quad$ Satisfaction - well-being of the individual (Dawis, 2005)

- $\quad$ Satisfactoriness - adequate performance in the environment (Dawis, 2005)

- Task requirements - requirements (skills, aptitudes) that are required to successfully complete a work-related task (Dawis, 2005)

- $\quad$ Tenure - length of time a worker stays with a job (Lofquist \& Dawis, 1969)

- Theory of Work Adjustment - trait-factor/person-environment interaction vocational theory that was developed by Lofquist and Dawis (1969) to anticipate and cope with 
adjustment in one's area of work. TWA emphasizes the mutual responsiveness of individual and environmental factors (Dawis, 2005).

- Skills - "repeatable behavior sequences performed in response to prescribed tasks" (Dawis, 2005, p. 12); can be sensory/perceptual, cognitive, affective, or motor/physical

- Transferable skills - specific abilities that can satisfy current task requirements that were learned in other settings (Parcover, Mettrick, Parcover, \& Griffen-Smith, 2009)

- Transition out of collegiate sport - process out of competitive play; retirement from collegiate sport

- Values - trait variables described by Dawis (2005) as being judged as important by the individual

\section{Autobiographical Statement}

According to Creswell (2008), it is important to include an autobiographical statement about the primary researcher's experiences with the chosen topic. As the author of this study, I am a former collegiate student-athlete at a Division III school and have identified as an athlete most of my life. I earned a master's degree in sport psychology where I first began to explore the topic of student-athletes' transitions. As a former collegiate student, player, and coach, I understand the demands put on student-athletes to fulfill both of their academic and sporting obligations. However, I also believe that preparation for the ultimate transition out of sport (which can occur at any age or level) is useful in order to be successful for the next stage in life; consequently, I believe it is essential to teach student-athletes about how to be successful in their transition before the transition occurs. 


\section{Summary}

A successful transition has been defined by Schlossberg (1981) as a positive perception of the individual's ratio of resources over deficits, with preparation and attitude towards transition being an important factor in creating a positive transition. Despite this recommendation of preparation, researchers have found that student-athletes who have transitioned out of collegiate sport have experienced a variety of psychological responses such as grief and loss, feelings of failure, depression, and isolation (Blinde \& Stratta, 1992; McKnight, et al., 2009; Petitipas, et al., 2009; Wooten, 2005), in addition to having high athletic identities (Brown \& Hartley, 1998; Murphy et al., 1996; Webb et al., 1998), and lower levels of career maturity (Brown \& Hartley, 1998; Linnemeyer \& Brown, 2010; Murphy et al., 1996). Although these responses are not pervasive among those who transition out of sport, it has been found in research to be a noteworthy concern, and one that may be addressed by preparing studentathletes before they transition out of sport.

Researchers (Harper \& Schoffner, 2004; Hesketh et al., 2011) have addressed using the vocational theory, TWA, in retirement counseling by proactively identifying skills and abilities of the individual, requirements of the environment, and the losses of those requirements after retirement. In other words, they addressed the importance of matching satisfaction and satisfactoriness (two key elements of TWA that have shown to be predictive of tenure or prolonged stay in an environment; Dawis, 1980). Once those losses are recognized, they can be used to identify an appropriate post-retirement environment in order to balance the person and environment fit again. Overall it was hypothesized that understanding and employing a theory such as TWA, and its elements, may be a great resource for those working with student-athletes before they begin to transition out of sport. However, it is unknown what is being taught with 
regards to athletic transition out of collegiate sport and whether the elements of TWA are currently being utilized with collegiate student-athletes. The purpose of this dissertation was to generate a consensus of expert opinion of those who work with collegiate student-athletes with regard to the potential use of TWA with student-athletes transitioning out of sport. 


\section{CHAPTER TWO \\ LITERATURE REVIEW}

\section{Vocational Psychology/Career Counseling}

There are different working definitions of the term used when describing vocational psychology. Work has been generally defined as a "central human activity that may be paid or unpaid and that is designed to fulfill tasks of daily living and ensure survival" (Miller \& McWhirter, 2006, p. 3). The definition of career has been more troublesome to define and has been described as a "lifestyle concept" that includes one's lifelong course of events, multiple roles, and the "totality of work in a lifetime" (Niles \& Harris-Bowlsbey, 2002, p. 7). Sharf (2002) simply defined career as "how individuals see themselves in relationship to what they do"

(p. 3). Vocation is simply defined as the inclusion of both work and career (Miller \& McWhirter, 2006). The field of vocational psychology includes numerous theories that examine vocational choice, work adjustment, and career counseling.

Vocational choice is described as complex due to the content of the choice and the decision-making process which is influenced by developmental perspectives of life-cycle patterns, the context of the individual's lived experience, and the role of interpersonal relationships (Walsh \& Savickas, 2005). Research on work adjustment have focused on the person-environment fit in the context of personality traits, goal setting, and several variables of an organization (Walsh \& Savickas, 2005). Career counseling scholars continue to generate different topics of research including the integration of diverse career assessments and models that include a broader range of major life transitions, among other variables (Walsh \& Savickas, 2005). In general, those who work as career counselors or vocational psychologists assist others 
with career concerns, including making career choices (job searching), coping with career transitions, and coping with job-related stress (Niles \& Harris-Bowlsbey, 2002).

Within vocational psychology, there are three main approaches to theories and their application: (a) developmental, (b) preventative, and (c) remedial. Developmental theories focus on how a person can grow from work, preventative theories refer to learning about oneself and a better fit for a career; and remedial theories refer to ameliorating a problem after it arises, such as sudden job loss. Using preventative theories and techniques allows the client to anticipate and possibly forestall any difficulties that might arise (Gelso \& Fritz, 2001), as well as "prevent and minimize social and emotional deprivations in retirement” (Gorbett, 1985, p. 288). Taking a proactive approach to any form of counseling reduces the need to remediate problems that could have been prevented, such as with anticipated career transitions (Parcover et al., 2009). In sum, proactive approaches reflect the element of preparation that is helpful for successful transitions

History of vocational psychology. Several scholars (Cappuzzi \& Staufer, 2006; Miller \& McWhirter; 2006) explained the history of vocational psychology in the United States in eight stages (as taken from the works of Pope, 2000 and Aubrey, 1977). The first stage stretched from 1890-1914. During this time, the American Industrial Revolution had an intense influence on consequent economic and demographic changes in the U.S. particularly due to shifts from agricultural lifestyle to urbanization (increase population in metropolitan areas; Miller \& McWhirter; 2006). The increase of immigrants and changes in work skills sparked a need for vocational guidance because individuals were now in the position to choose a career instead of being born into one. For example, many individuals from generations of families who lived and worked on the family farm or business moved to cities during the Industrial Revolution to find work on their own (Miller \& McWhirter, 2006). 
One of the most influential men of the Vocational Guidance Movement, Frank Parsons (Capuzzi \& Staufer, 2006), made his contributions to vocational psychology in the early years of the $20^{\text {th }}$ century. Parsons' emphasis on assessment tools "had a major influence on subsequent development of vocational assessments" (Miller \& McWhirter, 2006, p. 8). He has been recognized for numerous contributions to the field of vocational psychology, including "developing steps to be followed in the vocational progress of an individual," training other counselors, and using scientific tools of the time (Brewer, 1942, as quoted by Niles \& HarrisBowlsbey, 2002, p. 8).

The second stage occurred during 1914-1929. World War I provided vocational challenges for returning soldiers, especially wounded warriors and their families (Miller \& McWhirter, 2006). The U.S. Army also began using vocational assessments (1917 Army Alpha and Beta tests) as a quick method to match soldiers to positions in which their skills and aptitudes would be successfully employed (Cappuzzi \& Staufer, 2006; Miller \& McWhirter; 2006). The field of psychometrics (designing assessment tools) was also expanding at this time and being used to develop and validate vocational instruments that were being used in public schools (Cappuzzi \& Staufer, 2006).

The years following the Great Depression (1929-1939) comprised the third stage. At this time, unemployment rates were extremely high and the U.S. Government (The New Deal) became more involved with research that focused on developing vocational assessments (Miller \& McWhirter; 2006). In 1939, E.G. Williamson published How to Counsel Students, which included a six-step process specific for career counseling of students (Niles \& Harris-Bowlsbey, 2002). Also in 1939, the U.S. Government created the Dictionary of Occupational Titles (DOT), a comprehensive listing of vocational fields that provided extensive information about 
requirements, training, tasks, and occupational activities for different types of vocations (Miller $\&$ McWhirter; 2006). The creation of the DOT generated awareness of the importance of vocational psychology as it became the first "common organizational framework for occupations" on a national level (Capuzzi \& Staufer, 2006, p. 13).

Stage four in the history of vocational psychology occurred during the years of World War II and beyond (1940-1957). World War II required continued military assessments for current soldiers and for veterans, in addition to vocational assessments specifically to address the increase of women in the workplace (Capuzzi \& Staufer, 2006; Miller \& McWhirter, 2006). After World War II, the GI Bill was passed providing funding for college or job training for veterans, which increased the need for professional career counseling to assist veterans in finding and transitioning into new work (Capuzzi \& Staufer, 2006). Additionally, the national zeitgeist reflected a change (Capuzzi \& Staufer, 2006); "personal freedom and autonomy were dominant national themes" (Miller \& McWhirter, 2006, p. 14) which influenced individuals' desire to choose their own careers. Another important event of this time was the creation of Counseling Psychology, which was at first given the title of Counseling and Guidance, and consequently “subsumed vocational guidance into psychology” (Miller \& McWhirter, 2006, p. 16).

Stage five encompassed the years of 1958-1970 which was influenced by major political and worldwide events. The Space Race of the 1950s and 1960s influenced the use of vocational guidance in schools to enhance the talent of the youth and prove educational and scientific domination of the U.S. (Miller \& McWhirter, 2006). This push was influenced by the National Defense Education Act of 1958 which provided funding and training to those who provide education to youth as well as the creation of the National Association of School Psychology in 1969 (Capuzzi \& Staufer, 2006). 
The latter stages were divided between the remaining decades of the $20^{\text {th }}$ century. From 1970-1979, vocational psychology and research was influenced by prominent theories of the time: Bandura’s Social Learning Theory and self-efficacy concept $(1969,1970)$, Gysbers and Moore's Life Career Development Theory (1973) and Bronfenbrenner's Ecological Model of Human Development (1979; Miller \& McWhirter, 2006). The 1980s included research that recognized the growing diversity of the U.S. population and increasing need of technological skills in the workforce (Capuzzi \& Staufer, 2006; Miller \& McWhirter, 2006). Career psychology for women was also an expanding area of research and development as more women joined the workforce and were involved in dual-career marriages (Miller \& McWhirter, 2006). The 1990s diversity vocational research continued, which focused on multicultural aspects of the workplace (discrimination at work based on race and sexual orientation; Miller \& McWhirter, 2006). Miller and McWhirter (2006) suggested that future vocational psychology research should continue to focus on the ongoing shifting demographics within the workplace, e.g. individuals are beginning careers younger and retiring at older ages while diversity continues to expand. Additionally, individuals are experiencing many careers within a lifespan, not just one, which implies several career transitions. Therefore, scholars (Capuzzi \& Staufer, 2006; Miller \& McWhirter, 2006) also suggested focusing on existential and lifespan theories of career development. Overall, vocational psychology has been influenced by political and worldwide events of the time and continues to be an important area for current and future research and practice.

Major theories of vocational psychology. There are many theories of vocational psychology, usually grouped by three overarching themes: (a) trait-and-factor theories (which later influenced the person-environment correspondence theory), (b) vocational 
choice/personality theories, and (c) developmental theories. The following includes a summary of the main theories in each category.

Trait-factor theory. The trait-factor theory developed by Frank Parsons (1909) is described in a three-step process: (a) identify a clear understanding of oneself (self-concept), (b) survey occupations and develop knowledge of requirements and prospects of different types of work, (c) match the individual with the occupation. His work became advantageous to many vocational programs, including the Department of Veterans Affairs and colleges/universities because assessments were easily administered to match the individual to an occupation (Capuzzi \& Staufer, 2006; Niles \& Harris-Bowlsbey, 2002). Although Parsons' major contribution to the field of vocational psychology is the advantage of quick assessments, Parsons proposed that the process of career decisions be used in a traditional counseling session in order to understand the client better (Niles \& Harris-Bowlsbey, 2002).

One of the main assumptions of the trait-factor theory that separates it from other theories is that "occupational choice is a single, point-in-time event that is made through a cognitive decision making process" (Niles \& Harris-Bowlsbey, 2002, p. 10). Trait-and-factor theories have been criticized as static; they fail to focus on how interests, values, skills, and personalities change throughout a person's developmental history (Sharf, 1996). Summarily, trait-factor theories have been viewed as limiting due to its single factor emphasis.

Holland's personality types. John Holland (1959) proposed a theory that emphasized vocational personalities and work environments; he suggested that individuals select work because of the potential of satisfying personal needs that can be categorized by personality type (Osipow, 1983). Holland (1985) described six personality types: realistic, investigative, artistic, social, enterprising, and conventional, in addition to matching six model environments which are 
portrayed in Holland's hexagon model. Each personality type is comprised of unique characteristics, and these characteristics can be advantageous for job satisfaction in certain work environments. Holland (1985) suggested that vocational choice is an expression of personality, which can be assessed and matched through the use of personality interest measures. Past research supports the relationship of personality traits but researchers have mixed conclusions on the use of the hexagon model for conceptualization purposes (Capuzzi \& Staufer, 2006; Shoffner, 2006). Holland's model has also been criticized for not addressing cultural aspects of career matching (Capuzzi \& Staufer, 2006) but has been praised for its simplicity and practical use (Shoffner, 2006). (For a more detailed description of each personality trait, please refer to Holland, 1985).

\section{Super's theory of vocational development. Donald Super's Theory of Vocational} Development, which was initially proposed in 1953 and updated in 1996, is considered a comprehensive developmental theory (Capuzzi \& Stauffer, 2006). Super's (1996) theory describes vocational development in conjunction with life stages with consequent tasks and more recently is visualized as an archway model with nine major life roles. Two main assumptions of this theory are: (a) career development is a lifelong process and (b) self-concept is shaped as each stage in life is experienced (Shoffner, 2006). Super's relation of self-concept and personal meaning to career development has been deemed one of his distinctive contributions (Shoffner, 2006) and has been described, "to greatly influence the way we envision the career" (Capuzzi \& Staufer, 2006, p. 49). His model includes not only personal factors and psychological characteristics, but also societal factors such as economic resources, community, school, family, etc. Super (1996) explained, "success in adapting to each developmental task results in effective 
functioning and lays the groundwork for mastering the next task along the developmental continuum" (p. 131). (For a more detailed description of his model, please refer to Super, 1996).

\section{The Theory of Work Adjustment (TWA)}

Theory of Work Adjustment (Lofquist \& Dawis, 1969) developed from a trait-factor approach. It is a preventative/proactive theory that can be used to anticipate and cope with adjustment, or any type of general change or modification, in one's area of work. TWA was created out of vocational rehabilitation research to determine how effective rehabilitation programs were at matching occupations for individuals with disability (Lofquist \& Dawis, 1969). The research began out of the Work Adjustment Project that was conducted at the University of Minnesota throughout the 1960s and 1970s (Dawis, 1980). Although there are many vocational theories that include fundamental factors of the person-environment fit (the match of individual skills and abilities to the working environment), TWA emphasizes the role of the environment and matching its requirements to the characteristics of the individual (Dawis, 2005). Dawis (2005) recently described TWA as a person-environment correspondence theory as well as a person-environment interaction theory. The name of the theory was updated to PersonEnvironment Correspondence (PEC) in 1991 to demonstrate the "fit of a person for a particular work environment” (Capuzzi \& Staufer, 2006, p. 46) instead of focusing solely on work adjustment. TWA and PEC share a theoretical foundation, which emphasizes the dynamic interplay of influences between the individual and the work environment (Capuzzi \& Staufer, 2006; Shoffner, 2006). The goal of TWA is congruence of the individual and environmental factors; "interaction between individual and environment comes about because both parties have requirements that potentially can be fulfilled by the other [otherwise known as 'needs']" (Dawis, 1980, p. 268). This concept regarding needs of both the individual and work environment that 
can be mutually fulfilled is the foundation of TWA and described as "mutual responsiveness" (Dawis, 1980, p. 268).

Within TWA, there are two main indicators of a successful work relationship: satisfaction (well-being of the individual) and satisfactoriness (adequate performance in the environment) (Dawis, 2005). Satisfaction comes from a combination of interests, needs, and values as well as reinforcers from self, others, and the environment (Hesketh \& Griffin, 2005). Reinforcers maintain or increase one's level of action and in turn can satisfy the individual (Dawis, 1980). Satisfactoriness is the relationship of skills and abilities that an individual can do and the requirements of the environment (Hesketh \& Griffin, 2005). Skills are specific abilities that can satisfy the work environment requirements (Dawis, 1980). Therefore, the individual has needs and skills that parallel to the task requirements and reinforcers of the work environment. Overall work adjustment is the product of both satisfaction and satisfactoriness or what Lofquist and Dawis (1969) have termed tenure, the length of time a worker stays with a job. According to Dawis (1980), workers will continue performing their job if they are at least minimally satisfied or will leave if they feel dissatisfied. On the other hand, an employer will keep workers if their work is satisfactory or else they will be terminated. Tenure is the absence of both dissatisfaction of the worker and the work environment/employer (Dawis, 1980).

Updates to TWA. The authors of TWA (Dawis and Lofquist) continued to produce research and refine their work and updated the principles of the theory (as previously mentioned with the update of PEC; Dawis, 2005). TWA focuses on "adjustment to work" while the updated PEC "focuses on a fit of a person for a particular work environment" (Shoffner, 2006, p. 46). While the foundation of the two theories remains the same, the basic terms have been updated. For instance, the two terms on the person side of the equation of needs and skills have been 
replaced by values and abilities, respectively (Dawis, 2005). For terms that relate to the work environment, reinforcer factors and abilities requirements have replaced reinforcers and task requirements, respectively (Dawis, 2005). Therefore, the new PEC factors, using $\mathrm{P}$ to represent person and E to represent environment are: (a) the correspondence of P's values to E's reinforcer's factors, and (b) the correspondence of P's abilities to E's ability requirements (Dawis, 2005). Dawis and Lofquist constructed detailed propositions of the TWA that were updated in 2005 (Appendix A).

Dawis (2005) described other factors as moderators for success including the construct "personality style" which consists of four variables: (a) celerity or quickness of response, (b) pace or intensity of response, (c) rhythm or pattern of response, and (d) endurance or persistence (length of time) of response. Environmental style was also added as a construct to correspond with variables of one's personality style. Another style that was added was "adjustment style" which also consists of four variables: (a) flexibility, or the level of discorrespondence tolerated before engaging in adjustment behavior, (b) activeness, or attempts by $\mathrm{P}$ to adjust $\mathrm{E}$ to reduce discorrespondence, (c) reactiveness, or attempts by $\mathrm{P}$ to adjust him/herself to reduce discorrespondence, and (d) perseverance, or the length of time in attempting to adjust P or E behavior before giving up (Dawis, 2005). According to Dawis (2005), recognition of the type of adjustment style could be beneficial for those who assist workers who are trying to achieve tenure because these behavior tendencies become more stable over time. All of the previously mentioned styles influence an ideal "work culture" that both influences and is influenced by the individual and the environment (Capuzzi \& Stauffer, 2006) and are beneficial to know when working with an individual attempting to find a person-environment fit with his/her work environment. 
TWA as a predictive model. In TWA, satisfaction and satisfactoriness produce tenure, and are products of person-environment interaction; therefore, the person-environment interaction should be used as predictive factors of tenure or length of stay on a job. In their attempt to measure the predictive nature of the person-environment interaction Dawis and Lofquist (1980) developed the construct of "correspondence." Correspondence has two connotations: (a) "mutual responsiveness" of the individual to the environment and vice versa, and (b) how well the person and environment "match-up." In summary, "satisfaction can be predicted from the correspondence of the environment's reinforcer systems to the individual's needs, and the satisfactoriness can be predicted from the correspondence of an individual's skills to the environment's task or skill requirements" (Dawis, 1980, p. 269). TWA and PEC are generally trait-factor models, "however the important difference is that [TWA] assumes that both the individual and the work environment are subject to change and will influence each other (Capuzzi \& Staufer, 2006, p. 47). Most research conducted on TWA supports the relationship between satisfaction and satisfactoriness and the prediction of tenure (Bizot \& Goldman, 1993; Hesketh, McLachlan \& Gardner, 1992; Shoffner, 2006). Other strengths of the theory are its strong research foundation, empirical support, and adaptability to various populations (Shoffner, 2006). However, some concepts and relationships are difficult to conceptualize both in theory and in research, when compared to other career development theories (e.g., Holland's Personality Types; Capuzzi \& Stauffer, 2006; Shoffner, 2006). However, Capuzzi and Stauffer (2006) stated that the concepts of PEC (as compared to TWA) may be less complicated for clients and practitioners to conceptualize, although no known studies have attempted to demonstrate this hypothesis. 
According to Hesketh and Griffin (2005), TWA is "the best tradition of an empirically testable and applicable [vocational] theory" (p. 245) because of several principles: (a) sophisticated simplicity, (b) symmetry, (c) emphasis on structure and change process, (d) testability and measurement, (e) comprehensiveness, (f) generality, and (g) grounding in learning theory concepts. Succinctly, TWA is inclusive with a scientific foundation, generalizable, measurable, and easily explained. However, one limitation of TWA is that it does not provide specific information on career matching once appropriate elements are congruent (Harper \& Shoffner, 2004). There is no specific TWA listing of jobs and requirements that can be used once the individual identifies elements of satisfaction and satisfactoriness.

Dawis (2005) himself recognized the limitations of TWA. He stated that the predictability of the model could help individuals identify work possibilities that will likely have a person-environment fit that may end in the goal of tenure. However, "the predictive model brings no account of the work adjustment process - how the person and environment achieve correspondence when it is lacking or regain it when it is lost" (Dawis, 2005, p. 8). The model was constructed to explain how correspondence can be matched through person-environment interactions and can be helpful for those attempting to explore how a work environment may "fit" for them.

The following is a summary of the basic components of TWA: (a) each individual has a unique set of abilities; (b) each work environment requires a specific set of abilities; (c) each individual has a unique set of values; (d) each work environment has specific reinforcer factors. Matching abilities to ability requirements creates satisfaction while matching values with reinforcement factors achieves satisfactoriness. High rates of satisfaction and satisfactoriness are predicted to produce tenure or the duration of stay in a work environment. 


\section{Using TWA in retirement counseling}

Scholars have applied TWA as a comprehensive vocational theory that focused on adjustment factors with various populations and circumstances (Capuzzi \& Stauffer, 2006) including transition out of work or retirement (Harper \& Shoffner, 2004; Hesketh et al., 2011). Two sets of researchers offered their own recommendations for using TWA for retirement; Hesketh et al. (2011) offered a modified version of TWA to use with ageing clients while Harper and Shoffner (2004) suggested ways in which TWA may traditionally be used in any type of retirement.

Hesketh et al. (2011) proposed a framework for retirement transition based on TWA entitled Retirement Transition Adjustment Framework (RTAF). The authors offered tentative ideas for the adjusted framework specifically to work with ageing clients, including a change from the goal of tenure to "positive ageing" (Hesketh et al., 2011, p. 305). The authors also modified satisfactoriness of the environment factors to "coping performance" which can be thought of as behaviors involved in managing the performance requirements of retirement and ageing (such as managing retirement finances, fitness, and changes in social interactions); Hesketh et al., 2011, p. 305). They proposed that the predictors for correspondence between current abilities and needs would be subjective longevity, personality/adaptability, self-efficacy, and demographic variables, while the correspondence between required abilities and reinforcers would be both proactive and reactive adjustment behaviors (Hesketh et al., 2011). The researchers (Hesket et al., 2001) believe RTAF has potential to become a solid theory but they also admitted that further work will need to be completed "including developments in deep computing, visualization, statistical analysis skills as well as deep psychological theorizing" (p. 
312). Overall, this proposed framework specifically for ageing clients necessitates further development.

When applying the traditional model of TWA to general retirement counseling, Harper and Shoffner (2004) explained the concepts of a pre-retirement environment and a postretirement environment. In order for a successful transition into retirement, there must be an "understanding of the elements of the individual's work environment that would be lost as a result of retirement [in order to] create a career plan that identifies suitable replacements for the losses" (Harper \& Shoffner, 2004, p. 274). In other words, in addition to understanding satisfactoriness factors (skills and abilities), retirees should also be able to identify the satisfaction elements in their pre-retirement work environment that would be lost in the transition in order to be able to replace them in the new post-retirement environment (such as ability requirements, reinforcer traits, and work environment styles; Harper \& Schoffner, 2004). This proactive focus on retirement allowed for adequate planning to create a satisfying retirement environment to accommodate any loss in needs or values through the transition away from a prior career or job. Harper and Shoffner (2004) described it as finding the "post-retirement satisfaction in a non-working environment" (p. 275). Both adaptations of TWA for retirement counseling accentuate the preventative aspect of vocational theories and TWA's usefulness to prepare and assist individuals for a transition into retirement.

\section{Transition}

Retirement, or transition out of career, occurs at any age, not just in latter stages of life. Retirement is "a point of transition from an activity in which there has been a commitment of time and energy and role identification" (Baille \& Danish, 1992, p. 77). Commonly, a transition is defined as an "event or nonevent in which there is a change of assumptions about self and 
world" (Schlossberg, 1981, p. 5). Furthermore, transitions are "not discrete but are processes that commence when individuals begin to anticipate them and continue through their occurrence until the post-transition aftermath has been determined" (Stambulova \& Alfermann, 2007, p. 289).

Several types of models have described the transition process and responses to transitions; some are linked to chronological age, others to life stages, while others describe transitions being similar in youth and more diverse throughout the lifespan (Schlossberg, 1984). Schlossberg (1984), a prominent scholar on general transitions, created a model that included three main categories to human adaptation: characteristics of the transition, the person, and the environment. The model, later revised by Schlossberg et al. (1995), can be used as a less complicated guide for the individual and helping professionals in deciphering the ratio of personal resources to deficits by understanding and preparing for the Four S's of coping: (a) situation, (b) self, (c) support, and (d) strategies. For a favorable outcome, the ratio should be balanced, or even favored towards resources. Resources include any type of beneficial knowledge, or assistance from people or things - anything that can be used for preparation of the upcoming event (Schlossberg, 1981; Schlossberg, et al., 1995). According to this model, appropriate responses to transitions are based on a healthy level of resources, as well as a positive perception of the event (Schlossberg et al., 1995).

A career transition can be viewed as being either an end or a beginning - an end of an identity or a new chance to explore and change an identity (Petitpas, et al., 2009). Overall, Schlossberg (1984) affirmed that it is not the transition itself, but the perception of the event or nonevent that factors into a successful response. Therefore, one's attitude regarding preparation for the transition can be learned in order to experience a successful response. 


\section{Transitions for Student-Athletes}

Schlossberg's (1984) multidimensional model comprehensively describes the process of responding to transitions in general; however, it does not include specific factors for studentathletes' inevitable transition out of sport (Petitipas, et al., 2009). Although sport is a popular activity among many children, the number of student-athletes decreases as the competitive level increases (i.e., there are fewer student-athletes competing at the collegiate level than the high school level, and there are fewer elite athletes than collegiate student-athletes). The National College Athletic Association (NCAA, 2010) conducted a study that estimated the number of high school and college student-athletes that would play at the professional level. The statistics revealed that less than $1 \%(.03-.32 \%)$ of high school student-athletes and on average around $2 \%$ (.09-3.8\%) of collegiate student-athletes will play at the elite level. (These statistics were based on the 2010 estimated sample rate of student-athletes in men's and women's basketball, men's ice hockey, and football; baseball's statistics were considered an outlier and not included in these results.) Although the rate of becoming a professional athlete is extremely low, Petitpas et al. (2009) emphasized an alarming concern in the gap between student-athletes' aspiration level and level of athletic ability. Beamon and Bell (2002) found that $41-84 \%$ of male football Division I collegiate players reported that they expected to play at the professional level (the authors believed the large variation in the data is due to an uncontrolled variable of race, with more African-American players expecting to compete professionally). The authors stated that many young male student-athletes continue to have expectations of competing professionally "despite overwhelming evidence to the contrary" (Beamon \& Bell, 2002, p. 179). According to this study, approximately half to over three-fourths of the participants believed that they would continue to play competitive sports after graduation when in fact the overwhelming majority of student- 
athletes do not continue to play sports professionally. It is hypothesized that this misconception may affect the preparation or under-preparation of these particular student-athletes whose aspirations of competing at the next level of competition may not be a reality.

Despite the inevitability of this role exit, student-athletes do not respond to this event in an identical manner. The mode of the exit has an impact on the transitional response since transition out of sport may be due to several different factors. Unanticipated factors have included career-ending injury, being unsuccessful as a competitor (being cut from a team), or the decline of physical ability due to age (Blinde \& Stratta, 1992; Burnett, 2010; Taylor \& Oglive, 1994). Other than unanticipated events, there are transitions out of sport that can be planned for, although not necessarily desired, such as graduation from school.

The range of the reactions to transitioning out of sport varies. Some individuals have coped extremely well, welcoming the change as an opportunity and liberating experience while others likened the experience to a "social death" and described the transition similarly to KublerRoss's stages of grief and loss (Blinde \& Stratta, 1992; Petitipas et al., 2009). Other extreme psychological adjustment difficulties included feelings of failure, depression, disillusionment, and isolation (Blinde \& Stratta, 1992; McKnight et al., 2009). Participants in Kleiber and Brock's (1992) study suffered career-ending injuries and experienced a "disruption in [their] life's narrative" (p. 74) in addition to lower life satisfaction and lower self-esteem. Wooten (2005) reviewed the use of Emotional Freedom Technique as a counseling intervention by emphasizing and focusing on the loss and grief from sport transition. Blinde and Stratta (1992) stated that these dysfunctional feelings are extreme and most individuals exhibit more mild responses. An ongoing topic for researchers may be to identify the situational or individual differences that cause distinctive responses across similar transitions. 
Acquiring specific knowledge about individualized transitions has been difficult for some researchers because of the reluctance of many student-athletes to speak of the end of their sporting career. Student-athletes have been resistant to counseling because of the emphasis on feeling over action and having to talk about weaknesses (Birky, 2007; Parcover et al., 2009). Helping professionals who have the opportunity to assist student-athletes may need to overcome barriers to counseling within the athletic department in order to successfully work with them. For example, Watson (2003) stated several challenges of counseling student-athletes including: reluctance for student-athletes to seek out mental health services due to the social stigma of asking for help and the perception of student-athletes being independent and self-sufficient. Additional barriers possibly include attempting to work with self-sustaining athletic departments who are unwelcoming to outside influence, student-athletes who are unaware of other services on campus and/or who have a strong time commitment to team and sport with little time or effort left for seeking counseling (Watson, 2003).

Scholars also pointed out that it is unlikely that student-athletes will seek out career counseling centers on their own without the prompt of a coach or other sport leader (Martens \& Lee, 1998). Another potential hurdle identified by researchers is that male student-athletes are hesitant to speak to career counselors because discussing career plans outside of sport may bring into question their skills and abilities as performers (Murphy et al., 1996). (Since research on student-athletes is mainly conducted on revenue-producing sporting athletes, who tend to be males, a conclusion cannot be deduced at this time regarding female athletes' attitude or non revenue-producing student-athletes towards career counseling.) This barrier reflects the earlier mentioned gap of student-athletes' athletic aspiration and ability. 
Despite these difficulties, numerous factors have been studied and identified as important elements during the period of transitioning out of sport. Specifically, research demonstrated that planning for the upcoming change (Lally, 2006; McKnight et al., 2009; Torregrosa, Boixados, Valiente, \& Cruz, 2004), having good social support (Blinde \& Stratta, 1992; Gorbett, 1984; McKnight et al., 2009; Schlossberg, 1984; Stambulova \& Alferman, 2007), and having similar past experiences (Stambulova \& Alferman, 2007) may lead to healthy responses with any type of transition. Lally (2006) found that those student-athletes who "anticipated disrupted identities upon retirement... and who employed several coping strategies... precluded a major identity crisis or confusion upon and following athletic retirement” (p. 85). Although the qualitative study only included eight participants, Lally (2006) collected data at three discrete points throughout the transition process in order to gain a comprehensive look at those participants. While it is difficult to describe the exact process student-athletes experience, acquiring knowledge of the general trends can help student-athletes, and those who assist them, understand and possibly predict certain patterns of behavior (Petitpas et al., 2009).

Athletic identity. One of the most commonly researched barriers to successful transitions for student-athletes is their exclusive athletic identity (Petitpas et al., 2009). This identity most likely forms in early childhood and is described as "early and enduring" (Baille \& Danish, 1992). The time and commitment that is put into sports, especially when athletes begin at a young age, increases their exclusive, strong athletic identity (Sparkes, 1998). Studentathletes at any age may base their self-esteem on their sport performance (Baille \& Danish, 1992; Sparkes, 1998); how they perform on the field, court, etc., reflects how they feel about and define themselves (Beamon, 2012). Researchers agreed that student-athletes, especially those who begin to play competitively at a young age, gain a sense of self from their sport (Baille \& 
Danish, 1992; Beamon, 2012; Sparkes, 1998). Therefore, in order to improve upon and maintain high self-esteem, they put forth a considerable amount of time and energy towards specific factors that improve sport performance. Factors such as strong athletic identity as well as time and commitment devoted exclusively to sports may limit individuals who are already underprepared to transition out of sport into another field even before the transition takes place (Petitpas et al., 2009).

General identity development research has been based upon Erikson's (1959) theory of psychosocial development. The main focus of psychosocial development for adolescents (age 12-19) is identity vs. role confusion. At this age for student-athletes, adolescents have put forth a large percentage of their time and effort towards their sport. Therefore, student-athletes identify themselves as such, with other roles possibly as less important. Adolescents at this point, cannot continue to act as children with a "one who is given to" attitude, but instead, act more like adults with an attitude of "one who gives to others" (Marcia, 2002a, p. 201). Ego identity is defined by Marcia (2002a) as "a sense of who one is, based on who one has been and who one can realistically imagine oneself to be in the future" (p. 201). There is a delicate balance to maintain in order to gain a strong sense of self.

Marcia's (2002a) research on identity in adolescence used four categories of identity status: diffusion, foreclosure, moratorium, and achievement. All four categories describe different stages for individuals when choosing a vocational path. In identity diffusion, individuals are unwilling or unable to commit to occupational and ideological goals. These individuals have the most insecure sense of self. Experiencing identity foreclosure includes having a solid, but inflexible identity (Marica, 2002a). Those who experience identity foreclosure usually do so based upon psychosocial comfort in their childhood identity, which 
may result in a limited outlook and lack of options for exploring other forms of identity. The moratorium stage includes exploration and occurs when adolescents are aware of options but are unsure as to which career appropriately suits them. The last identity status is identity achievement in which individuals have chosen a field to pursue and are searching for specific information on their career of choice. These stages are not always linear and the initial identity formation in late adolescence is not the only identity crisis experienced in life (Marcia, 2002a). Individuals of all ages can experience an identity crisis, however, the success rate of achieving identity status can affect future developmental processes (Marcia, 2002b) and the typical and optimal path towards achieving identity is beginning in the foreclosure stage, moving through moratorium, until identity is achieved.

Using Marcia's (2002a) identity status system, it is hypothesized that student-athletes who have an exclusive identity are likely to be stuck in an identity foreclosure stage. If studentathletes have been playing sports since childhood with a strong sense of self associated with sport performance, they will have a strong but inflexible identity as student-athletes. Once student-athletes are competing in their senior year of college, they most likely would have been student-athletes for the past sixteen years if they began playing competitive sports starting at age five. During this time, student-athletes have been sheltered by the culture of the team, coach, and the athletic department (Pinkney \& Tebbe, 2009) and had very few chances of experiencing adaption on their own. Those who continue to play at the competitive level of collegiate athletics do so with a strong commitment to their sport and therefore, usually do not explore other options for careers and may not move on to identity moratorium and eventual identity achievement. Student-athletes' high athletic identity is tied to their commitment to their sport and consequently, limits the amount of time they can allocate to non-sport related activities, such 
as career planning (Martens \& Lee, 1998). In addition, Burns, Jasinski, Dunn, and Fletcher (2012) found in a study with 175 NCAA athlete participants that exclusive athletic identity (categorized as both exclusivity and social identity) was negatively related to athletic satisfaction. Beamon (2012) and Webb et al. (1998) found the resulting identity foreclosure of high athletic identity had a negative effect on transition and resulted in difficulties in their participants' sport retirement. In Beamons's (2012) study, the participants described their "struggle to redefine identities" after sport (p. 204). Exclusive athletic identity, formed during adolescence, can be beneficial for sport performance; however it may lead to difficulties when transitioning out of sport and into other career paths as an older student-athlete.

It should be noted that most published research conducted on student-athletes who are at Division I institutions. There are three divisions of university athletics (I, II, and III) in which the main differences are a required number of sports for each gender and a specified amount of financial aid given to student-athletes in each division for playing sports (NCAA, 2010). Since a higher number of sports (for each gender) is required for certain divisions, each division is closely related to institution size (i.e. Division I institutions have a larger student population than Division III). All Division I and II institutions are required to offer a minimum amount of financial compensation for athletes (Division I institutions have more money to disperse among numerous sports) while Division III institutions are not allowed to offer scholarships based on athletic performance (NCAA, 2010). Division I athletes, because of their higher level of financial athletic compensation, are recruited to attend college in order to play a specific sport for four years. According to Etzel and Watson (2007), some student-athletes may not have chosen to attend college if they were not recruited for sports. Athletics, for some, is the main incentive to receive a college education. Since the focus and motivation is assumed to be more intense for 
Division I athletes, most research for student-athletes is conducted for this specific population and one must be careful when generalizing to other student-athlete populations.

Career maturity. An individual's career maturity level has been used as a quantifiable measure of a person's ability to make appropriate vocational decisions. Super (1983) divided career maturity into five major categories: (a) planfulness (autonomy, reflection on experience/anticipation of the future and self-esteem); (b) exploration (querying, use of resources, participation); (c) information gathering (the world of work, the preferred occupational group, occupational and other life-career goals); (d) decision-making; (e) reality orientation (selfknowledge, realism to outlets, consistency of preferences, crystallization of values, and work experience). Summarizing Super's theory, individuals need to be knowledgeable about the work world, both in general and for preferred choice, and be able to decide upon a career path that realistically matches their interests and abilities.

For student-athletes, these previously mentioned steps outlined by Super (1983) might not be fulfilled considering the difficulties mentioned previously (foreclosure of identity that limits career exploration and the gap level between aspiration and athletic ability). Sharf (2002) asserted that Super's research reveals the importance of the individual's "readiness to make good choices," especially realistic ones (p. 194). Realism is simply referred to as the match between one's abilities and abilities needed to be successful in a specific vocation (Sharf, 2002). Petitpas et al. (2009) stated, "while most graduating students are preparing to enter their professional careers through employment or specialized graduate study, most student-athletes have to cope with the end of their formal sport career" (p. 283). Hence, student-athletes may focus more on their past athletic performances or an unrealistic future upon retirement from sport, instead of planning for a more appropriate or realistic career. 
Murphy et al. (1996) found a negative relationship between identity foreclosure and career maturity in 124 student-athletes (99 males and 25 females) in a Division I institution. This study was exclusively conducted using participants in Division I athletics and may not be generalizable for all student-athletes. However, they concluded that "identifying strongly and exclusively with the student-athlete role may reduce examination of nonsport career possibilities" (Murphy et al., 1996, p. 244). Beamon (2012) also found that high "athletic identity can negatively affect transition out of athletics as they struggle to redefine their identities" (p. 195). Identity foreclosure has therefore been linked negatively to both career maturity level and transition out of sport. Additionally, student-athletes who fail to explore roles outside of their athletic identity were believed to have lower self-esteem in terms of career decision-making (Brown, Glastetter-Fender, \& Shelton, 2000). Overall, commitment and dedication to sport may limit or hinder the student-athlete's exploration of the world outside of sport (Beamon \& Bell, 2002; Harrison, 2000; Murphy et al., 1996; Shurts \& Shoffner, 2004) and therefore, negatively affect their transition out of sport when that time comes.

In addition to the research on factors that contribute to lower career maturity levels or negative transitional events, scholars have advocated for the general interests of student-athletes when leaving their sports. Burnett (2010) believed that there is an essential need to support student-athletes to "succeed in a role other than that of an active competitor" (p. 201). Hence, scholars (Burnett, 2010; Martens \& Lee, 1998) have called for an equal push for research and practical support for athletes to succeed in the world of professional careers as well as on the court, field, etc.

Student-athlete assistance. In terms of academic assistance, NCAA colleges and universities provide programs for student-athletes (NCAA, 2008). These academic support 
services provide assistance either directly to a team or for the general student-athlete population. One of the most commonly recognized programs for student-athletes that were offered through the NCAA was titled CHAMPS/Life Skills (Challenging Athlete's Minds for Personal Success). CHAMPS/Life Skills was created in 1991 and was used in more than 600 institutions in all three NCAA divisions as of 2008 (NCAA, 2008). The program has been in transition the past few years and renamed Student-Athletic Development in which several Division I universities continue to use the five foundational principles of CHAMPS: academics, athletics, personal development, career planning, and community service (NCAA, 2008; Stauffer, 2012). According to their mission, CHAMPS/Life skills was "to maintain intercollegiate athletics as an integral part of the campus educational program and the athlete as an integral part of the student body" and "to promote student-athletes' ownership of their academic, athletic, career, personal, and community responsibilities" (NCAA, 2008, p. 1). One of the main emphases of CHAMPS/Life Skills was to offer programs that assist student-athletes in their career planning while also assisting in identifying and applying transferable skills (NCAA, 2008). The program offered a needs assessment instrument to determine the priority of student-athletes' needs, followed by guidelines and supplemental teaching and supportive material to assist in educating student-athletes (NCAA, 2008). Currently, schools continue to use the information and resources from CHAMPS/Life Skills but the decisions are up to each university individually instead of the governing body of NCAA (Stauffer, 2012).

Through these and similar services, the priorities of student-athletes depend upon their year of college (Petitpas et al., 2009). For instance in the student-athlete's first year, the focus is orientation and exploration, the second year is focused on continued exploration and academic goal-setting, the third year specifically emphasizes connection with campus support for career 
planning and exploring work options while the fourth year concentrates on job searching, finding, and maintaining (Petitpas et al., 2009). The third year of college is the most important, both for athletes and non-athletes, in order to work on internships and gain hands-on experiences with different careers for their impending transition to making a living after college graduation (Petitpas et al., 2009). However important the third year is, time demands for sport may interfere with possibilities of career exploration and therefore hinder career options for athletes (Petitpas et al., 2009). These areas of concentration primarily offer guidelines for institutions to follow. The support most likely given is concentrated on incoming first years and the transition from high school to college. However, there seems to be less support for student-athletes transitioning out of sport, even though it is inevitable that the majority of student-athletes will have to do so, either due to graduation or unanticipated factors.

Student-athletes and career development intervention models. Several researchers (Martens \& Lee, 1998; Shurts \& Shoffner, 2004; Stankovich, Meeker, and Henderson, 2001) have focused on career developmental interventions specifically for student-athletes over the years. Martens and Lee (1998) argued for the necessity for assisting student-athletes in their career development despite previously stated challenges. They suggested an outreach program to "bridge the resources available in a career center with the needs of [student-athletes]" (Martens \& Lee, 1998, p. 126). The model was framed around life-career development in terms of a holistic perspective of the individual as an athlete, student, and individual. The proposed model emphasizes collaboration with the athletic department and helping professional in addition to identifying specific program goals. While setting goals, the helpers are advised to appreciate the student-athletes' athletic identity, address logistical barriers, promote independence, and expand options (Martens \& Lee, 1998). The model is divided by each collegiate school year 
(similar to CHAMPS/Life Skills) and promotes different tasks in order to address the career development needs of the student-athlete and their multiple roles. The main emphasis of the model is that the student-athletes' athletic identity is appreciated which suggests that athletic identity and commitment to sport should be used as an asset to the transition process, instead of a barrier. However, there was no other research found on the effectiveness or use of this model.

Stankovich et al. (2001) described the Positive Transitions Model for sport retirement, which was designed to address both psychosocial and vocational issues pertaining to transition out of collegiate sport. This model is taught in a 2-credit hour, 10-week course and focuses on identity development, transferable athletic skills, and career exploration. The student-athletes are given opportunities to explore their identity and values, to learn about transferable skills, and to learn foundational job-finding skills. Evaluations made by Stankovich et al. (2001) revealed an increase in career maturity, confidence in decision-making, readiness to retire and a decrease in the student-athletes' level of athletic identity. Overall, Stankovich et al. (2001) found through anecdotal evidence, that the Positive Transitions Model was successful in the perspective of the student-athlete because of the class' emphasis on preparation for the next phase of life after sports.

Shurts and Schoffner (2004) took another approach to working with student-athletes' career development and suggested the use of Krumboltz's Learning Theory of Career Counseling (LTCC; 1996). The authors argued that LTCC's focus on learning new skills, interests, and beliefs could facilitate student-athletes' career exploration after their transition out of sport. They ascertained that LTCC is a "good fit" for student-athletes because student-athletes' needs may be "addressed through structured learning experiences and expansion of interests, skills, and beliefs" (Shurts \& Shoffner, 2004, p. 99). They also suggested that LTCC could be useful when 
working with student-athletes who may be resistant to career development outside of sport by discussing current life roles and patterns of skills and abilities (Shurts \& Schoffner, 2004). No other outside research was found that empirically studied the use of LTCC with student-athletes.

All three models emphasized appreciation for the identity of the student-athlete and using their strengths in order to explore new possibilities for a non-sporting career. While strong athletic identities may have been recognized as a barrier to non-sporting career exploration, their skills and abilities as competitors can be strengths. Sparkes (1998) described the positive and negative aspect of athletic identity as either "Hercules muscle" or "Achilles heel" (p. 644). Identifying patterns and strengths that have been successful in sports can assist student-athletes' transition into other aspects of their life. According to McKnight et al. (2009), "the core of [student-athletes'] transition must ensure that the athletes derive personal meaning from their non-sporting career as they did from their sporting career” (p. 70). This acknowledged appreciation for sport is most likely a widely beneficial component for any student-athlete career development model or intervention. Overall, student-athletes should receive proactive, educational assistance and support for the transition out of sport into a new career (Burnett, 2010; Lally, 2006; Martens \& Lee, 1998; Sparkes, 1994).

\section{TWA and Student-Athletes}

The TWA model may be beneficial for student-athletes transitioning out of sport, however no known studies on this particular topic have been conducted. A limited number of articles and dissertations have been written over the years that focused on student-athletes and vocational theories. Krylowicz (1999) completed a dissertation study that utilized Super's framework of vocational and personal development with Division I male and female basketball players using several quantitative instruments. Harrison and Lawrence (2003) explored 
perceptions of 26 African American student-athletes from a Division II program on their athletic career transition utilizing the Life after Sports Scale. No known study has focused on using the theoretical framework of TWA for student-athletes transitioning out of sport.

Using TWA terminology, it can be assumed that student-athletes are satisfied by sport because of the competitive environment and the reinforcing factors (e.g., of individual or team recognition and collaboration with teammates and coaching staff, etc.). Through practice over the years, student-athletes have perfected their skills and abilities to match the requirements of the competitive environment. Therefore, most student-athletes match their level of satisfactoriness from the sporting environment with the satisfaction from their abilities. As previously mentioned, this commitment to athletic identity and perfection of athletic skills may have cost them career maturity as they are stuck in identity foreclosure. McKnight et al. (2009) remarked that athletes often fail to recognize their skills that can transfer to other domains, creating a "tunnel" or "closed-off vision." (p. 63). However, it was hypothesized that recognition of transferrable skills, as well as finding a post-retirement environment to match those skills and satisfaction levels, may lead to a successful retirement from sport despite high athletic identity. Using Harper and Schoffner's (2004) idea, the goal for retiring student-athletes should be to finding post-athletic retirement in a non-sporting environment.

Student-athletes, especially at the highly competitive level of collegiate athletics, can generally transfer many skills that made them a success on the game field, court, etc. to a career. These skills include but are not limited to: discipline, strong work ethic, perseverance, accountability, leadership, balance, commitment, assertiveness, competitive drive, and the ability to overcome opposition (Baille \& Danish, 1992; Jordan \& Denson, 1990; McKnight et al., 2009; Nathanson \& Kimmel, 2008). One can acknowledge transferable skills by identifying a 
successful situation, recognizing personal attributes that caused such success, and applying those skills to other settings (Parcover et al., 2009). Danish, Petitpas, and Dale (1992) described six steps for student-athletes in terms of transferable skills: (a) understand how one's skills may be valuable in other areas, (b) believe that one's skills are valuable, (c) understand how one's skills may be useful in contexts other than sports, (d) understand how feelings of anxiety may accompany transition, and overcome this anxiety, (e) develop a new identity, and (f) develop appropriate social supports. There are many transferable skills that have been identified as useful in both athletic and career settings, and once identified (with assistance), student-athletes may be able to match those skills to appropriate ability requirements in working environments.

However, matching appropriate reinforcer factors in a non-sporting environment may be more complex. Exploring values and needs of the student-athlete and what reinforcer factors are prominent in the student-athletes' pre-retirement environment may be helpful. For instance, MacLean and Hamm (2008) described a variety of values student-athletes find in sporting environments including but not limited to: compassion, companionship, health and fitness, personal achievement, public image, sportsmanship, team cohesion, and winning. Understanding the importance of these values and their priority in student-athletes' lives before transitioning out of sport may assist them in producing ideas for post-transition environments in which they may feel successful. Those ideas can be further explored or experimented to match a person-environment fit similar to that of the pre-retirement sporting environment.

\section{Delphi Technique}

The Delphi technique is a method to achieve data by combining written responses from a group of identified "experts" and to generate a consensus among the participants (Bulgar \& Housner, 2007; Delbecq, VendeVen, \& Gustafson, 1975; Fink, Kosecoff, Chassin, \& Brook, 
1984; Keeney, Hasson, \& McKenna, 2011; Murphy, Black, Lamping, McKee, Sanderson, Askham et al., 1998; Powell, 2003). More specifically, it is a "systematic effective, and comprehensive technique for administrating a group communication process that enables a collection of knowledgeable individuals to reach a consensus... when information is relatively incomplete or multidisciplinary in nature" (Bulger \& Housner, 2007, p. 59). There are several rounds in the Delphi technique; the first round includes a broad question (ranging from problems to suggestions) followed by subsequent rounds that are "built upon responses to the preceding questionnaire" (Delbecq et al., 1975, p. 83).

Currently, there are no known published Delphi panel studies regarding student-athletes and transition out of sport or student-athletes and the use of vocational theories. One study by Beck, Bennett, Maneval, and Hayes (2001) examined faculty perceptions of student-athlete's academic performances by using the Delphi technique. There are several current Delphi panel studies that focued on opinions and solutions to problems or concerns within higher education. For example, Graham (2010) used a Delphi panel of Australian university faculty and staff members in order to gain a consensus on the contributions of general staff members to the academic outcome of students. Shelton (2010) conducted a six-round Delphi panel study to examine the administration quality of online education programs and create a "quality scorecard" for online programs. Bulger and Housner (2007) used a two-round modified Delphi technique to investigate the importance of exercise science competency in physical education teacher education programs. All of these researchers that utilized the Delphi technique confirmed a need for more knowledge in their respective area of study and subsequently sought out to achieve a consensus by either identifying problems and generating possible solutions or rating the importance of information to create guidelines. 
Delphi technique used in psychological research. Several scholars have utilized the Delphi method in order to conduct research within the field of psychology, specifically when guidelines were needed or group opinions were explored. Since Delphi techniques require the use of identified experts, the methods were chosen by the authors to attain authentic data because individuals who are active in the targeted field of psychology would generate genuine insights of professional knowledge (Cicarelli, 1984; Neimeyer, Taylor, \& Rozensky, 2012).

Neimeyer et al. (2012) conducted a Delphi poll to evaluate the current and future "halflife" of professional knowledge (in other words, how long it would take for someone to become half as knowledgeable due to the development of new knowledge within the field of psychology). The authors' goal was to obtain a panel of undisputed experts on the subject matter and invited individuals from the APA's Commission for the Recognition of Specialties and Proficiencies in Professional Psychology and the independent Council on Specialties in Professional Psychology to be experts on the Delphi panel. Overall, 15 out of 31 individuals participated in two rounds of polling (Neimeyer et al., 2012).

Various authors have used the Delphi panel to create a definition for either professional or research purposes. Tasse, Sabourin, Garcin, and Lacavalier (2010) conducted a Delphi study to attain a consensus from experts in Quebec in the field of intellectual disability and serious behavior disorders on definitions of specific disorders within that particular population. Through two rounds, the experts produced an $85 \%$ level of agreement on two definitions and 14 of the 15 factors needed to establish the degree of the problematic behavior. Bond et al. (2009) conducted a Delphi study to achieve agreement on criteria to create a working definition for meditation "for use in a comprehensive systematic review of therapeutic use of meditation" (p. 129). 
Other Delphi study researchers have explored the opinions of experts in order to create guidelines for curriculum or programs. Joiner and Landreth's (2005) Delphi panel consisted of play therapy experts and play therapy instructors who were asked opinions on necessary core curriculum and experiences for play therapy training within a developmental approach. The resulting data were used to create a scale that was sent out to play therapy professors to which the data was used to develop play therapy training curriculum. Speight, Thomas, Kennel, and Anderson (1995) used a poll of experts who were identified based on publication records to achieve a consensus on multicultural attributes in both doctoral programs and internships. The goal of the authors was to provide information to create guidelines for training psychologists to be multiculturally competent while in doctoral programs and internships.

The Delphi Panel has also been used in order to "predict" the future of a profession, including psychotherapy. Norcross, Hedges, and Prochaska conducted studies in 1982, 1992, and 2002 using the Delphi method to predict trends in psychotherapy for the following decade. The experts were identified as "distinguished mental health professionals with a mean of 30 years of post-doctoral clinical experience" (Norcross, Hedges, \& Prochaska, 2002, p. 317). The instrument for the most recent study was a Likert-scale questionnaire that was updated from previous research and was used to explore the experts' opinions on the future of theoretical orientations and interventions, role of psychotherapists, therapy formats, and forecast scenarios. Researchers within the field of psychology have utilized the Delphi method in order to achieve consensus, either by generating definitions, guidelines, or general opinions within the targeted discipline. The purpose of this study was to generate a consensus on the current status of the use of TWA elements with student-athletes and to rate the importance and likelihood of using such elements with student-athletes who are about to transition out of sport. 


\section{Summary}

Transitions occur in any stage of life; research has been conducted on the many different transitions with a portion of the research focusing on transitions out of career. Career transition does not necessarily refer only to traditional vocational changes, but can be used to describe the process of other transitions, including student-athlete retirement, or transition out of sport.

Related literature on student-athletes indicates that student-athletes have put forth an enormous amount of commitment and dedication throughout their athletic career (Baille \& Danish, 1992; Petitpas et al., 2009; Sparkes, 1998); however, the vast majority of student-athletes will retire upon graduation from college and transition out of competitive sport (NCAA, 2010; Petitpas et al., 2009). Research has shown that strong athletic identity (which was beneficial for studentathletes' sport performance) is correlated with low career maturity levels (the realistic planning of an individual in reference to career exploration; Murphy et al., 1996). Therefore, exploratory behavior is limited and may negatively affect retirement from sport. According to scholars, there is a need to support student-athletes as they explore roles other than in sport (Burnett, 2010; Martens \& Lee, 1998).

A successful transition has been defined by Schlossberg (1981) as a positive perception of the individual's ratio of resources over deficits, with preparation and attitude towards transition being an important factor in creating a positive transition. Researchers (Harper \& Schoffner, 2004; Hesketh et al, 2011) have addressed using the vocational theory, TWA, in retirement counseling by proactively identifying skills and abilities of the individual, requirements of the environment, and the losses of those requirements after retirement. In other words, they addressed the importance of matching satisfaction and satisfactoriness (two key elements of TWA that have shown to be predictive of tenure or prolonged stay in an 
environment; Dawis, 1980). Once those losses are identified, they can be used to recognize an appropriate post-retirement environment in order to balance the person and environment fit again. Overall, it was hypothesized that understanding and employing a theory such as TWA may be a great resource for those working with student-athletes who are transitioning out of sport.

However, it was currently unknown as to what is being taught or discussed with student-athletes as they make this transition.

Given the past research on student-athletes and the impact of athletic identity on career maturity, TWA and retirement counseling, and the unknown connection of student-athletes' transition out of sport within the TWA framework, there was a need for more research within the area of transition out of collegiate sport. The Delphi technique was chosen for this study in order to gain insight from identified experts who work with student-athletes and explore the applicability and potentiality of using elements of TWA with student-athletes. The purpose of this dissertation was to generate a consensus of expert opinion of those who work with studentathletes with regard to what is being currently discussed and if there was a potential use of the core elements of TWA with student-athletes transitioning out of collegiate sport. 


\section{CHAPTER THREE \\ METHODS AND PROCEDURES}

This chapter presents the methods and procedures that were used in this study including (a) an introduction to the Delphi technique, (b) research design, (c) sample and identification of participants, (d) data collection procedures, (e) data analysis, and (f) autobiographical statement.

\section{Delphi Technique}

The Delphi technique, developed by Helmer and Dalkey in 1969, is a type of survey design used to gather data from a group of individuals (Keeney et al., 2011). The name is derived from the ancient Greek myth of a Delphic oracle who communicated with the Greek god Apollo to receive answers to the community's questions and predict the future; however the main focus of the current technique is to achieve consensus among many perspectives, not just one (Keeney et al., 2011; Murphy et al, 1998). According to Keeney et al. (2011), the main assumption of the Delphi technique is that "group opinion is more valid than an individual one" (p. 3); a single response is unlikely to include all the perspectives from a group (Graham, 2010). The other assumption of the technique is to achieve a consensus on an issue when no other consensus has previously been made (Delbecq et al., 1975; Hanafin et al., 2007; Keeney et al., 2011; Murphy et al., 1998).

There are several types of Delphi processes, which are chosen dependent upon the requested data (Keeney et al., 2011; Murphy et al., 1998). The original Delphi process, also known as the Classical Delphi, includes four rounds; the first round includes broad, open-ended questions (ranging from problems to suggestions) followed by subsequent rounds of either questions that are founded in the preceding answers or a request to rank the statements collected from the first round (Keeney et al., 2011). Although the Classical Delphi technique includes four 
rounds, many techniques have been modified to include any number of rounds until consensus can be achieved (Keeney et al., 2011). However, one must use caution as too many rounds may result in participation fatigue (Keeney et al., 2011), which has been cited by McKeena (2004) to possibly occur after two rounds. Researchers have stated that consensus can usually be achieved after three rounds, with little research showing significant increases in the reliability of the data after more than two rounds (Murphy et al., 1998).

\section{Research Design}

The Delphi technique is an exploratory, multi-stage survey design that seeks to gather information from a specified group of individuals characterized as experts to address a particular issue (Keeney et al., 2011) and organize group communication (Powell, 2003). Since the technique includes both quantitative and qualitative elements, researchers have debated its epistemological origin (Hanafin et al., 2007; Keeney et al., 2011; Murphy et al., 1998; Powell, 2003; Sackman, 1975). Ultimately, it seems that the Delphi technique fails to fit into one mold and is considered by Keeney et al. (2011) to have a "hybrid epistemological status" (p. 19). This definition fits with the current study in that the hybrid status defines the exploratory part of the study in conjunction with data that were generated by a panel of experts. The epistemology of this study comes from a theoretical foundation and the practical knowledge of the participants.

The unique characteristic of the Delphi method is its reliance on the identified experts; as Cicarelli (1984) stated, "the Delphi is its panel" (p. 140). Therefore, the design of Delphi panels is usually derived from a pragmatic point of view due to its focus on the identifying problem and using all approaches available to understand the problem, including mixed methods (Creswell, 2008). A pragmatic worldview also includes an emphasis on "application... and solutions to problems" (Patton, 1990 as cited in Creswell, 2008, p. 10). This study used both closed and 
open-ended questions, using both qualitative and quantitative analyses in a sequential mixed methods approach (Creswell, 2008).

A modified Online Delphi technique (which is similar to the Classical Delphi technique with the exception of being completed online) was used for this study. Examining the transition out of sport for student-athletes within the realm of the Theory of Work Adjustment (TWA) has not been found in the literature. Therefore the aim of this study was to gather data from identified experts to reach a consensus on the importance of TWA and its potential use with collegiate student-athletes who are transitioning out of sport. The two main research questions for the current study were:

1) What is being taught to or discussed with student-athletes who are about transition out of sport?

2) Are elements of TWA being used?

If elements of TWA were not currently being used, secondary questions included: Are they important to be used with student-athletes transitioning out of sport? Are they applicable to be used with student-athletes transitioning out of sport? Do they have the potential to be used with student-athletes transitioning out of sport?

There are three quantitative instruments that have been developed to use when conducting studies on TWA: the Minnesota Importance Questionnaire (MIQ; Gay, Weiss, Hendel, Dawis, \& Lofquist, 1971), the Minnesota Satisfaction Questionnaire (MSQ; Weiss, Dawis, England, \& Lofquist, 1967) and the Minnesota Satisfactoriness Scale (MSS; Gibson, Weiss, Dawis, \& Lofquist, 1970). However, since these instruments were generated to measure the values, satisfaction, and abilities of current workers, they were not relevant to the current research questions and therefore were not used in this study. 


\section{Sample and Identification of Participants}

Given that the research design is based on the opinions of experts, a purposeful sample was used for the study. The term expert has been defined as "those with the highest degree of subject matter expertise regarding the survey content" (Bulgar \& Housner, 2007, p. 60) or a "representative of their profession and have the power to implement the findings" (Fink et al., 1984, p. 981). Due to the combined nature of this topic, subject matter experts included those with 10 years or more of experience with student-athletes in academic services, sport psychology consulting, and counseling psychology. Ericsson (2008) found through his research on experts that all performers, including those in sports, sciences, and arts need at least 10 years of "intense involvement" to reach an established international level of expertise (para. 11); therefore ten years was used as a minimum criterion for experts in this study.

The experts were recruited from three professional organizations: National Association of Academic Advisors for Athletics (N4A), Association for Applied Sport Psychology (AASP), and Division 47 of the American Psychological Association (APA). The mission of N4A, which was originally formed in 1975 , is to assist student-athletes in both their student and athletic roles by improving opportunities for academic success in student-athletes and enhancing communication between academics and athletic community (NACDA, 2013). Professional members of N4A (currently over 1,000) include "any person whose purpose is to assist student-athletes in pursuit of academic goals and holds a position at an educational institution" (N4A, 2013, para. 5). AASP was founded in 1986 and emphasizes its international and multidisciplinary focus on topics such as sport, exercise, and health psychology (AASP, 2013). One primary purpose is to deliver services to athletes and those who assist them in areas focusing on health, sport, and social psychology (AASP, 2013). The organization comprises of over 1,700 members who are 
trained in either sport sciences or psychology (counseling, lifespan development, clinical, or social focus; AASP, 2013). There is no official listserv of AASP, therefore the "unofficial" listserv, out of Temple University, which the vast majority of AASP members use, was used for the study. Division 47 - Sport and Exercise Psychology - was formed in 1986 to bring together psychologists and exercise and sport scientists for clinical, training, and educational purposes (APA47, 2013) and includes over 1,000 members on their listserv. One goal of Division 47 is to enhance "training in the development and use of psychological skills for optimal performance in athletes, in the well-being of athletes, [and] in the systemic issues associated with sport settings" (APA47, 2013, para 1). Members of all of these organizations are trained to work with the specific population of athletes with different emphases; N4A has an academic focus, AASP stresses the importance of transferable life skills, and Division 47 has a more broad focus of psychological skills training. Since transition out of collegiate sport has demonstrated (by previous statements) to have an impact on or be influenced by, academics, career maturity, identity, and psychological wellbeing, all three professional organizations offer some expertise in working with student-athletes and their transition out of sport.

Identifying experts for the Delphi technique has been a matter of debate since, according to Keeney et al. (2011), possessing knowledge should not be the only qualification. Instead, the scholars stated there should be a balance between knowledge and interest of the subject, as well as an unbiased motivation and willingness to participate in the study (Goodman, 1987; Keeney et al., 2011; Powell, 2003). Delbecq et al. (1975), seemingly one of the most cited research teams on the Delphi method, stated the four critical conditions for participation as (a) being personally involved in the problem of concern, (b) having pertinent information to share, (c) having high participant motivation, and (d) feeling that the potential consensus will be valuable. Adequate 
time and communication skills have also been viewed as important criteria for experts (Delbecq et al., 1975; Murphy et al., 1998). Therefore, the inclusion criteria for this study were (a) holding a current position in an academic college or university, (b) having at least 10 years working with student-athletes (through academic services/counseling, through direct clinical hours, supervising counseling/clinical/or sport psychology graduate students working with student-athletes), and (c) willingness to participate.

Size and composition. The size of the expert panel is dependent upon the proposed question, however scholars have stated that a minimum of 10 participants should suffice for the panel, with a target number of 15 (Delbecq et al., 1975; Okoli \& Powlowski, 2004; Powell, 2003). Although it is assumed that an increased number of participants equates for better reliability for the study, Murphy et al. (1998) affirmed there is a lack of empirical evidence to conclude a significant effect based on the number of participants or the reliability or validity of the results. The primary investigator for this study set out to recruit at least 18 participants for the proposed study, to counter participant dropout rate. However, after one month of recruitment attempts by e-mail, the initial number was not acquired. Therefore, the study commenced with 14 individuals who met all of the criteria.

Recruitment of participants. After IRB approval was granted (See Appendix B), participants were recruited through three listservs: N4A (over 1,000 members), SportPsy, a listserv of professionals from AASP and APA (approximately 1,250 members), and APA Division 47 (over 1,000 members). The coordinators of the organizations were contacted directly, asking for permission and assistance to recruit members. The initial contact also included an explanation of the purpose and structure of the study (See Appendix C). Once permission was approved, a detailed e-mail about the study was sent out to possible participants 
over the listserv, including information about the researcher, the proposed study, the value of the results, and the expectations of the participants (including anticipated number of rounds, time commitment and participation requirements; Keeney et al., 2011). The researcher used an adapted e-mail used by Bulgar and Housner, 2007 (See Appendix D) and asked those participants who were interested to respond by filling out the Demographics questionnaire (See Appendix H). The participants were initially given a two-week time frame to respond if interested, however only two participants filled out the demographics questionnaire in the first recruitment round. The primary investigator sent out another e-mail to the listserv coordinators requesting they resend the email recruitment letter and potential participants were given another two weeks to respond. Although the initial number of recruited participants set in the proposal was not met, the primary investigator, with permission of her chair, closed recruitment at 14 participants since no other participants were recruited at this time. The background of the participants varied across the three expert fields and the total number of 14 was over the minimum of ten (Delbecq et al., 1975; Okoli \& Powlowski, 2004; Powell, 2003) and still allowed for an attrition rate.

Those who were interested and met the final criteria received a follow-up e-mail for the commencement of Round 1 (using an adapted e-mail script used by Bulgar and Housner, 2007; See Appendix E). Keeney et al. (2011) stressed the importance of making the participants feel important to the proposed topic and suggested that the researcher should "remind participants that each round is constructed entirely on their response to previous rounds encouraging ownership and active participation" (p. 12). The primary investigator included this information as well as appreciation for their participation at the beginning of each round. 
Participant demographics. Fourteen panelists originally completed the demographics questionnaire during the recruitment process. However, after the first round was distributed via e-mail (with two reminder e-mails), only 11 panelists completed Round 1 . The same 11 panelists also completed Round 2. Unfortunately, only eight panelists completed Round 3 after four e-mails (one initial and three reminder e-mails). The three panelists who did not complete the final round are unknown as responses in the last round were anonymous.

The 11 original expert panelists represented a variety of vocational experiences and training, as well as current positions and duties (See Appendix J). Panelists reported working in 11 different universities including eight Division I institutions and three Division II institutions. The study also included panelists from all four main regions of the United States: two from the Northeast, one from the Midwest, four from the South, and four from the West. Overall, the panelists represented a comprehensive and generalized picture of those working with collegiate student-athletes across the country. Although the number of participants was smaller than intended, the panelists in this study represented a nationwide sample of those working with student-athletes, providing a geographically comprehensive opinion of experts in the field.

The current positions of the panelists included four directors, three academic counselor/advisors, two associate directors, one assistant director, and one consultant. These positions were spread out between academic advising departments for athletics (5), athletic departments (4), and university counseling departments (2). Duties performed by the panelists were diverse (multiple duties were noted for some panelists): four had supervisory roles, three performed administrative duties, three delivered performance enhancement training to university teams, three worked directly with student athletes through academic advising, and two delivered academic support programs or workshops. Other individual duties included sport administration, 
performing counseling/assessment on student-athletes, generating alumni connections for student-athletes, and working as the campus communications liaison.

In terms of training background, the panelists were allowed to choose more than one. Training in both higher education/administration and sport and exercise psychology was represented in 55\% of the panelists. Training in counseling psychology was also commonly represented in $45 \%$ of the panelists. One panelist represented training in clinical psychology, one in counseling, and two panelists listed "other" for their training. One of the "other" was described as training in psychology at the bachelor degree level; the additional "other" was not described. Three panelists earned doctoral degrees while eight earned master's degrees. One criterion for identifying experts is 10 years or more of experience in the related field; the average number of years that panelists reported working with student-athletes in the study was 14.72 , with a maximum value of 28 years.

Panelists were asked to rank order the field with which they identify (they had the opportunity to choose up to four different fields in order of prominence; see Appendix H). The most commonly identified field was in academic/counseling services with sport and exercise psychology as the next most commonly identified field. Counseling psychology was the third most commonly ranked identified field, however, this field was the second highest in primary identification. Three panelists ranked "other" as an identified field that was later described in an open-ended description of: working with concussed athletes in a private clinic, NCAA compliance, and alumni affairs.

\section{Data Collection Procedures}

Pilot study. In order to determine the appropriateness of the open-ended questions to be used in the study, a pilot study was conducted using a smaller panel of four individuals with 
extensive experience with collegiate student-athletes. Participants in the pilot study included a licensed counseling psychologist who worked as a liaison between a Division I athletic department and a university counseling center for over twenty years, and three dual sport and exercise psychology and counseling graduate students. All students had experiences as sport psychology consultants for collegiate athletics, with one working for university academic services, two receiving training at university counseling centers, and one with experience as a CHAMPS/Life instructor. These panelists were not invited for participation in the actual survey; however feedback from the participants was used to make minor changes in question structure and wording in the instructions (as suggested by Powell, 2003). The pilot study also gave the primary investigator practice conducting a Delphi panel through the online survey website.

Initial round. As previously mentioned, the Classical Delphi technique includes four rounds, however the modified technique allows the researcher to use as little as two to three rounds if consensus is achieved at that time and to avoid response exhaustion (Fink et al., 1984; Keeney et al., 2011; McKeena, 2004; Powell, 2003). Therefore, the number of rounds in this study was three, one open-ended and two subsequent ranking rounds. At the commencement of Round 1, an e-mail was sent to all of the potential panelists repeating the explanation of the study, the importance of the findings, as well as an estimated amount of time that will be requested for the duration of the study (approximately 15-20 minutes; See Appendix D). Round 1 of the Delphi technique was semi-structured (Powell, 2003) and included an open-ended set of questions (See Appendix H). Open-ended questions are "recognized to increase the richness of data collected" (Powell, 2003, p. 378), can be useful to gain access to the insight of the panelists, and are used to generate ideas and allows the panelists to have freedom with their initial responses (Delbecq et al., 1975; Keeney et al., 2011). 
Subsequent rounds. After the primary investigator analyzed the content of the first round (see Analysis section), the panelists were provided instructions via e-mail (See Appendices E \& F) and asked to rate the subsequent results from Round 1 in terms of importance, applicability, and potential use on a Likert scale of 1-5 with one representing "not at all" and five representing “very” (Bulgar \& Housner, 2007; Graham, 2010; See Appendix M). The subsequent rounds included an analysis summary (a list of statements and emerging themes made by the panelists from Round 1 and an indication of where each participant's scores were in relation to the group for Rounds 2 and 3; Delbecq et al., 1975; Graham, 2010; Powell, 2003; See Appendix L). Hanafin et al. (2007) stated that providing individual and group ranks would allow the panelists to view their responses in the broader context. The data for Round 2 identified areas of disagreement, areas of agreement, and items in need of clarification (Delbecq et al., 1975). The same procedure from Round 1 of using a follow-up e-mail was used in order to ensure a prompt response for the remaining rounds.

In Round 3, the panelists were given a chance to reevaluate any of their responses based on the analysis summary of Round 2 (Bulger \& Housner, 2007; Delbecq et al., 1975), with the goal of increasing the probability of generating consensus (Keeney et al., 2011). This round was considered closure for the study as the panelists were given a last look at the data in order to make any desired changes (Delbecq et al., 1975).

\section{Analysis}

As a mixed-methods design, the Delphi technique included both qualitative and quantitative elements in order to first capture the views of the panelists (qualitative approach) before attempting to achieve a collective consensus on the opinions gathered (quantitative approach). The first round included a qualitative content analysis of the open-ended questions 
(Fleming \& Monda-Amaya, 2001) to identify emergent themes (as used by Bulger \& Housner, 2007). Content analysis was used to generate categories for textual data in order to reduce data to manageable segments; it is considered atheoretical because its aim is to answer practical research questions (Forman \& Damschroder, 2008). According to Forman and Damschroder (2008), there are three steps in qualitative content analysis: (a) immersion, (b) reduction, and (c) interpretation. Immersion involves initial analysis of the data by reading over and commenting on first impressions of the information given (Forman \& Damschroder, 2008). Reduction includes creating mutually exclusive topics found in the data (Forman \& Damscroder, 2008). Because the data were gathered through a semi-structured document, the investigator used deductive analysis because the topics were decided upon a priori in relation to the elements in TWA. Topics were generated with the assistance of an independent rater to achieve a goal of a 95\% agreement rate ([agreement/(agreement + disagreement) $]$ X 100) on the data (as used by Fleming and Monda-Amaya; 2001). The second rater for this study was a third year counseling psychology Ph.D. candidate with whom the primary investigator had worked on other research projects. The rater had no experience working with student-athletes or extensive clinical work in vocational psychology, which provided an independent, unbiased perspective for this investigation. The primary investigator and second rater were able to achieve $100 \%$ agreement rate with content analysis. Although interpretation is listed as a "third step," Forman and Damschroder (2008) explained that interpretation of the content occurs at all levels of analysis.

Group Consensus. There is no set agreement among Delphi researchers on the best method of measuring group consensus with the quantitative data. Several studies within the psychology and education literature used the pattern of standard deviations change while also including a cut-off criterion for data from previous rounds (Bulgar \& Housner, 2007; Shelton, 
2010). According to Shelton (2010) "mean and median scores along with standard deviation and mode analysis may be used in Delphi studies to determine consensus as well as percentage of responses" (p. 40), indicating the use of descriptive statistics in the analysis of Delphi data. The mean is a measure of central tendency, or simply the average of responses, while standard deviation indicates deviation from the mean as well as frequency of that deviation among the responses. When attempting to achieve a collective consensus, one looks for a high level of agreement around a particular score that also has a low standard deviation.

For this particular study, data from Round 2 that achieved a mean score of four out of five on the 5-point Likert scale and a panel member agreement of 70\% for each item was used for Round 3, which has been most commonly cited in literature (Bulgar \& Housner, 2007; Fleming \& Monda-Amaya, 2001; Shelton, 2010). Determining group consensus in the third round included analysis of the standard deviation of the remaining items (Neimeyer et al., 2012; Norcross et al., 2002). This pattern follows several other studies found in psychology. For example, Neimeyer et al. (2012) looked at the standard deviations in the responses to the survey questions, defining group consensus as a reduction in standard deviations, "indicating a developing convergence of opinion" (p. 367) since lowered standard deviations indicate less variability and less variability indicate collective agreement.

Confidentiality. To ensure confidentiality during analysis, the researcher kept all contact information in a password-protected document to which the primary investigator had sole access. The primary investigator was the only one with knowledge as to which statements belong to whom in order to give appropriate feedback summaries to the panelists in Round 3. The term “quasi-anonymity" (McKenna, 2004) best describes the identification process of panelists in Delphi studies since the primary investigator knew the owner of each response while the other 
respondents did not. In order to ensure anonymity with the panel (and throughout publication), all panelists received a random number that was used as an identifier throughout the data collection and analysis.

The recruitment e-mail was sent though the primary investigator's university email address to ensure the panelists of the academic nature of the study - however the following e-mails were sent through the online survey website. For Round 1 and 3, all panelists used a URL link to a web-based survey to ensure that no information collected through the qualitative process would be used to lead back to and identify panelists. However, as all panelists were informed from the recruitment e-mail, information from Round 2 was anonymous to other panelists but was identifiable by the primary researcher in order to provide specific feedback to each participant regarding his/her ranking in terms of the ranking of the group. All contact information was deleted after the study was completed (both electronically deleted and shredded).

\section{Bracketing/autobiographical statement}

Due to the qualitative nature of this study, bracketing was completed in order to explore potential biases on the part of the primary researcher. As Mason (2002) stated, "a tenet of qualitative research is that the researcher is the primary instrument of the research, and bring with her particular experiences, assumptions, and points of view that will affect interpretation of the data" (as cited in Forman \& Damschroder, 2008, p. 54). An autobiographical statement was written prior to the start of the study, which included the primary investigator's experiences with the chosen topic. Furthermore, the primary investigator's worldview is pragmatic in that she believes that the origin of knowledge stems from objective and subjective points of view and answers may be generated from both qualitative and quantitative methods of research. While she believes it is difficult to find exact causal relationships for social and psychological issues, one 
can analyze data in order to obtain strong (perhaps multiple) correlations. Her experiences in the sport and academic world, as well as her pragmatic worldview, may have influenced the study in that her intention was to find a beneficial topic that could assist student-athletes and those who work with them. Steps to prevent this bias included using an independent rater to reach a high level of agreement during content analysis, using direct quotes from the panelists in the feedback analysis, keeping a decision trail for procedures, and following up with the panelists on their reaction to the summarized data. 


\section{CHAPTER FOUR}

\section{RESULTS}

This chapter includes the results of the study: (a) descriptive statistics, (b) group consensus, and (c) qualitative analysis.

\section{Descriptive Statistics}

In the first round of the study, the panelists were asked to rate how often they discuss five different topics with collegiate student-athletes on a Likert scale of one to five with five representing all of the time and one representing never (See Table 1 \& Appendix K). Each topic represented a main element of TWA: an individual's transferable skills, the working environment, task requirements of the working environment, an individual's personal and professional values, and matching the individual's values to the working environment. These topics were adapted for this study to student-athlete (individual) and a non-sporting postretirement environment (working environment). Among the 11 original panelists, five participants reported discussing transferable skills often (45\%), three of them all of the time $(27 \%)$, one of them reported discussing it sometimes $(9 \%)$, and two individuals reported discussing it rarely $(18 \% ; \mathrm{M}=3.82, \mathrm{SD}=1.08)$. The topic of post-retirement environment is rarely discussed by four panelists (36\%), sometimes by three $(27 \%)$, and often or all of the time by two panelists each $(18 \% ; \mathrm{M}=3.18, \mathrm{SD}=1.17)$. Out of the 11 panelists, six reported discussing taskrequirements of non-sporting careers sometimes (60\%), two reported discussing it rarely (20\%) and two reportedly do not discuss it at all $(20 \% ; \mathrm{M}=2.40, \mathrm{SD}=0.84)$. One panelist did not answer this question. With regards to reportedly discussing personal and professional values, four of the panelists rarely discuss it (40\%), three discuss it often (30\%), two discuss this topic all of the time $(20 \%)$, and one discusses it sometimes $(10 \% ; \mathrm{M}=3.30, \mathrm{SD}=1.25)$. One panelist did not 
answer this question. Seven panelists reportedly rarely discuss matching values with the new non-sporting environment (78\%), one discusses it all of the time (11\%) and one does not discuss the topic at all $(11 \% ; \mathrm{M}=2.22, \mathrm{SD}=1.09)$. Two panelists did not answer this question.

Table 1

Round 1 Descriptive Statistics

\section{Question Stem:}

How often do you discuss... with student-athletes?
Mean

Standard Deviation

\begin{tabular}{lcc}
\hline Transferable skills & 3.82 & 1.08 \\
\hline Post-retirement environment & 3.18 & 1.17 \\
\hline Task requirements of non-sporting careers & 2.40 & 0.84 \\
\hline Personal and professional values of student-athletes & 3.30 & 1.25 \\
& & 1.09
\end{tabular}

After ranking each topic, the panelists were given the opportunity to provide more detail on how they discuss the topic with student-athletes. The panelists were given instructions that emphasized the information gathered in Round 1 would generate the quantitative data necessary for the subsequent rounds. Data from Round 1, analyzed through content analysis by the primary investigator and an independent rater, resulted in 24 separate statements. From the original five TWA topics, the following number of statements were generated from each topic: seven related to transferable skills, four related to the working environment, five related to task requirements of the working environment, five related to personal and professional values, and three related to matching values to the working environment.

In Round 2, the panelists were asked to rank each of the 24 statements on a Likert scale of 1-5 on the statement's importance, applicability, and potential use, with five representing very and one representing not at all. In other words, each discussion statement was rated on the importance of having that discussion with collegiate student-athletes who are about to transition 
out of sport, how applicable the discussion statement is as a tool when working with studentathletes towards the end of collegiate competition, and the potential use of the statement by those working with collegiate student-athletes. Panelists were also given the opportunity to anonymously provide a rationale for their ranking of each statement for others to view in the final round.

Each statement was analyzed through descriptive statistics. Statements that generated a group mean of four or higher (out of five) on the Likert scale by at least $70 \%$ of the group were used in the third round. Five original statements were not included in Round 3 because they did not meet the cutoff criteria (Statements 11, 16, 21, 22, and 23; See Appendix M). Additionally, certain rankings did not meet the cutoff criteria for Statement 9 (applicability and potential use), for Statement 10 (importance and potential use), and for statement 17 (potential use) all of which were not ranked as well. (The statements were left in the survey for those interested in knowing which statements were not included in the final round.) Overall, 19 statements met the cutoff criteria for Round 3 (16 with all three rankings of importance, applicability, and potential use, and three statements with one or two of the three rankings).

After Round 2, each panelist received a personalized summary table of scores that included his/her personal ranking of each statement. The summary table also included the group statistics for each ranking (mean/standard deviation). The purpose of the summary table was to provide feedback to allow panelists to consider his/her own response in comparison to the group, which may subsequently change his/her opinion, allowing the panel to move towards consensus (Keeney et al., 2011). Additionally, anonymous rationales from the panelists in Round 2 were provided with each statement to consider before each panelist re-ranked (See Appendix L). The panelists were asked to use the summary table as a reference when completing Round 3. 


\section{Group Consensus}

In Round 3, the standard deviations of each remaining statement were analyzed to determine if a consensus was achieved (See Appendix M) by examining if the standard deviation decreased at all from Round 2 to Round 3. Group consensus is defined as any reduction in standard deviations since a lowered standard deviation indicated less variability, which indicated collective agreement (Neimeyer et al., 2012). The final analysis produced 11 statements in which a deduction in the standard deviation from Round 2 was determined (See below).

The following statements generated a decrease in standard deviations from Round 2 to Round 3 for the specified ranking and were considered, as a group, either important, applicable, or of potential use by the panelists. (The number represents the decreased quantity in standard deviation.)

- Discussions about the following transferable skills: leadership, motivation, communication, hard work, sacrifice, prioritizing, being accountable, discipline, overcoming obstacles, positive thinking, and preparation (Importance: -0.13 , Potential Use: -0.23$)$

- Stressing transferable skills that student-athletes are developing through participation in their sport because they often do not have the opportunity to gain professional experience in a summer job or internship due to the demands of their sport (Importance: -0.09, Applicability: -0.06)

- Discussions about asking the student-athletes what they believe are their transferable skills and filling in the gaps of what they might have left out (Applicability: -0.19 , Potential Use: -0.19) 
- Using challenging sporting experiences to discuss transferable communication skills of student-athletes and how they may apply to skills in future situations (Importance: -0.05)

- Discussions about transferable skills with student-athletes by an expert in the vocational field (i.e. Career Services; Importance: -0.08, Applicability: -0.10, Potential Use: -0.16)

- Assisting student-athletes with getting involved in activities, social groups, major clubs, etc. outside of athletics because athletics too often become an identity and they should be well- rounded individuals with other avenues of social support (Potential Use: -0.11)

- Discussions with student-athletes including getting used to free time and lack of structure without sports (Applicability :-0.17)

- Discussions with student-athletes including comparison of sporting environment to working environment (career to practice, boss to coach, etc.; Importance: -0.10, Potential Use: -0.02)

- Encouraging hands-on work experience for student-athletes (Importance: -0.23, Potential Use: -0.08$)$

- Conducting discussions with student-athletes through structured organizational activities (e.g. Life Skills/Professional Development programs, 1st year study courses, etc.; Applicability: -0.07)

- Having an identified staff member address career-related tasks for student-athletes (Importance:-0.21, Potential Use: -0.13)

Group consensus with IQD. Some statements achieved a low standard deviation (SD) in the initial round of rankings but did not meet the criteria for Round 3 to be included in the final analysis, prompting a different look at achieving group consensus. Another system to determine consensus used by researchers is the interquartile deviation (IQD), which examines the 
interquartile range or the absolute value of the difference between the upper and lower percentiles of the responses (Rayens \& Hahn, 2000). Smaller values less than one (1), indicate a higher degree of consensus (Raskin, 1994; Rayens \& Hahn, 2000). This formula only takes into consideration the variation of one round of rankings and not the change in ranking between Round 2 and 3 as such the analysis of the SD was previously used in the study. The following are statements in which interquartile range was between 4 and 5 with an IQD of less than one: discussions with athletes including professionalism (punctuality, hard work, discipline, etc.; Importance, Applicability, Potential Use), discussing these topics with student-athletes all throughout their academic career (Importance, Applicability, Potential Use), discussions about transferable skills learned from sport and how they are applied towards academics or the workplace (Importance only), and discussing values with student-athletes within the framework of their decision-making process in academics and other aspects of their lives (Importance only). Although they did not meet the criteria of a reduced SD between the rounds, they all achieved an IQD less than 1 and therefore considered to be of value (see Table 2 below). 
Table 2

Group Consensus with IQD

\begin{tabular}{lccc}
\hline Statement & \multicolumn{1}{c}{ IQD } \\
\hline & Importance & $\begin{array}{c}\text { Applicability } \\
\text { Use }\end{array}$ \\
\hline $\begin{array}{l}\text { Discussions with athletes including } \\
\text { professionalism (i.e. punctuality, hard work, } \\
\text { discipline, etc.) }\end{array}$ & 0.25 & 0.00 & 0.50 \\
\hline $\begin{array}{l}\text { Discussing these topics with student-athletes } \\
\text { all throughout their academic career }\end{array}$ & 0.00 & 0.50 & 0.50 \\
$\begin{array}{l}\text { Discussions about transferable skills learned } \\
\text { from sport and how they are applied towards } \\
\text { academics or the workplace }\end{array}$ & 0.50 & $\mathrm{~N} / \mathrm{A}$ & $\mathrm{N} / \mathrm{A}$ \\
$\begin{array}{l}\text { Discussing values with student-athletes within } \\
\text { the framework of their decision-making } \\
\text { process in academics/other aspects }\end{array}$ & 0.50 & $\mathrm{~N} / \mathrm{A}$ & $\mathrm{N} / \mathrm{A}$ \\
\hline
\end{tabular}

\section{Qualitative Analysis}

Two open-ended questions were analyzed through content analysis with the assistance of an independent rater. The first round of the study requested information on how the panelists discuss transitioning out of sport with collegiate student-athletes (asking who, what, when, and how; See Appendix N). According to self-report, all panelists discuss this topic with current student-athletes, some discuss this topic with prospective student-athletes during their recruitment phase, and some discuss certain themes specific for revenue-producing/high profile sports (i.e. men's basketball and football). Discussions contained an array of topics: future vocational skills (assisting in both development and identification of skills), general academic topics, transitional topics, and topics of identity development. Topics on vocational skills included transferable skills of time management, being coachable, and working with a team, vocational skills of career networking, resume/cover letter writing, interview techniques, and internship or work experience. Topics on general academia included academic advising, degree 
requirements, information on graduate education, and an overall emphasis on the importance of academics. Transitional topics included common emotional and physical reactions, "preparing to be a professional," and plans after graduation. Topics specific for revenue-producing sports included money management, job search skills, the importance of networking, and future plans after retirement from sport. Another topic of discussion was identity development and included encouraging a multidimensional identity (inside and outside of athletics).

The timing of these topic discussions with student-athletes varied between panelists. Two panelists stated they began discussions about transitioning out of sport during the recruitment phase with potential student-athletes. Three stated they communicated about transitions throughout the student-athletes' college career. Three panelists have attempted to communicate this topic before the student-athlete's junior year (around the time majors are officially selected). Two other panelists stated these discussions occur during the studentathletes' junior and senior years. One panelist stated these discussions occur upon the request of student-athletes while another panelist stated these discussions are an integral part of his/her work with student-athletes.

These discussions were reported to occur through many different venues. Some occurred in individual sessions, either through academic advising appointments, initial recruitment meetings, or scheduled weekly meetings while other discussions occurred in groups such as team presentations, workshops, structured classes, or by guest lecturers.

Round 3 included a final question inquiring about the impact of this study on the panelists' viewpoint and/or approach to transitions out of collegiate sport. Of the six panelists who responded, one stated there was no change. Three stated the study generated additional thoughts and ideas. Two panelists stated the study reinforced their current viewpoints. In terms of any 
impact on their approach to discussions on transitioning out of collegiate sport, three panelists stated no change, two stated the study reinforced their current behavior, and one reported an increased recognition in communicating personal and professional values. 


\section{CHAPTER FIVE \\ DISCUSSION}

The purpose of this study was three-fold: (1) to explore what is currently being discussed with student-athletes who are transitioning out of collegiate sport, (2) to explore if elements of TWA were being used and how often, and (3) to inquire identified experts about the importance, applicability, and potential use of the elements of TWA with said population. The results of the current Delphi panel revealed some interesting and potentially practical information for those working with collegiate student-athletes. The following section presents (a) current discussions on transitioning out of sport, (b) occurrence of TWA elements, (c) rankings of TWA elements, (d) limitations and strengths of the study, and (e) summary and future directions.

\section{Current Discussions on Transitioning out of Sport}

This study examined the use of the elements of TWA, a vocational theory that posits matching the individual's skills and abilities to the requirements of the working environment AND matching the working environment's reinforcer system to the individual's values will result in a successful adjustment (Dawis, 1980). TWA has been used in retirement counseling (Harper \& Shoffner, 2004; Hesketh et al., 2011) in order to proactively identify elements that may be lost through the transition of retirement. Harper and Shoffner (2004) recommended that accommodations to these changes, either the individual or post-retirement environment, can be made with adequate planning and exploration in skills, abilities, and values of the individual in their existing environment. For this study, the retirees were student-athletes within their sporting environment. The initial step for this study was to explore how discussions about the inevitable transition out of collegiate sport are currently being made with student-athletes. 
With regard to the first research question, there is a wide variety in how, when, what, and with whom discussions on transitions out of collegiate sport are occurring according to the panelists. Some experts are generating these discussions during the initial meeting with potential athletes during recruitment visits while others are not opening the discussion until the junior or senior year in college. Although some panelists stated that these discussions occur throughout the student-athletes' collegiate careers, implying significance, the range in timing of these topics indicates a current lack of consensus as to when to approach this topic. There are several avenues being used to discuss these topics including individual weekly meetings, obligatory academic advising appointments, or group presentations either offered to the entire studentathletic body (e.g. workshops, classes) or in specific team presentations. The different avenues being used indicate a widespread utilization of resources or again, a lack of general consensus.

The content of the topics being discussed for student-athletes by the current panelists covered four main areas: (a) future vocational skills, (b) general academic information, (c) transitional topics, and (d) identity development. In relation to the vocational theory, the current discussions held by panelists include only half of the topics presented in TWA. The main elements of TWA are transitional skills of the individual, task requirements of the environment, values of the individuals, and matching the values to environmental reinforcers (Dawis, 2005). According to this group, only the first part of the theory is discussed through topics of transferable and vocational skills as well as discussing plans for graduation and offering a "preparing to be a professional" class (See Appendix N). Values, as an important TWA element for both the individual and the environment, was not expressed by experts as a specific topic in transitional discussions; however, the topic of values was rated somewhat commonly discussed when ranked in the initial quantitative portion of the study (see next section). 
A surprising topic that was provided by panelists was identity development. While it is not a specific element of TWA, it is found to be very useful in both transition and studentathletic identity literature, and therefore, a valuable finding of this study. The topic of athletic identities and its challenges has been discussed in the literature on student-athletes (Baille \& Danish, 1992; Beamon, 2012; Petitpas et al., 2009). Notably, student-athletes' exclusive athletic identity, which is developed through considerable time devoted to their sport, may hinder their time and commitment to outside activities (Petitpas et al., 2009; Sparkes, 1998), produce low career maturity levels (Murphy et al., 1996), and negatively affect their pursuit for an additional identity (Beamon, 2012). Given that researchers have noted challenges in having an athletic identity, one assumes it to be a beneficial and relevant topic for transitioning out of sport.

\section{Occurrence of TWA Elements}

In order to identify the occurrence of TWA elements in transitional discussions by the panel, this study used a Likert scale of 1-5 with one representing never and five representing all of the time. There was no surprise on the prominence of transferable skills found through the statistical analysis from Round 1. Panelists rated their discussion for transferable skills the most likely to occur (3.82 out of 5.0). These findings on transitional skills are supported by the literature, particularly for student-athletes (i.e., the emphasis on the usefulness of discipline, strong work ethic, perseverance, accountability, leadership, balance, commitment, assertiveness, competitive drive, and the ability to overcome opposition; Baille \& Danish, 1992; Jordan \& Denson, 1990; McKnight et al., 2009; Nathanson \& Kimmel, 2008).

Current panelists rated the element of personal and professional values as being discussed sometimes (3.30 out 5.0), although the topic of values was never mentioned in the open-ended question on how current discussions are conducted, as previously mentioned. Additionally, 
matching the values with a new non-sporting environment was reportedly discussed the least (2.2 out of 5.0). Seemingly, these panelists recognize the worth of exploring student-athletes' values, but have rarely attempted to match those values with a post-transition work setting. Additionally, only one statement referring to values was categorized under personal and professional values of the student-athlete in the final analysis. Moreover, the higher occurrence of discussing values in transitional talks indicates the usefulness for this topic, even though these panelists rarely use matching values with an environment as a current tool. The panelists found discussing values to be helpful, but may not be aware of how to conduct conversations on this topic regularly. This denotes the potential worth of TWA elements with student-athletes due to its inclusion of transferable skills, values, and matching values with a new work environment (Sharper \& Hoffner, 2004). Overall, this unique attribute of TWA may have a practical place in this setting but a remaining question for future research may be how we can apply this tool to this population.

\section{Ranking of TWA Elements}

As for the third research question, the current panel agreed that eleven statements, all of which can be categorized under one of the four elements of TWA, are either important, applicable, or of potential use with student-athletes transitioning out of collegiate sport. Seven statements were agreed to have importance and/or potential use while five statements were deemed applicable to this population (See Appendix O).

Overwhelmingly and not unexpected from the literature, the topic of transferable skills generated the most agreed upon statements with this panel. Important topics for this study included exploring the transferable skills that are developed through participation in sport and using challenging sporting experiences to discuss transferable communication skills. The statements from this study corresponded with what researchers have identified as skills that 
student-athletes learn through competition that can be transferred to their career including, but not limited to, discipline, strong work ethic, perseverance, leadership, balance, and commitment (McKnight et al., 2009; Nathanson \& Kimmel, 2008; Parcover et al., 2009). The current experts added an emphasis on communication skills and valued their personal role to help studentathletes identify lessons learned from challenging situations. As one participant stated, "challenging situations are the best lessons for student-athletes because they will often lose these skills when getting started on a career path and redefining themselves." These tools are most likely valued because they are proactive; transferable skills are important to identify before upcoming transitions.

Other statements deemed important were to compare sporting environments to working environments and stressing hands on work experience (if appropriate with sporting schedule). Several participants cited the obstacle of time restraints for student-athletes because of their commitment to their sport, however they believed outside activities were important to promote "While I encourage internships and practical experience, it is often not possible due to sport related demands." Additionally, participants stressed the importance of helping the studentathletes reframe their strengths - "oftentimes [student-] athletes say they have no job experience when they leave college because all of their time was spent playing sports...I often tell [them] that they did work full-time in college - as an athlete."

Statements that were deemed applicable for student-athletes were not always agreed upon as important, aside from discussions on transferable skills. These statements were more germane to the student-athlete population and included ideas that addressed topics specifically for studentathletes. These statements incorporated having discussions on getting used to free time and lack of structure without competitive sports, and conducting these discussions through structured 
organizational activities (i.e. LifeSkills, Professional Developmental Programs). Given that student-athletes spend a majority of their time in sport related activities (Beamon, 2012; Petitpas et al., 2009; Sparkes, 1998), participants mentioned the extreme change in post-transition free time:

The shocking change in lifestyle once competitive sport is over is not talked about often enough with student-athletes. This transition is difficult to deal with and may lead to poor decision making to fill the time or numb the loss of identity.

An identified challenge to these discussions was addressed by another panelist: "student-athletes are often too engrossed in their current time pressures to even consider what they would do with free time." Therefore, utilizing other resources such as organizational activities specific for student-athletes may provide an opportunity for them to explore these topics.

An additional step acknowledged as applicable by the current panelists was to "fill in the gap" of skills student-athletes may have missed. One participant identified that student-athletes “developmentally...do not understand [skills] while they are competing but do so after leaving the sport." This demonstrates a responsibility for the expert to be accountable to student-athletes to help guide them in this process. Additional applicable challenges for student-athletes have included losing their athletic identity, which, as previously mentioned, can be strong and enduring (Petitpas et al., 2009; Sparkes, 1994). As one panelist stated,

[It is] important to spell out how the skills [learned in sport] can be used in the real world after sport. From my experience, student-athletes understand the skills that will help them, but may not necessarily be ready to face some of the disappointment of losing their identity as a student-athlete.

Again, this denotes the responsibility of the expert to assist student-athletes by having these discussions before they begin their transition out of sport.

Of worthwhile significance are the statements ranked of potential use by the panelists. The majority of panelists, by the nature of the number of years in the field, are in positions of 
authority and influence (seven panelists are either a Director, Assistant Director, or Associate Director). These themes may carry the most weight since they were ranked as a group to be potentially useful for student-athletes: transferable skills (i.e., having discussions on transferable skills and filling the gap for what the student-athletes may have left out), decreasing high athletic identities (assisting student-athletes with getting involved in activities outside of athletics), and preparing for a new work environment (comparing sporting environment to work environment and encouraging hands-on work experience). Yet again, these statements identified potential duties of the experts including assisting student-athletes on exploring and identifying transferable skills and professional demands, as well as encouraging other identities. One panelist stated, "I find when I stress the skills they are learning, they gain more perspective," while another panelist emphasized that "just the act of discussing these issues can raise awareness." Any of these discussions can be of use and the responsibility to provide this information is (partly) with the professional.

Although all of these statements were considered important, applicable, and/or of potential use by the current expert panel, there seems to be several barriers to making these tools practical with student-athletes. One major hurdle that was repeatedly mentioned was time restraints, either placed by the coaching and athletic staff or due to the realistic schedule of being an athlete and student (the rigorousness of the sport schedule depends on the Division of the school). Another challenge seemed to be the scope of practice for those working with studentathletes on these topics. Panelists agreed on the value of having these discussions conducted by an identified career expert, indicating a call for programs to recognize this position. However, only one panelist mentioned having an identified career expert working in the department, which may be due to administrative or financial challenges: "utilizing a designated staff member to 
address career issues is a luxury that we currently can't afford but it was very beneficial when we had it previously." Other factors included the knowledge and training of such identified staff members to consist of topics such as comprehension about vocational psychology/career counseling, collegiate athletics, NCAA compliance, while also being appropriately trained in basic helping techniques. Another participant stated, "advisors need to be aware of when they are inadvertently providing counseling and referral is necessary," indicating a potential problem with scope of practice for individuals who are not appropriately licensed counselors/ psychologists.

While only eleven topics were included in the final analysis, certain statements achieved consensus by using a different mode of analysis, the interquartile deviation (IQD). Although they did not meet the required criteria of achieving a lower standard deviation (SD) between rounds, the SD in Round 2 for all statements were initially low, indicating an early convergence of opinion on all or some rankings (importance, applicability, and potential use). The first topic was discussing these topics with student-athletes all throughout their academic career (see statement 16 in Appendix M). Although there was no consensus on when these discussions were currently being conducted (as previously mentioned), the panelists agreed that these topics should occur at all points in the student-athletes' collegiate career. Additionally, the idea that values can be discussed with student-athletes within a framework of their decision makingprocess in academics and other aspects of their lives (see statement 18 in Appendix M) achieved high consensus when analyzing the IQD. This indicates potential discussion points to which values can be explored with student-athletes. Other topics included how transferable skills can be applied to academics and the importance of professionalism (See statements 5 and 11 respectively in Appendix M). Again, there is not current consensus as to when or how these 
discussions are currently being conducted, but there is some agreement on how they should and could be conducted in the future.

\section{Limitations and Strengths}

Reliability and Validity. Reliability and validity of the results has been an ongoing focus for Delphi scholars (Fink et al., 1984; Murphy et al., 1998; Powell, 2003; Sackman, 1975). Since the Delphi technique is dependent upon the response of the identified experts, the objectiveness and nature of "truth" has been questioned (Powell, 2003) and consequently the objectiveness of the data. Although the Delphi technique has been criticized for its lack of reliability measurements and scientific validity (Fink et al., 1984; Sackman, 1975), Murphy et al. (1998) countered the criticism by stating that the Delphi technique generates a consensus of existing opinions and therefore the technique should not be considered as a scientific tool for creating new data and criticized because of it. Delphi researchers explore and combine ideas to reach a consensus that may include novel ideas from existing expert opinions; they do not produce novel information using interventions or techniques. Therefore, once the experts are adequately identified, their opinions should be considered legitimate (Keeney et al., 2011; Powell, 2003; See Methods section). Additionally, as suggested by Powell (2003), follow-up inquiries were provided for panelists to respond to determine credibility of results. No individuals responded when this opportunity was provided in this study.

Limitations. Since the resultant data are a reflection of the panel members, one major limitation of the Delphi technique is the inability to replicate the exact data with another set of participants as a different group of panelists may reach another set of conclusions (Bulgar \& Housner, 2007; Graham, 2010). The size and make-up of the panel is dependent upon the response rate of those invited to participate and may have an effect on the consensus (Bulgar \& 
Housner, 2007; Fleming \& Monda-Amaya, 2001). Although there is no agreed upon number of participants for the Delphi panel, the original number of participants was proposed to be 18, with a comfortable allowance for attrition rate during the three rounds. However, participant recruitment was an obstacle for this study. During the recruitment process, only two participants were interested in the first recruitment round after a two-week period. A second recruitment letter was sent out and potential participants were given another two weeks to respond. Although the initial number of recruited participants set in the proposal was not met, the primary investigator, with permission of her chair, closed recruitment at 14 participants since no other participants were willing at that time. The background of the participants varied across the three fields and 14 participants at the commencement for the study was approved. However, after the first round was distributed via e-mail (with two reminder e-mails), only 11 panelists completed Round 1. The same 11 panelists also completed Round 2. Unfortunately, only eight panelists completed Round 3 after four e-mails (one initial and three reminder e-mails). The three panelists who did not complete the final round are unknown as responses in the last round were anonymous.

One explanation for the unsuccessful recruitment and attrition of panelists was the timing of the study. All panelists worked within an academic calendar, and the timing of the surveys spilled over into winter break. Stress from the holidays, vacation, ending and beginning semesters may have all been factors to a higher attrition rate than anticipated. Still, the panelists were made aware of the time frame of the three surveys before they agreed to participate, and the primary investigator provided an extra week to respond to Rounds 2 and 3 since they were given in the midst of the winter holidays. Given this fact, there may have been participation fatigue after the initial round of surveys. Additionally, there may have been potential bias for those who 
completed all three surveys (e.g., those with an interest in either the use of vocational theories or transitional research). Future studies should keep timing of the survey distribution into account. Another limitation of the study was the quasi-anonymity of the design. While the participants were well informed of the nature of anonymity in this study, there was a change in rank order between round 2 and 3, which is not considered a pattern of generating a consensus (reduction in standard deviation). Some participants may have changed their rankings entirely for Round 3 since it was completely anonymous to the primary investigator. Therefore, future studies should keep the entire study quasi-anonymous instead of just one round in order to improve consistency.

A last limitation of the study was the lack of consensus among researchers to determine group consensus. The primary investigator used a reduction in SD in the final round to determine group consensus, as found in the literature (Neimeyer et al., 2012; Norcross et al., 2002). In addition, the IQD of remaining statements was also used to determine other statements of value that were not included in the final analysis (Rayens \& Hahn, 2000).

Strengths. The Delphi technique is a research design that is growing in popularity, especially in the health sciences (Keeney et al., 2011; Murphy et al., 1998). The Delphi technique has been praised for its relative ease for participants (Hanafin et al., 2007; Powell, 2003), flexibility and adaptability in different settings (Powell, 2003), efficiency (Hanafin et al., 2007; Murphy et al., 1998; Powell, 2003), transparency (Hanafin et al., 2007), and inclusion of several different views while providing information for the group (Keeney et al., 2011; Murphy et al., 1998). Overall, Hanafin et al. (2007) described the Delphi technique as "a comprehensive, systematic, transparent, and novel approach" to achieving a consensus (p. 100).

One of the most significant benefits of the Delphi method is that it does not physically 
constrain the panelists to meet in the same place at the same time (Fink et al., 1984; Murphy et al., 1998), "thereby reducing the logistical constraints of the study... [making] the Delphi method highly suitable for practice-based research" (Graham, 2010, p. 216). This was also a benefit of the current study as participants from across the country provided a geographical representation of the data. The opinions generated were from a group of identified experts with an average of 14 years of experience in the fields of counseling psychology, sport and exercise psychology, and academic advising for athletics. The majority of participants had training and identified in more than one of these fields. The panel represented different positions, from different universities, from all regions of the country. Overall, the generalizability of the results is limited to the specific opinions of the panelists who completed all three rounds (Bulgar \& Housner, 2007; Fleming \& Monda-Amaya, 2011; Graham, 2010; Hanafin et al., 2007). However, the use of a nation-wide sample of identified experts in achieving a collective agreement in this exploratory study can be used as a solid stepping-stone for future research.

\section{Summary and Future Directions}

Overall, data from this study provided initial evidence into what is currently being discussed with student-athletes on the topic of transitioning out of collegiate sport. There was disparity into how, when, and what is currently being discussed with student-athletes. However, there was an agreement that these discussions should occur throughout the collegiate career and should include certain topics. The current data supported the use of transitional skills, as an important, applicable, and potentially useful tool (as seen in previous literature and with general vocational theories). The study also explored the use of elements of the vocational theory TWA in which the distinguishing characteristic is the additional emphasis on an individual's values and matching those values with a new working environment. Discussion about values were 
deemed important by this expert panel, however it was surprising that is was not a specific topic of discussion and was rarely discussed in relation to matching values with a new environment. Most of the elements of TWA (i.e., individual's skills and values and the environment's requirements) were deemed important, applicable, or of potential use when asked specifically.

The results of the study provided valuable answers but generated more questions as well. For example, what are the responsibilities of the providers for student-athletes? Many of the experts provided several examples of addressing the issue of transitioning out of sport including when, how, and why. While the resultant data provided good advice on how to approach this topic, primarily spelling out transferable skills of student-athletes, filling in the gap of what they missed, and/or providing encouragement for vocational experience, there was no consensus on what should be discussed. Therefore what should be the standard, what should be discussed with every student-athlete before they transition out of sport?

This study included counseling psychologists, sport psychology consultants, and academic advisors for athletics, all with different education, training, and scope of practice. Being able to hold (possibly mandatory) discussions on transitions seems to necessitate knowledge about collegiate athletics and vocational theories, as well as counseling skills somewhat of a specialty. Therefore a follow-up question is what position would hold these responsibilities and who can be trained in this specialty? It was clear from this panel that having an identified staff member to address vocational concerns, not just academic issues, is essential for student-athletes. Future research can focus on evaluating programs that have an identified vocational staff member or program and/or create pilot programs to evaluate the applied use of the elements of TWA within the student-athlete population. 
One limitation for professionals working with student-athletes that was addressed by some panelists in this study was the concept of athletic identity and the barriers of time and commitment to sport. The topic of athletic identity has been a focus of past research, indicating usefulness in competition but a barrier to achieving other vocational identities and vocational maturity. Additionally, the time and commitment demanded by competitive sports (particularly high revenue producing sports) is a core element of collegiate athletics. Another follow-up question to pursue in future research is how can we practically use student-athletes' core values in sports to help them in their transition? Instead of attempting to fight against athletic identities and commitment to sport, how can we work with these concepts to help smooth the studentathletes inevitable transition?

As an exploratory study, the data indicate a need for further evaluation on how the elements of TWA can be practically used with student-athletes by generating an instrument to measure its occurrence and effect. Further studies can address the use of this theory for specific populations (e.g., revenue vs. non-revenue producing athletes, Division I vs. Division III, etc.). Other topics to consider are the potential barriers for using this tool (e.g., time restraints of the student-athlete to explore other identities, financial strain of creating a new position in athletic departments, etc.) and how to overcome these barriers.

Additional research opportunities can also examine the usefulness of TWA with other specific populations preparing for transition and loss of identity - such as military service men and women transitioning to civilian life as veterans. Transitioning out of the military may be considered a form of retirement and therefore, TWA may be practical for this population as well.

From a counseling psychology perspective, the importance of this study relates to the fundamental themes of counseling psychology to include education and career development, 
person-environment interactions, and a focus on an individual's strengths and assets. While this study examined student-athletes' transition from a career development model, future implications from this study could include environmental/organizational analyses (i.e. ecological systems approach) to include how groups and individuals from the NCAA, university, athletic department, counseling department, and other departments focused on student-athletes affairs could work together to support the student-athlete prepare for their transition. Additionally, counseling psychologists are trained to create a therapeutic relationship, emphasizing a strengthbased approach by identifying the individual's skills, values, and past achievements in order to assist him/her in the current situation. Overall, due to their training in basic counseling techniques, communication skills, and vocational education, counseling psychologists can offer direction and support for student-athletes transitioning out of sport. 


\section{References}

Association of Applied Sport Psychology (AASP; 2013). Retrieved from: http://www. appliedsportpsych.org/about

American Psychological Association (APA47; 2013). Division 47: Exercise and sport psychology. Retrieved from: http://www.apadivisions.org/division-47/about/index.aspx

Baille, P. H., \& Danish, S. J. (1992). Understanding the career transition of student-athletes. The Sport Psychologist, 6, 77-98.

Beamon, K. (2012). 'I'm a baller': Athletic identity foreclosure among African-American former student-athletes. Journal of African American Studies, 16(2), 195-208. doi: $10.1007 / \mathrm{s} 12111-012-9211-8$

Beamon, K., \& Bell, P. A. (2002). 'Going pro': the deferential effects of high aspirations for a professional sports career on African-American student-athletes and White studentathletes. Race and Society, 5(2), 179-191. doi:10.1016/j.racsoc.2004.01.006

Beck, J., Bennett, G., Maneval, M., \& Hayes, H. (2001). A pilot study: Faculty perceptions of the academic performance of student-athletes. Applied Research in Coaching and Athletic Annual, 16, 125-143.

Birky, I. (2007). Counseling student-athletes as a specialization. In J. A. Lippencott (Ed.), Special populations in college counseling: A handbook for mental health professionals (pp. 21-35). Alexandria, VA: American Counseling Association.

Bizot, E. B., \& Goldman, S. H. (1993). Prediction of satisfactoriness and satisfaction: An 8-year follow-up. Journal of Vocational Behavior, 43, 19-29.

Blinde, E. M., \& Stratta, T. M. (1992). The "sport career death" of college student-athletes: Involuntary and unanticipated sport exits. Journal of Sport Behavior, 15, 3-20. 
Boerner, W. A. (2011). Transitional leadership: Perceptions of interim mid-level student affairs professionals. Dissertation Abstracts International Section A: Humanities and Social Sciences, VOl71(11-A), 3938.

Bond, K., Ospina, M.B., Hooten, N., Bialy, L., Dryden, D. M., et al. (2009). Defining a complex intervention: The development of demarcation criteria for "meditation." Psychology of Religion and Spirituality, 1(2), 129-137. doi: 10.1037/a0015736

Brown, C., \& Hartley, D. L. (1998). Athletic identity and career maturity of male college student athletes. International Journal of Sport Psychology, 29(1), 17-26.

Brown, C., Gasteletter-Fender, C., \& Shelton, M. (2000). Psychosocial identity and career control in college student-athletes. Journal of Vocational Behavior, 56, 53-62. doi: 10.1006/jvbe.1999.1691

Bulgar, S. M., \& Housner, L. D. (2007). Modified Delphi investigation of exercise science in Physical Education Teacher Education. Journal of Teaching in Physical Education, 26, 57-80.

Burnett, C. (2010). Student versus athlete: Professional socialisation influx: psychosocial perspectives of sports. African Journal for Physical Health Education, Recreation and Dance: Special Issue 1, 16, 193-203.

Burns, G. N., Jansinski, K., Dunn, S. C., \& Fletcher, D. (2012). Athletic identity and athlete satisfaction: The nonconformity of exclusivity. Personality and Individual Differences, 52(3), 280-284. doi: 10.1016/j.paid.2011.10.020

Capuzzi, D., \& Stauffer, M. D. (2006). Career counseling: Foundations, perspective, and applications. Boston: Pearson Education. 
Cicarelli, J. (1984). The future of economics: A Delphi study. Technological Forecasting and Societal Change, 25, 139-157.

Chow, B. C. (2001). Moving on? Elite Hong Kong female athletes and retirement from competitive sport. Women in Sport \& Physical Activity Journal, 10(2), 47.

Creswell, J. W. (2008). Research design: Qualitative, quantitative, and mixed method approaches. Thousand Oaks CA: Sage Publications.

Creswell, J. W. (2009). Editorial: Mapping the field of mixed methods research. Journal of Mixed Methods Research, 3(2), 95-108.

Danish, S. J., Petitpas, A. J., \& Hale, B. D. (1992). A developmental-educational intervention model of sport psychology. The Sport Psychologist, 6, 403-415.

Dawis, R. V. (1980). Personnel assessment from the perspective of the Theory of Work Adjustment. Public Personnel Management Journal 9(4), 268-273.

Dawis, R. V. (2005). The Minnesota Theory of Work Adjustment. In S.D. Brown and R.W. Lent (Eds.), Career development and counseling: Putting theory and research to work (pp. 3-23). Hoboken, NJ: John Wiley \& Sons, Inc.

Delbecq, A. L., Van de Ven, A. H, \& Gustafson, D. H. (1975). Group techniques for program planning; A guide to nominal group and Delphi process. Glenview IL: Scott, Foresman, \& Company.

Ericsson, K. A. (2008). Deliberate practice and acquisition of expert performance: A general overview. Academic Emergency Medicine 15(11), 988-994. doi: 10.111/j.15532712.2008.00227.x

Erikson, E. H. (1959, 1980). Identity and the Life Cycle. NY: W.W. Norton \& Co. 
Etzel, E., \& Watson, J. (2007). Ethical challenges for psychological consultations in intercollegiate athletics. Journal of Clinical Sport Psychology, 1, 304-317.

Fassinger, R. E. (2005). Theoretical issues in the study of women's career development:

Building Bridges in a brave new world. In W. B. Walsh and M.L. Savickas (Eds.), Handbook of vocational psychology, (3 ${ }^{\text {rd }}$ ed.) (pp. 85-124). Mahwah, NJ: Lawrence Erlbaum Associates, Inc.

Fink, A., Kosecoff, J., Chassin, M., \& Brook, R. H. (1984). Consensus methods: characteristics and guidelines for use. American Journal of Public Health, 74(9), 979-983.

Fleming J. L., \& Monda-Amaya, L. E. (2001). Process variables critical for team effectiveness: A Delphi study of wraparound team members. Remedial and Special Education, 22(3), 158-171. doi: 10.1177/074193250102200304

Forman, J., \& Damschroder, L. (2008). Qualitative content analysis. In L. Jacoby \& L.A. Sminoff (Eds.), Empirical methods of bioethics: A primer (pp. 39-62). Amsterdam: Elsevier

Gay, E. G., Weiss, D. J., Hendel, D. D., Dawis, R. V., \& Lofquist, L. H. (1971). Manual for the Minnesota Importance Questionnaire. Minnesota Studies in Vocational Rehabilitation (No. XXVIII), 1-83. Minneapolis: University of Minnesota, Industrial Relations Center. Gelso, C., \& Fritz, B. (2001). Counseling Psychology (2 ${ }^{\text {nd }}$ ed.). Belmont, CA: Wadsworth, Cengage Learning.

Gibson, D. L., Weiss, D. J., Dawis, R. V., \& Lofquist, L. H. (1970). Manual for the Minnesota Satisfactoriness Scale. Minnesota Studies in Vocational Rehabilitation (No. XXVII), 151. Minneapolis: University of Minnesota, Industrial Relations Center. 
Goodman, C. M. (1987). The Delphi technique: Critique. Journal of Advanced Nursing, 12, 729734.

Goodman, J., \& Pappas, J. G. (2000). Applying Schlossberg 4S Transition Model to retired university faculty: Does it fit? Adultspan: Theory Research \& Practice, 2(1), 15-29. doi: 10.1002/j.2161-0029.2000.tb00088.x

Gorbett, F. J. (1985). Psychosocial adjustment of student-athletes to retirement. In L. K. Bunker, R. J. Rotella, \& A. Reilly (Eds.), Sport psychology: Psychological considerations in maximizing sport performance (pp. 288-294). London: Movement Publishers.

Graham, C. (2010). Hearing the voices of general staff: A Delphi study of the contributions of general staff to student outcomes. Journal of Higher Education Policy and Management, 32(3), 213-223. doi: 10.1080/13600801003743315

Hanafin, S., Brooks, A-M. Carroll, E., Fitzgerald, E., Gabhainn, S. N., \& Sixsmith, J. (2007). Achieving consensus in developing a national set of child well-being indicators. Social Indicators Research, 80, 79-104. doi: 10.1007/s11205-006-9022-1

Harper, M. C., \& Shoffner, M. F. (2004). Counseling for continual career development after retirement: An application of the Theory of Work Adjustment. Career Development Quarterly, 52(3), 272-284.

Harrison, K. (2000). Black athletes at the millennium. Society, 37, 35-39. doi: $10.1007 / \mathrm{BF} 02686172$

Harrison, C. K., \& Lawrence, S. M. (2003). African-American student-athletes' perceptions of career transitions in sport: a qualitative and visual elicitation. Race, Ethnicity, \& Education, 6(4), 373-394. doi: 10.1080/136133203000146384 
Hesketh, B., \& Griffin, B. (2005). Work adjustment. In W. B. Walsh and M.L. Savickas (Eds.), Handbook of Vocational Psychology (3 ${ }^{\text {rd }}$ ed.) (pp. 245-266). Mahwah, NJ: Lawrence Erlbaum Associates, Inc.

Hesketh, B., Griffin, B., \& Loh, V. (2011). A future-oriented retirement transition adjustment framework. Journal of Vocational Behavior, 79, 303-314. doi: 10.1016j.jvb.2011.03.008

Hesketh, B., McLachlan, K., \& Gardner, D. (1992). Career compromise: An alternative account to Gottffedson's theory. Journal of Counseling Psychology, 37, 49-56.

Holland, J. L. (1959). Theory of vocational choice. Journal of Counseling Psychology, 6, 35-45.

Holland, J. L. (1985). Making vocational choices: A theory of vocational personalities and work environments ( $2^{\text {nd }}$ ed.). Englewood Cliffs, NJ: Prentice Hall, Inc.

Joiner, K. D., \& Landreth, G. L. (2005). Play therapy instruction: A model based on objective developed by the Delphi technique. International Journal of Play Therapy, 14(2), 4968. doi: $10.1037 / \mathrm{h} 0088902$

Jordan, J. M., \& Denson, E. L. (1990). Student services for student-athletes: A model for enhancing student-athlete's experiences. Journal of Counseling and Development, 69, 95-97. doi: 10.1003/j.1556.6676.1990.tb01467.x

Keeney, S., Hasson, F., and McKenna, H. (2011) The Delphi Technique, in The Delphi Technique in Nursing and Health Research, Oxford, UK: Wiley-Blackwell doi: 10.1002/9781444392029.ch1

Kleiber, D. A., \& Brock, S. C. (1992). The effect of career-ending injuries on the subsequent well-being of elite college athletes. Sociology of Sport Journal, 9(1), 70-75. 
Krylowicz, B. J. (2000). Student-athlete or athlete-student? An investigation of athletic and vocational identity of Division I male and female collegiate basketball players. Dissertation Abstracts International: Section B: The Sciences and Engineering, 60(11B), 5823 .

Lally, P. (2006). Identity and athletic retirement: A prospective study. Psychology of Sport and Exercise, 8(1), 85-99. doi: 10.1016/j.psychsport.2006.03.003

Linnemeyer, R. M., \& Brown, C. (2010). Career maturity and foreclosure in student-athletes, fine arts students, and general college students. Journal of Career Development, 37(3), 616-634. doi: 10.1177/0894845309357049

Lofquist, L., \& Dawis, R. V. (1969). Adjustment to work. New York: Appleton Century Crofts. MacLean, J., \& Hamm, S. (2008). Values and sport participation: Comparing participating groups, age, and gender. Journal of Sport Behavior, 31(4), 352-367.

Marcia, J. M. (2002a). Adolescence, identity, and the Bernardone family. Identity: An International Journal of Theory and Research, 2(3), 199-209.

Marcia, J. M. (2002b). Identity and psychosocial development in adulthood. Identity: An International Journal of Theory and Research, 2(3), 7-28.

Martens, M. P., \& Lee, F. K. (1998). Promoting life-career development in the student-athlete: How can career centers help? Journal of Career Development, 25(2), 123- 134. doi: 10.1023/A:1022903627665

Mason, M. (2010). Sample size and saturation in Ph.D. studies using qualitative interviews. Qualitative Social Research, 11(3), Art. 8.

McKenna, H. P. (1994) The Delphi technique: A worthwhile approach for nursing. Journal of Advanced Nursing, 19, 1221-1225. 
McKnight, K., Bernes, K., Gunn, T., Chorney, D., Orr, D., \& Bardick, A. (2009). Life after sport: Athletic career transition and transferable skills. Journal of Excellence, 13, 63-77.

Miller, D. S., \& McWhirter, E. H. (2006). The history of career counseling: From Frank Parsons to twenty-first century challenges. In D. Capuzzi \& M.D. Stauffer (Eds.), Career counseling: Foundations, perspectives, and applications (pp. 3-39). Boston: Parsons Education, Inc.

Murphy, G. M., Petitpas, A. J., \& Brewer, B. W. (1996). Identity foreclosure, athletic identity, and career maturity in intercollegiate student-athletes. The Sport Psychologist, 10, 239246.

Murphy, M. K., Black, N., Lamping, D. L., McKee, C. M., Sanderson, C. F. B., Askham, J. et al. (1998). Consensus development methods and their use in clinical guideline development. Health Technology Assessment, 2 (3).

N4A (2013). National Association of Academic Advisors for Athletics. Retrieved from: http://grfx.cstv.com/photos/schools/nacda/sports/nfoura/auto_pdf/201213/misc_non_event/contandbylaw.pdf

NACDA (2013). National Association of Collegiate Athletic Directors. Retrieved from: http://www.nacda.com/nfoura/aboutus.html

Nathanson, B., \& Kimmel, A. (2008). The college student-athlete's guide to academic success. Upper Saddle River, New Jersey: Prentice Hall Publishing.

NCAA (2008). NCAA CHAMPS/Lifeskills Program 2007-2008 (online PDF). Retrieved from http://fs.ncaa.org/Docs/library/general/champs_life_skills/champs_life_skills.pdf 
NCAA. (2010). Estimating probability of competing in athletics beyond the high school interscholastic level [Website]. Retrieved from http://www.ncaa.org/wps/wcm/ connect/public/ncaa/issues/recruiting/probability + of + going + pro

Neimeyer, G. J., Taylor, J. M., \& Rozensky, R. H. (2012). The diminishing durability of knowledge in professional psychology: A Delphi Poll of specialties and proficiencies. Professional Psychology: Research and Practice, 43(4), 364-371. doi:10.1037/a0028698

Niles, S. G., \& Harris-Bowlsbey, J. (2002). Career development interventions in the $21^{\text {st }}$ century. Upper Saddle River, NJ: Merrill Prentice Hall.

Norcross, J. C., Hedges, M., \& Prochaska, J. O. (2002). The face of 2010: A Delphi poll on the future of psychology. Professional Psychology: Research and Practice, 33(3), 316322. doi: $10.1037 / 0735-7028.33 .3 .316$

Okali, C., \& Pawlowski, S. D. (2004). The Delphi method as a research tool: An example, design considerations and applications. Information \& Management, 42(1), 15-29. doi: 10.1016/j.im.2001.11.002

Osipow, S. H. (1983). Theories of career development ( $3^{\text {rd }}$ ed.). Englewood Cliffs, NJ: Prentice Hall, Inc.

Parcover, J. A., Metrick, J., Parcover, C. A. D., \& Griffen-Smith, P. (2009). University and college counselors as athletic team consultants: Using a structural family therapy model. Journal of College Counseling, 12(2), 149-161. doi: 10.1002/j.21611882.2009.tb00112.x

Parsons, F. (1909). Choosing a vocation. Boston: Houghton-Mifflin. 
Petitpas, A. J., Brewer, B. W., \& Van Raalte, J. L. (2009). Transitions of the student-athlete: Theoretical, empirical, and practical perspectives. In E. Etzel (Ed.), Counseling and psychological services for college student-athletes (pp. 283-302). Morgantown, WV: Fitness Information Technology.

Petrie, T. A., \& Denson, E. L. (2003). The student-athlete guide to college success: Peak performance in class and life ( $2^{\text {nd }}$ ed.). Belmont, CA: Wadsworth Thomson Learning. Pinkney, J. W., \& Tebbe, C. (2009). The college student-athlete experience and academics. In E. Etzel (Ed.), Counseling and psychological services for college student-athletes (pp. 257-282). Morgantown, WV: Fitness Information Technology.

Powell, C. (2003). The Delphi technique: Myths and realities. Journal of Advanced Nursing, 41(4), 376-382. doi: 10.1046/j.1365-2468.2003.02537.x

Raskin, M. S. (1994). The Delphi study in field instruction revisited: Expert consensus on issues and research priorities. Journal of Social Work Education, 30, 75-89.

Rayans, M. K., \& Hahn, E. J. (2000). Building consensus using the policy Delphi Method. Policy, Politics, \& Nursing Practice, 1(4), 308-315.

Sackman, H. (1975). Delphi Critique. Boston: Lexington Books.

Schlossberg, N. K. (1981). A model for analyzing human adaptation to transition. The Counseling Psychologist, 9, 2-18. doi:10.1177/001100008100900202.

Schlossberg, N. K., Waters, E. B., \& Goodman, J. (1995). Counseling adults in transition: Linking practice with theory ( $2^{\text {nd }}$ ed.). New York: Springer Publishing. doi: $10.1080 / 0380127840100507$

Sharf, R. S. (1996). Theories of psychotherapy and counseling: Concepts and cases. Pacific Grove: CA; Brooks/Cole Pub. Co. 
Sharf, R. S. (2002). Applying career development theory to counseling ( $3^{\text {rd }}$ Ed.). Pacific Grove, CA: Wadsworth Group.

Shelton, K. (2010). A quality scorecard for the administration of online education programs: A Delphi study. Journal of Asynchronous Learning Networks, 14(4), 36-48.

Shoffner, M. F. (2006). Career counseling: Theoretical perspectives: In D. Capuzzi \& M.D. Stauffer (Eds.), Career counseling: Foundations, perspectives, and applications (pp.4068). Boston: Parsons Education, Inc.

Shurts, W. M., \& Shoffner, M. F. (2004). Providing career counseling for collegiate studentathletes: A learning theory approach. Journal of Career Development, 31(2), 95-109. doi: $10.1007 / \mathrm{s} 10871-004-0567-4$

Sparkes, A. C. (1998). Athletic identity: An Achilles' heel to the survival of self. Qualitative Health Research, 8(5), 644-664. doi: 10.1177/104973239800800506

Speight, S., Thomas, A. J., Kennel, R. G., \& Anderson, M. E. (1995). Operationalizing multicultural training in doctoral programs and internships. Professional Psychology:Research and Practice, 26(4), 401-406. doi: 10.1037/0735-7028.26.4.401

Stambulova, N., \& Alfermann, D. (2007). Career transitions and career termination. In G. Tennanbaum \& R.C. Eklund (Eds.), Handbook of sport psychology $\left(3^{\text {rd }}\right.$ ed.) (pp.712733). Hoboken, NJ: John Wiley \& Sons Inc.

Stankovich, C. E., Meeker, D. J., \& Henderson, J. L. (2001). The Positive Transitions Model for sport retirement. Journal of College Counseling, 4, 81-84. doi: 10.1002/j.21611882.2001.tb00186.x

Stauffer, L. B. (2012, Spring). CHAMPS/Life Skills program supports student-athletes. Retrieved from: http://news.illinois.edu/postmarks/spring_2012/champs.html. 
Super, D. E. (1953). A theory of vocational development. American Psychologist, 8, 185-190.

Super, D. E. (1983). Assessment in career guidance: Toward truly developmental counseling. Personnel \& Guidance Journal, 61(9), 555-563. doi: 10.111/j.2164-4918.1983.tb00099.x

Tasse, M. J., Sabourin, G., Garcin, N., \& Lacavalier, L. (2010). Definition of serious behavior disorder of people with intellectual disabilities. Canadian Journal of Behavioral Sciences, 42(1), 62-69. doi: 10.1037/a0016249

Taylor, J., \& Ogilvie, B. C. (1994). A conceptual model of adaptation to retirement among athletes. Journal of Applied Sport Psychology, 6, 1-20. doi: 10.1080/10413209408406462

Torregrosa, M., Boixados, M., Valiente, L., \& Cruz, J. (2004). Elite athletes' image of retirement: The way to relocation in sport. Psychology of Sport \& Exercise, 5(1), 35-44. doi: 10.1016/S1469-0292(02)00052-3

Voelker, R. (2012). Hot careers: Sport psychology. Retrieved from http:/www.apa.org/gradpsych/2012/11/sport-psychology.aspx

Walsh, W. B., \& Savickas, M. L. (2005) Current issues and innovations in vocational psychology. In W. B. Walsh \& M. L. Savickas (Eds.), Handbook of vocational psychology ( $3^{\text {rd }}$ ed.) (pp. 3-11). Mahwah NJ: Lawrence Erlbaum Associates, Inc.

Watson, J. C. (2003). Overcoming the challenges of counseling college student-athletes. ERIC Clearinghouse on Counseling and Student Services, EDO-CG-03-01

Webb, W. M., Nasco, S. A., Riley, S., Headrick, B. (1998). Athlete identity and reactions to retirement from sports. Journal of Sport Behavior, 21(3), 338-362.

Weiss, D. J., Dawis, R.V., England, G. W., \& Lofquist, L. H. (1967). Manual for the Minnesota Satisfaction Questionnaire. Minnesota Studies in Vocational Rehabilitation (No. XXII), 1-119. Minneapolis: University of Minnesota, Industrial Relations Center. 
Wooten, H. R. (2005). Healing into life after sport: Dealing with student-athletes' loss, grief, and transition with EFT. Journal of Creativity in Mental Health, 1(3/4), 89-102. doi: 10.1300/J450v01n03_06

Wylleman, P., Alfermann, D., \& Lavallee, D. (2004). Career transitions in sport: European perspectives. Psychology of Sport \& Exercise, 5(1), 7-20. doi: 10.1016/S14690292(02)00049-3 


\begin{abstract}
Appendix A
Propositions of the Theory of Work Adjustment

Dawis \& Lofquist (2005)
\end{abstract}

Person $(\mathrm{P})$ in an Environment $(\mathrm{E})$

Proposition I. Work adjustment at any time is indicated by the current levels of $\mathrm{P}$ satisfaction and P satisfactoriness.

Proposition II. Satisfaction if predicted from E Reinforcers to P Value Correspondence, provided that there is $\mathrm{P}$ Abilities to E Ability requirements Correspondence

Corollary IIa. Knowledge of E Reinforcers and P Satisfaction permits the inference of $\mathrm{P}$

Values.

Corollary IIb. Knowledge of P Values and P Satisfaction permits the inference of E

Reinforcers.

Proposition III. Satisfactoriness is predicted from P Abilities to E Ability Requirements

Correspondence, provided that there is E Reinforcers to P Values Correspondence.

Corollary IIIa. Knowledge of P Abilities and P Satisfactoriness permits the inference of E Ability Requirements.

Corollary IIIb. Knowledge of E Ability Requirements and P Satisfaction permits the inference of P Abilities

Proposition IV. Satisfactoriness moderates the prediction of P Satisfaction from E Reinforcers to

P Values Correspondence

Proposition V. Satisfaction moderates the prediction of P Satisfactoriness from P Abilities to E

Ability Requirements Correspondence

Proposition VI. The probability that $\mathrm{P}$ will quit $\mathrm{E}$ is inversely related to $\mathrm{P}$ Satisfaction

Proposition VII. The probability that $\mathrm{E}$ will fire $\mathrm{P}$ is inversely related to $\mathrm{P}$ Satisfactoriness

Proposition VIII. P Tenure is predicted from P Satisfaction and P Satisfactoriness

Given Propositions II, III, \& VIII:

Corollary VIIIa. Tenure is predicted from E Reinforcers to P Values Correspondence and P Abilities to E Ability Requirements Correspondence.

Corollary VIIIb. P Tenure is predicted from P-E Correspondence

Proposition IX. P-E Correspondence increases as a function of $\mathrm{P}$ Tenure

Proposition X. P Style to E Style Correspondence moderates the prediction of P Satisfaction and P Satisfactoriness from P Values/Abilities to E Reinforcers/Requirements Correspondence Proposition XI. P Flexibility moderates the prediction of P Satisfaction from E Reinforcers to P Values Correspondence

Proposition XII. E Flexibility moderates the prediction of P Satisfactoriness from P Abilities to E Ability Requirements Correspondence

Proposition XIII. The probability that P Adjustment Behavior will occur is inversely related to P Satisfaction.

Corollary XIIIa. Knowledge that this probability associated with P Satisfaction permits the determination of the P Flexibility threshold Proposition XIV. The probability that E Adjustment Behavior will occur in inversely related to $\mathrm{P}$ Satisfactoriness

Corollary XIVa. Knowledge that this probability associated with P Satisfactoriness permits the determination of the E Flexibility threshold Proposition $\mathrm{XV}$. The probability that $\mathrm{P}$ will quit $\mathrm{E}$ is inversely related to $\mathrm{P}$ Perseverance 
Corollary XVa. Knowledge of this probability associated with P's quitting E permits the determination of the P Perseverance threshold

Proposition XVI. The probability that $\mathrm{E}$ will fire $\mathrm{P}$ is inversely related to $\mathrm{E}$ Perseverance

Corollary XVIa. Knowledge of this probability associated with E's firing P permits the determination of the E Perseverance threshold.

Given Propositions VII, XV, \& XVI:

Proposition XVII. P Tenure is predicted jointly from P Satisfaction, P Satisfactoriness, P

Perseverance, and E Perseverance 
Appendix B

IRB Approval

Document ID: 4578

Status: Active

Initiator: Last Updated: jyoung3: 11:24 AM 11/13/2013

Submission Status: Approved

Protocol \#: 1306054453

Expiration Date: 10/13/2016 


\section{Appendix C \\ Permission for Recruiting Participants through List-Serve Introductory E-mail}

Dear [coordinator of list-serve],

My name is Jes Leonard. I received my masters in Sport Psychology at Ithaca College and am now earning my Ph.D. in Counseling Psychology at West Virginia University. Currently I am conducting my dissertation (under the supervision of Chris Schimmel, Ed.D. and in fulfillment of my program research requirements). The purpose of my research study is to explore what is currently being discussed with collegiate student-athletes who are about to transition out of collegiate sport and if elements of the vocational Theory of Work Adjustment (TWA) would be applicable to use with them. My plan is to conduct a Delphi panel and I am writing to request permission to recruit participants from the N4A list-serve. The N4A list-serve includes highly trained individuals who have a variety of experiences working with collegiate student-athletes. Their participation is completely voluntary and would be greatly appreciated.

The criteria for participation:

(a) you must be 18 years or older

(b) you must hold a current position in an academic college or university

(c) you must have an average of at least 10 years* working with collegiate student-athletes (through academic services/counseling, through direct clinical hours, supervising counseling/clinical/or sport psychology graduate students working with student-athletes) *can include pre-doctoral work

This study will be conducted through three rounds of on-line surveys. The initial round will be anonymous and include open-ended questions regarding student-athletes transition out of sport. In the two subsequent rounds, they will be asked to rank statements according to the data analyzed from the previous rounds. These rounds will be anonymous to other participants but will not be to the primary investigator in order to offer specific feedback to each participant after each round. Each round of the surveys should take about 20-30 minutes (maximum) to complete. Demographic data will be kept confidential (only myself and my chair will have access to the information in a password protected file). The information will only be used for descriptive statistics on educational level, training/education, and number of years working with studentathletes. Please note that participation is completely voluntary; participants' status will not be affected by refusal to participate in the study or if they choose to withdrawal from the study at any time. Additionally, participants do not need to answer every question. Furthermore, there are no anticipated risks for participation.

This study has been reviewed and I have received permission to conduct it from WVU's IRB (\#1306054453).

If you have any questions, please do not hesitate to call or contact me through e-mail. Thank you very much for your time.

Sincerely,

Jes Leonard

Jes.Leonard@mail.wvu.edu

(240) 298-3041
Chris Schimmel, Ed.D.

Chris.Schimmel@mail.wvu.edu

(304) 293-2266 
Dear [list-serve] members,

\author{
Appendix D \\ Participant Recruitment \\ Introductory E-mail
}

Are you interested in assisting student-athletes transition out of sport? Your practical experience, insight, and judgment are wanted for an exploratory study!

My name is Jes Leonard. I received my masters in Sport Psychology at Ithaca College and am now earning my Ph.D. in Counseling Psychology at West Virginia University. Currently I am conducting my dissertation (in fulfillment of my program research requirements and under the supervision of Chris Schimmel, Ed.D.). The purpose of my study is to explore what is currently being discussed with collegiate student-athletes who are about to transition out of collegiate sport and if elements of the vocational Theory of Work Adjustment (TWA) would be applicable to use with them. My plan is to conduct a Delphi panel from related fields (academic services, sport psychology, and counseling psychology). I am writing to request your participation. Again, your experiences and opinions would be an asset to this study!

This study will be conducted through three rounds of on-line surveys. The initial round will be anonymous and include open-ended questions regarding student-athletes transition out of sport. In the two subsequent rounds, you will be asked to rank statements according to the data analyzed from the previous rounds. These rounds will be anonymous to other participants but will not be to the primary investigator in order to offer specific feedback to each participant after each round. Each round of the surveys should take about 20-30 minutes (maximum) to complete. This study has been reviewed and I have received permission to conduct it from WVU's IRB (\# 1306054453).

The criteria for participation:

(a) you must be 18 years or older

(b) you must hold a current position in an academic college or university

(c) you must have an average of at least 10 years* working with student-athletes (through academic services/counseling, through direct clinical hours, supervising counseling/clinical/or sport psychology graduate students working with student-athletes) *can include pre-doctoral work

If you are interested in participating, please fill out the attached demographics questionnaire and respond by [insert date]. Demographic data will be kept confidential (only myself and my chair will have access to the information in a password protected file). The information will only be used for descriptive statistics on education level, training/education, and number of years working with student-athletes. Please note that your status will not be affected by refusal to participate in the study or by withdrawal from the study; participation is completely voluntary and participants do not need to answer every question.

Again, your experiences would be useful and your participation would be greatly appreciated! Thank you for your time. If you have any questions, please do not hesitate to call or contact me through e-mail.

Jes Leonard, M.S.

Jes.Leonard@mail.wvu.edu (240) 298-3041
Chris Schimmel, Ed.D.

Chris.Schimmel@mail.wvu.edu

(304) 293-2266 


\section{Appendix E \\ Participant Recruitment \\ Follow-up e-mail}

Dear TWA Delphi Panel Member,

Welcome! Thank you for agreeing to participate as an expert panel member in this modified Delphi study as a requirement for my doctoral dissertation. Your practical experience, insight, and judgment are vital to the success of this study.

As an expert panelist, your will complete three rounds of the online survey. The initial round will include open-ended questions regarding student-athletes transition out of sport that you will be asked to answer, give examples when possible, and rate their frequency of occurrence. After all panelists have completed round 1, the data will be analyzed. For round 2, you will be asked to rate the importance, applicability, and potentiality for statements from the previous round and you will have the opportunity to add rationales to your ratings. Once all panelists have complete round 2, the data will be analyzed. Individual ratings, group averages, as well as anonymous rationales for rating each statement will be sent out to all participants in round 3. In the concluding round, you will be asked to rate each statement again in an attempt to achieve group consensus. Each round of the surveys should take about 20-30 minutes (maximum) to complete. Your responses in the surveys will be anonymous to all other participants (only myself and my chair will have access to any identifying information, which will be kept confidential in a password protected document). For Round 1, all data will be completely anonymous (even to me) so please feel free to answer as honest as possible.

The final date for the Round 1 survey is indicated on the accompanying e-mail. Round 2 will be sent out once all results are analyzed; therefore, your timely completion of each round is greatly appreciated. The proposed timeline is for all rounds to be completed by mid-late January.

As a result of your participation in all three rounds of surveys, expert panelists of those who work with student-athletes will generate a consensus that can be used to spur further research for assisting student-athletes and those who work with student-athletes who are beginning to transition out of collegiate sport.

Your participation in this study is completely voluntary, and refusal to participate or withdrawal will involve no penalty or loss to you. Please note that you are in no way obligated to answer every question. The primary researcher received permission to conduct this study from WVU's IRB (\#1306054453) and is being supervised by her chair, Chris Schimmel Ed.D.: Chris.Schimmel@mail.wvu.edu (304) 293-2266.

Thank you for your time and input! Please do not hesitate to call or contact me through e-mail with questions or concerns: Jes.Leonard@mail.wvu.edu (240) 298-3041.

Please follow the link in the accompanying email to begin the first round. 


\section{Appendix F \\ Participant Instructions for Round 2}

Dear TWA Delphi Panel Member,

Thank you for completing the first round! Your answers have been summarized through content analysis and each statement is ready to be rated for Round 2.

In this round, you are asked to rate statements on the importance, applicability, and potential use with regard to student-athletes transitioning out of collegiate sport (statements 1 and 2 have accompanying examples). There are a total of 24 statements that were coded from all responses in Round 1.

You also have the opportunity to add rationales to your ratings if you choose to do so. This opportunity is offered in order to emphasize your opinions regarding each rating with the hope to increase the probability of reaching a consensus while respecting differing viewpoints. The rationales will be kept anonymous to all other participants in Round 3 so please feel free to be honest in your responses.

Once everyone completes Round 2, the data will be analyzed by determining individual ratings and group averages so that you can see where your ratings fit within the group. Each participant will be sent a summary chart with his/her individual rating and group average for each question, as well as all rationales.

As always, your responses in the surveys will be anonymous to all other participants however they will NOT be anonymous to me for Round 2 in order for your individual rating to be calculated and sent to you as personalized feedback. All identifying information will be kept confidential in a password-protected document.

This round is expected to take less than 20 minutes. I know we are close to the holidays so I am keeping it open for two weeks from today (December 23); your timely completion of each round is greatly appreciated. Round 3 will be sent out following the New Year holiday.

Thank you for your time and input! I hope everyone has a restful holiday season.

Please do not hesitate to call or contact me through e-mail with questions or concerns: Jes.Leonard@mail.wvu.edu or (240) 298-3041. 


\section{Appendix G \\ Participant Instructions for Round 3}

Dear Delphi Panel Member,

Thank you for completing the second round! Your answers have been analyzed and the attached document is a summary table with feedback that includes your individual rating for each statement in addition to the group mean/standard deviation. Additional anonymous rationales for ratings from fellow panel members are given with each statement in order to include all viewpoints. Please use your summary table as a reference for your final rankings. In this final round, you are asked to rate each statement ONE more time in terms of the importance, applicability, and potentiality with regard to student-athletes transitioning out of collegiate sport. (Please note that not all statements and or rankings for each statement met the cutoff criteria for the final round - see instructions in survey and in attached document). There is an additional open-ended question at the end of the survey as well. The final round is expected to take approximately 20 - 25 minutes. Once everyone completes Round 3, the data will be analyzed to determine if any level of consensus has been achieved with regard to each statement.

The final date for the Round 2 survey will be January 20, 2013. The final analysis of the data will be sent back to all participants for individual review. At this point, there will be an opportunity for you to write any comments about the findings. Your responses in the surveys will be anonymous to all other individuals.

Thank you again for your time and input throughout the entire process! I could not have done this without you!

Please do not hesitate to call or contact me through e-mail with questions or concerns: Jes.Leonard@mail.wvu.edu (240) 298-3041 or my chair, Chris Schimmel Ed.D.:

Chris.Schimmel@mail.wvu.edu (304) 293-2266. 


\section{Appendix H}

Demographics Questionnaire

(Formatted in online survey for the study)

Name and e-mail address

Defined position in college/university

Please describe duties in current position

Highest educational degree:
Ph.D./Psy.D./Ed.D.
M.A./M.S./M.S.W
B.A./B.S.
other

Training and education in (can choose more than one):

\begin{tabular}{|c|c|c|}
\hline Counseling Psychology & Clinical Psychology & _ Sport \& Exercise Psychology \\
\hline Counseling & Social Work & Other \\
\hline
\end{tabular}

With what field(s) do you professionally identify? (can choose more than one but please rank a primary field)

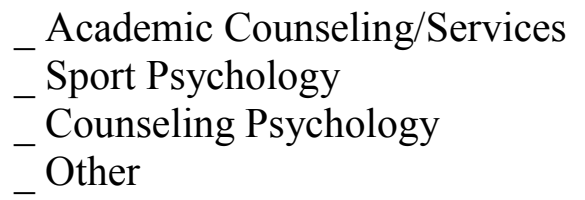

Number of years working in academic services/counseling within/for an athletic department

Number of years with direct client contact with student-athletes

*can include supervised pre-doctoral experiences

Number of years supervising sport psychology or counseling/clinical graduate students working with student-athletes

Total number of years working with collegiate student-athletes

*Please clarify responses as needed. 


\section{Appendix I \\ Round 1 Questionnaire \\ (Formatted in online survey for the study)}

Please describe how you discuss the transition out of sport with your student-athletes (including what, when, how, and with whom).

Please check how often you discuss this.
Never
Rarely
Sometimes
Often
Always

Below are different types of information that may be discussed with student-athletes. Please rank how often you discuss each topic with your student-athletes. If you do discuss that information with student-athletes, please describe how.

1. Transferable skills (skills that were used to make them successful as student-athletes that can be used to make them successful in their chosen career/non-sporting career)

Please check how often you discuss this.
Never
Rarely
Sometimes
Often
Always

If you discuss this, please describe how:

2. Task requirements of non-sporting careers (what non-sporting environments expect from workers)

Please check how often you discuss this.

Never Rarely Sometimes Often Always

If you discuss this, please describe how.

3. Post-retirement environment (non-sporting environment when the student-athlete transitions out of competitive sport)

Please check how often you discuss this.

$\begin{array}{llll}\text { Never } & \text { Rarely } & \text { Sometimes } & \text { Often }\end{array}$

If you discuss this, please describe how.

4. Personal and professional values of the student-athletes

Please check how often you discuss this.
Never
Rarely
Sometimes
Often
Always

If you discuss this, please describe how. 
5. Matching personal and professional values with the new non-sporting environment Please check how often you discuss this.

Never Rarely Sometimes Often Always

If you discuss this, please describe how. 


\section{Subsequent Round Questionnaires}

Directions:

Statements from the first round are summarized here (similar statements were grouped together). For each statement, please rate the following:

- Overall importance for collegiate student-athletes who are about to transition out of sport

- Applicability as a tool when working with collegiate student-athletes towards the end of collegiate competition

- Potential use for those working with collegiate student-athletes

If you would like, please give your rationale for your rating.

Thank you.

*Statement 1:

\section{Importance}

Not at all

Minimal

Somewhat

Mostly

Very

\section{Applicability}

Not at all

Minimal

Somewhat

Mostly

Very

Potentiality

Not at all

Minimal

Somewhat

Mostly

Very

\section{Rationale}

*Statement 2:

\section{Importance}

Not at all

Minimal

Somewhat

Mostly

Very

Applicability

Not at all

Minimal

Somewhat

Mostly

Very 


\section{Potentiality}

Not at all

Rationale
Minimal

Somewhat

Mostly

Very 


\section{Appendix J}

Demographics Statistics

\begin{tabular}{lcc}
\hline \multicolumn{1}{c}{ Category } & Response & $\%$ \\
\hline Director & 4 & 36 \\
Academic Counselor/Advisor & 3 & 27 \\
Associate Director & 2 & 18 \\
Assistant Director & 1 & 9 \\
SPC/Coach & 1 & 9 \\
Department & & 45 \\
Academic Advising (Athletics) & 5 & 36 \\
Athletic Department & 4 & 18 \\
Counseling Department & 2 & \\
Duties (more than one) & 4 & 36 \\
Supervisory Role & 3 & 27 \\
Administrative Responsibilities & 3 & 27 \\
Performance Enhancement & 3 & 18 \\
Athletic Academic Advising & 2 & 9 \\
Support Programs/Workshops & 1 & 9 \\
Sport Administrator & 1 & 9 \\
Counseling/Assessment & 1 & 9 \\
Alumni connections for student- & & \\
athletes & 1 & 27 \\
Campus communications & & 73 \\
Highest Education Degree & 3 & \\
Ph.D./Psy.D./Ed.D. & 8 & 55 \\
M.A./M.S./equivalent & & 55 \\
Training and Education (more than & & 45 \\
one) & 6 & 1 \\
Higher Education/Administration & 6 & 18 \\
Sport and Exercise Psychology & 5 & \\
Counseling Psychology & 1 & \\
Clinical Psychology & 2 & \\
Counseling & & \\
Other & &
\end{tabular}

\begin{tabular}{cccccc}
\hline Identified Field & $\begin{array}{c}\text { Primary } \\
\text { Field }\end{array}$ & $\begin{array}{c}\text { Secondary } \\
\text { Field }\end{array}$ & $\begin{array}{c}\text { Tertiary } \\
\text { Field }\end{array}$ & $\begin{array}{c}\text { Quaternary } \\
\text { Field }\end{array}$ & Total Responses \\
\hline Academic & 5 & 2 & 1 & 1 & 9 \\
$\begin{array}{c}\text { Counseling/Services } \\
\text { Sport and Exercise }\end{array}$ & 1 & 4 & 2 & 0 & 7 \\
$\begin{array}{c}\text { Psychology } \\
\text { Counseling }\end{array}$ & 3 & 1 & 1 & 1 & 6 \\
$\begin{array}{c}\text { Psychology } \\
\text { Other }\end{array}$ & 1 & 2 & 0 & 0 & 3 \\
TOTAL & 10 & 9 & 4 & 2 & - \\
\hline
\end{tabular}




\section{Appendix K}

Round 1 Descriptive Statistics

Question Stem: How often do you discuss... with student-athletes?

Transferable skills (skills that were used to make them successful as student-athletes can be used to make them successful in their chosen non-sporting career/job

\begin{tabular}{cccc}
\hline Likert number & Answer & Response & $\%$ \\
\hline 1 & Never & 0 & 0 \\
2 & Rarely & 2 & 18 \\
3 & Sometimes & 1 & 9 \\
4 & Often & 5 & 45 \\
5 & All of the time & 3 & 27 \\
\hline \multicolumn{2}{r}{ Total } & 11 & 100 \\
\hline & & Standard Deviation=1.08
\end{tabular}

Post-retirement environment (non-sporting environment when the student-athlete transitions out of collegiate sport)

\begin{tabular}{cccc}
\hline Likert number & Answer & Response & $\%$ \\
\hline 1 & Never & 0 & 0 \\
2 & Rarely & 4 & 36 \\
3 & Sometimes & 3 & 27 \\
4 & Often & 2 & 18 \\
5 & All of the time & 2 & 18 \\
\hline \multicolumn{2}{r}{ Tetal } & 11 & 100 \\
\hline
\end{tabular}

Task requirements of non-sporting careers/jobs (expectations of workers in non-sporting work environment

\begin{tabular}{cccc}
\hline Likert number & Answer & Response & $\%$ \\
\hline 1 & Never & 2 & 20 \\
2 & Rarely & 2 & 20 \\
3 & Sometimes & 6 & 60 \\
4 & Often & 0 & 0 \\
5 & All of the time & 0 & 0 \\
\hline \multicolumn{2}{r}{ Total } & 10 & 100 \\
\hline
\end{tabular}

Personal and professional values of student-athletes

\begin{tabular}{cccc}
\hline Likert number & Answer & Response & $\%$ \\
1 & Never & 0 & 0 \\
2 & Rarely & 4 & 40 \\
3 & Sometimes & 1 & 10 \\
4 & Often & 3 & 30 \\
5 & All of the time & 2 & 20 \\
\hline \multicolumn{2}{r}{ Tetal } & 10 & 100 \\
\hline
\end{tabular}


Matching personal and professional values with the new non-sporting work environment (career/job)

\begin{tabular}{cccc}
\hline Likert number & Answer & Response & $\%$ \\
\hline 1 & Never & 1 & 11 \\
2 & Rarely & 7 & 78 \\
3 & Sometimes & 0 & 0 \\
4 & Often & 0 & 0 \\
5 & All of the time & 1 & 11 \\
\hline \multicolumn{2}{r}{ Total } & 9 & 100 \\
\hline & \multicolumn{2}{c}{ Standard Deviation=1.09 } \\
\hline
\end{tabular}




\section{Appendix L}

Statements and Anonymous Rationales from Round 2

Statement 1

Discussions about the following transferable skills: leadership, discipline, motivation, communication, hard work, sacrifice, prioritizing, being accountable, overcoming obstacles, positive thinking, and preparation

Anonymous Rationales:

- Oftentimes, athletes say they have no job experience when they leave college because all of their time was spent playing sports... Helping them recognize they do have transferable skills is important. I often tell the athletes that they did work full time in college ... as an athlete.

- Many student-athletes are unable to gain related professional experience during their collegiate careers due to time limitations because of their sport. Due to this lack of practical experience, it is essential that they understand how to market themselves based on the transferrable skills they have developed through their athletic participation. These are conversations that we need to have with our student-athletes form the time they are freshman to the time when they transition out of sport.

- Many student-athletes believe that participating in a sport hinders their opportunities for transitioning to work because of the lack of time to do internships, work in a job, etc. However, it is extremely important for them to realize the things that they do every day (attend practice, be on time, balance school and athletics, be coachable, etc.) are transferable skills that many employers can view favorably in lieu of job or work experience.

- Many student-athletes recognize the importance of these skills after they leave college. Developmentally, they often do not understand this while they are competing, but do after leaving sport. It would be great if we could determine how to increase awareness during their competing years.

- We are preparing young men and women to go out into the work force after their college careers have ended. Many will not make it to the professional sports level, so they need to understand the importance of these different ideas in relation to the real working world.

Statement 2

Stressing that transferable skills that student-athletes are developing through participation in their sport because they often do not have the opportunity to gain professional experience in a summer job or internship due to the demands of their sport

Anonymous Rationales:

- Same rationale as \#1... Often times athletes say they have no job experience when they leave college because all of their time was spent playing sports... Helping them recognize they do have transferable skills is important. I often tell the athletes that they did work full time in college ... as an athlete.

- Student-athletes need to understand how they are able to market the skills they have developed through participation in athletics. Some employers understand what it means to be student-athletes but for others, they need to be told the skills that have been 
developed.

- Same as Question 1...Many student athletes believe that participating in a sport hinders their opportunities for transitioning to work because of the lack of time to do internships, work in a job, etc. However, it is extremely important for them to realize the things that they do every day (attend practice, be on time, balance school and athletics, be coach able, etc.) are transferable skills that many employers can view favorably in lieu of job or work experience.

- This question assumes that student-athletes aren't getting the benefit of internships and summer jobs, when about 50-60\% probably do get both the benefits of what athletics can teach as well as other outside experiences.

- During the daily grind, student-athletes often lose perspective of why they are competing. I find that when I stress the skills they are learning, they gain more perspective.

- Again, any way we can connect these ideas to the real working world after leaving college, it is important.

- From my experience it is extremely important, applicable, and useful to teach student athletes as many transferable skills as possible, but also even more important to spell out how the skills can be used in the real world after sport. From my experience studentathletes understand the skills will help them, but may not necessarily be ready to face some of the disappointment of losing their identity as a student-athlete. For those who struggle with the transition due to this obstacle, it is more difficult for them to transfer the skills they learned while playing.

Statement 3

Discussions about asking the student-athletes what they believe are their transferable skills and filling in the gaps of what they might have left out

Anonymous Rationales:

- Just as employers do not always understand the skills that student-athletes have gained, the students are sometimes unsure as to how the skills they have developed are transferrable. It is sometimes difficult for them to equate working with a coach can be used as an example of working with a boss or other related answers to behavioral questions.

- Depending on the student and sport, this is something that can be discussed anywhere from freshman year up until graduation. However, it is definitely important to discuss it because very few student athletes have professional sports careers which will carry them into retirement age and almost all will need to find a career to transition into, whether it is immediately after college or down the line once their professional athletic career is over.

- Great approach.

- Just the act of discussing these issues can raise awareness.

- Although very important, applicable, and useful these conversations are easier while still competing and in the student-athlete role. Once out of this role is where the conversations need to continue on.

\section{Statement 4}

Using challenging sporting experiences to discuss transferable communication skills of studentathletes and how they may apply to skills in future situations 
Anonymous Rationales:

- Very useful and important, depending on the experience. It's effective to teach that things may not always go their way and how do they respond to challenges and obstacles.

- I often tell athletes how much more prepared they will be because of their time in sport.

- Helps former student-athletes tremendously in business settings.

- Challenging situations are the best lessons for student athletes because they will often use these skills when getting started on a career path and redefining themselves.

\section{Statement 5}

Discussion about transferable skills learned from sport and how they are applied towards academics or the workplace

Anonymous Rationales:

- For many students this works, however some students have never been encouraged or motivated through academics like they have through sport, so it may be difficult for them to see the correlation.

\section{Statement 6}

Discussions about transferable skills learned from sport and how they are used in studentathletes' career exploration (e.g. job interviewing, resume building, networking etc.)

Anonymous Rationales:

- Career exploration is critical; however, student-athletes are often put in situations where they have little voice. Certain majors and careers go unexplored because of their practice schedule or not knowing how to advocate for their own interests. Often, eligibility and retention are more important than finding a career fit.

- If a student athlete has a clear view of what they want to do as a career I believe the transferable skills are useful, important, and applicable, but for the portion of studentathletes who do not have a clear view the skills may not be as helpful.

Statement 7

Discussions about transferable skills with student-athletes by an expert in the vocational field (i.e. Career Services)

Anonymous Rationales:

- Depends on the speaker. They typically should be someone who can relate to the athlete in some way, which makes their message more salient.

\section{Statement 8}

Assisting student-athletes with getting involved in activities, social groups, major clubs, etc. outside of athletics (because athletics too often become an identity and they should be wellrounded individuals with other avenues of social support) 
Anonymous Rationales:

- While athletics takes up a large percentage of a student-athletes time, it is important for them to become involved in activities outside of their sport and classroom. This can be difficult due to time constraints, but I have found that if a student-athlete is interested in becoming involved, they will find the time. Once a member of these organizations, it is also important for the individual to take an active or leadership role.

- I think this is the most important of all, however coaches sometimes hinder this by discouraging their student athletes from participating in extracurricular activities.

- I believe that athletes need to venture out of their athletic circle; however, there is very little time left to do that. I think coaches often make athletes feel bad for wanting that external life and create rules and activities that inadvertently keep them from pursuing an outside life.

- Most of the time they do this on their own without prompting from us.

- This is most important, applicable, and useful because these things can help student athletes pursue other interests outside of athletics that if not offered the opportunity they may never have been able to discover. The athlete identity is one-dimensional many times and there is not often time do develop other interests on the college level.

Statement 9

Preparations dealing with the post-retirement/non-sporting environment that include: bringing in former student-athletes as guest speakers, hosting a panel with professionals

Anonymous Rationales:

- As advisors, we can tell students what they can expect to hear time and time again but they often do not actually hear what we are saying until they hear it from a peer. I have often been told that they "wished I had told them..." when I have been preaching on that subject, they just never heard me.

- Never really thought about this part of it.

Statement 10

Discussions with student-athletes including getting used to free time and lack of structure without sports

Anonymous Rationales:

- I discuss this quite often, but student-athletes are often too engrossed in their current time pressures to even consider what they would do with free time. This varies greatly from Division I to Division II and III.

- The shocking change in lifestyle once competitive sport is over is not talked about often enough with collegiate student-athletes. This transition is difficult to deal with and may lead to poor decision making to fill the time, or numb the loss of identity.

Statement 11

DID NOT MEET CUTOFF CRITERIA FOR ROUND 3

Not discussing the topic of non-sporting environment with student-athlete until senior year or after student-athlete transitions out of collegiate or professional sport 
Statement 12

Discussions with student-athletes including professionalism (punctuality, hard-work, discipline, and professional attire, respect)

Anonymous Rationales:

- More important than many would expect.

Statement 13

Open discussions with student-athletes on career specific requirements (further schooling, licenses, etc.)

Anonymous Rationales:

- Encouraging our student-athletes to utilize the career center is important.

- Student-athletes may not be able to attend outside seminars and professional days due to games and practices, study halls, film, weights, etc. so the more that people can help them map a course the better they will plan and transition.

Statement 14

Discussions with student-athletes including comparison of sporting environment to working environment (career to practice, boss to coach, etc.)

Anonymous Rationales:

NONE

Statement 15

Encouraging hands-on work experience for student-athletes

Anonymous Rationales:

- While I encourage internships and practical experience, it is often not possible due to sport related demands.

- This is important, but again, their time is limited and therefore they do not take advantage of these opportunities.

\section{Statement 16}

DID NOT MEET CUTOFF CRITERIA FOR ROUND 3

Conducting discussions on task requirements of non-sporting environments with student-athletes if time permits or when decisions made by student-athlete could impact how future employers approach them

Statement 17

Conducting discussions with student-athletes through structured organizational activities (e.g. Life Skills/Professional Development programs, 1st year study courses, etc.) 
Anonymous Rationales:

- Life Skills courses are imperative.

Statement 18

Discussing these topics with student-athletes all throughout their academic career

Anonymous Rationales:

- Offering life skills courses throughout their career will enhance the likelihood to "catch" them when they are developmentally ready to hear the message.

Statement 19

Having academic advisors discuss personal and professional values with student-athletes

Anonymous Rationales:

- This is important in a mentor relationship; however, advisors need to be aware of when they are inadvertently providing counseling and referral is necessary

Statement 20

Discussing values with student-athletes within the framework of their decision-making process in academics and other aspects of their lives

Anonymous Rationales:

NONE

Statement 21

DID NOT MEET CUTOFF CRITERIA FOR ROUND 3

Having student-athletes create a document discussing their ethical principles and professional values

Statement 22

DID NOT MEET CUTOFF CRITERIA FOR ROUND 3

Emphasizing how to match personal and professional values with the new non-sporting work environment in conversations with student-athletes

Statement 23

DID NOT MEET CUTOFF CRITERIA FOR ROUND 3

Student-athletes finding a non-sporting work environment that they find fun, interesting, and/or proud of

Statement 24

Having an identified staff member address career-related tasks for student-athletes

Anonymous Rationales:

- Utilizing a designated staff member to address career issues is a luxury that we currently can't afford, but it was very beneficial when we had it previously.

- It should be a department wide task, not just one person. 
- This would be invaluable to have just for student athletes because they often have no direction even though they have picked a major. They also do not know all that is out there to choose from, paths they can take, etc. and designated staff member for student athletes would help with this. 


\section{Appendix M}

Round 2 and 3 Descriptive Statistics

*Bolded statements achieved group consensus by a reduction in standard deviation in Round 3

\begin{tabular}{|c|c|c|c|}
\hline & $\begin{array}{c}\text { Round } 2(11) \\
\text { Mean/SD }\end{array}$ & $\begin{array}{c}\text { Round } 3(8) \\
\text { Mean/SD }\end{array}$ & Change in SD \\
\hline \multicolumn{4}{|l|}{ Statement 1} \\
\hline Importance & $4.73 / 0.65$ & $4.63 / 0.52$ & -0.13 \\
\hline Applicability & $4.73 / 0.47$ & $4.5 / 0.53$ & +0.06 \\
\hline Potential Use & $4.45 / 0.69$ & $4.25 / 0.46$ & -0.23 \\
\hline \multicolumn{4}{|l|}{ Statement 2} \\
\hline Importance & $4.50 / 0.85$ & $4.50 / 0.76$ & -.09 \\
\hline Applicability & $4.50 / 0.85$ & $4.57 / 0.79$ & -.06 \\
\hline Potential Use & $4.50 / 0.85$ & $4.38 / 0.92$ & +.07 \\
\hline \multicolumn{4}{|l|}{ Statement 3} \\
\hline Importance & $4.64 / 0.67$ & $4.50 / 0.93$ & +0.26 \\
\hline Applicability & $4.45 / 0.93$ & $4.38 / 0.74$ & -0.19 \\
\hline Potential Use & $4.45 / 0.93$ & $4.38 / 0.74$ & -0.19 \\
\hline \multicolumn{4}{|l|}{ Statement 4} \\
\hline Importance & $4.45 / 1.04$ & 3.88/0.99 & -0.05 \\
\hline Applicability & $4.50 / 0.85$ & $3.88 / 0.99$ & +0.14 \\
\hline Potential Use & $4.64 / 0.81$ & $3.88 / 1.13$ & +0.32 \\
\hline \multicolumn{4}{|l|}{ Statement 5} \\
\hline Importance & $4.64 / 0.67$ & $4.25 / 1.04$ & +0.37 \\
\hline Applicability & $4.45 / 0.93$ & $4.00 / 1.07$ & +0.14 \\
\hline Potential Use & $4.55 / 0.69$ & $4.13 / 1.13$ & +0.44 \\
\hline \multicolumn{4}{|l|}{ Statement 6} \\
\hline Importance & $4.36 / 0.81$ & $3.88 / 1.13$ & +0.32 \\
\hline Applicability & $4.36 / 0.81$ & $3.75 / 1.16$ & +0.35 \\
\hline Potential Use & $4.27 / 0.79$ & $3.63 / .92$ & +0.13 \\
\hline \multicolumn{4}{|l|}{ Statement 7} \\
\hline Importance & $4.27 / 1.01$ & $4.00 / .93$ & -0.08 \\
\hline Applicability & $4.36 / .81$ & $3.75 / .71$ & -0.10 \\
\hline Potential Use & $4.27 / .90$ & $3.63 / .74$ & -0.16 \\
\hline \multicolumn{4}{|l|}{ Statement 8} \\
\hline Importance & $4.40 / 0.84$ & $4.25 / 0.89$ & +0.05 \\
\hline Applicability & $4.20 / 0.92$ & $3.88 / 1.13$ & +0.21 \\
\hline Potential Use & $4.27 / 1.10$ & $3.88 / 0.99$ & -0.11 \\
\hline \multicolumn{4}{|l|}{ Statement 9} \\
\hline Importance & $4.09 / 1.22$ & $4.00 / 1.31$ & +0.09 \\
\hline Applicability & \multicolumn{3}{|c|}{ DID NOT MAKE CUTOFF CRITERIA FOR ROUND 3} \\
\hline Potential Use & \multicolumn{3}{|c|}{ DID NOT MAKE CUTOFF CRITERIA FOR ROUND 3} \\
\hline \multicolumn{4}{|l|}{ Statement 10} \\
\hline Importance & \multicolumn{3}{|c|}{ DID NOT MAKE CUTOFF CRITERIA FOR ROUND 3} \\
\hline Applicability & 4.00/1.00 & $3.88 / 0.83$ & -0.17 \\
\hline Potential Use & \multicolumn{3}{|c|}{ DID NOT MAKE CUTOFF CRITERIA FOR ROUND 3} \\
\hline
\end{tabular}




\begin{tabular}{|c|c|c|c|}
\hline \multicolumn{4}{|l|}{ Statement 12} \\
\hline Importance & $4.82 / 0.60$ & $4.63 / 0.74$ & +0.14 \\
\hline Applicability & $4.82 / 0.60$ & $4.75 / 0.71$ & +0.11 \\
\hline Potential Use & $4.82 / 0.60$ & $4.50 / 0.76$ & +0.16 \\
\hline \multicolumn{4}{|l|}{ Statement 13} \\
\hline Importance & $4.64 / 0.50$ & $4.38 / 0.92$ & +0.42 \\
\hline Applicability & $4.55 / 0.69$ & $4.25 / 0.89$ & +0.20 \\
\hline Potential Use & $4.45 / 0.69$ & $4.00 / 0.93$ & +0.24 \\
\hline \multicolumn{4}{|l|}{ Statement 14} \\
\hline Importance & $4.20 / 1.03$ & $3.5 / 0.93$ & -0.10 \\
\hline Applicability & $4.20 / 1.03$ & $3.5 / 1.07$ & +0.04 \\
\hline Potential Use & 4.18/1.08 & $3.38 / 1.06$ & -0.02 \\
\hline \multicolumn{4}{|l|}{ Statement 15} \\
\hline Importance & 4.45/0.69 & $4.75 / 0.46$ & -0.23 \\
\hline Applicability & $4.40 / 0.70$ & $4.25 / 0.89$ & +0.19 \\
\hline Potential Use & $4.27 / 0.79$ & $4.25 / 0.71$ & -0.08 \\
\hline \multicolumn{4}{|l|}{ Statement 17} \\
\hline Importance & $4.18 / 0.87$ & $4.38 / 0.92$ & +0.05 \\
\hline Applicability & $4.27 / 0.90$ & $4.13 / 0.83$ & -0.07 \\
\hline Potential Use & \multicolumn{3}{|c|}{ DID NOT MAKE CUTOFF CRITERIA FOR ROUND 3} \\
\hline \multicolumn{4}{|l|}{ Statement 18} \\
\hline Importance & $4.91 / 0.30$ & $4.88 / 0.35$ & +0.05 \\
\hline Applicability & $4.91 / 0.30$ & $4.63 / 0.52$ & +0.22 \\
\hline Potential Use & $4.82 / 0.40$ & $4.63 / 0.52$ & +0.12 \\
\hline \multicolumn{4}{|l|}{ Statement 19} \\
\hline Importance & $4.70 / 0.67$ & $4.25 / 1.04$ & +0.37 \\
\hline Applicability & $4.73 / 0.65$ & $4.00 / 0.93$ & +0.28 \\
\hline Potential Use & $4.73 / 0.65$ & $3.55 / 1.13$ & +0.48 \\
\hline \multicolumn{4}{|l|}{ Statement 20} \\
\hline Importance & $4.80 / 0.42$ & $4.38 / 1.06$ & +0.64 \\
\hline Applicability & $4.70 / 0.48$ & $4.13 / 0.83$ & +0.35 \\
\hline Potential Use & $4.82 / 0.40$ & $3.75 / 1.28$ & +0.88 \\
\hline \multicolumn{4}{|l|}{ Statement 24} \\
\hline Importance & $4.36 / 0.67$ & $4.25 / 0.46$ & -0.21 \\
\hline Applicability & $4.18 / 0.75$ & $4.00 / 0.76$ & +0.01 \\
\hline Potential Use & $4.00 / 0.89$ & $4.00 / 0.76$ & -0.13 \\
\hline
\end{tabular}




\section{Appendix N}

Qualitative Analysis: Initial Statement

Please describe how you discuss the transition out collegiate sport with your student-athletes (including what, when, how, and with whom).

WHO:

All student-athletes (specifically prospective student-athletes, revenue-producing, high-profile athletes

\begin{tabular}{|c|c|c|c|}
\hline Future Vocational Skills & General Academia & Transitional Topics & $\begin{array}{c}\text { Identity } \\
\text { Development }\end{array}$ \\
\hline $\begin{array}{l}\text { Skill Development } \\
\text { (internship/work } \\
\text { experience) }\end{array}$ & $\begin{array}{c}\text { Emphasis on importance } \\
\text { of academics }\end{array}$ & $\begin{array}{c}\text { Emotional/ physical } \\
\text { changes }\end{array}$ & $\begin{array}{c}\text { Encourage } \\
\text { multidimensional } \\
\text { Identity } \\
\text { development }\end{array}$ \\
\hline $\begin{array}{c}\text { Transferable Skills } \\
\text { (time management, } \\
\text { being coachable, } \\
\text { working on a team) }\end{array}$ & Academic Advising & $\begin{array}{l}\text { Plans after } \\
\text { graduation }\end{array}$ & \\
\hline $\begin{array}{l}\text { Vocational Skills } \\
\text { (career networking, }\end{array}$ & $\begin{array}{l}\text { Graduate education } \\
\text { requirements }\end{array}$ & $\begin{array}{l}\text { "Preparing to be a } \\
\text { professional" class }\end{array}$ & \\
\hline & & $\begin{array}{l}\text { Topics specific to } \\
\text { revenue-producing } \\
\text { sports: money } \\
\text { management, } \\
\text { networking, } \\
\text { retirement from } \\
\text { professional sports }\end{array}$ & \\
\hline \multicolumn{4}{|l|}{ WHEN: } \\
\hline \multicolumn{2}{|c|}{ Time Frame } & \multicolumn{2}{|c|}{ \# Responses } \\
\hline \multicolumn{2}{|c|}{ During recruitment process } & \multicolumn{2}{|l|}{2} \\
\hline \multicolumn{2}{|c|}{ All throughout college career } & \multicolumn{2}{|l|}{3} \\
\hline \multicolumn{2}{|c|}{ By junior year } & \multicolumn{2}{|l|}{4} \\
\hline \multicolumn{2}{|c|}{ During junior/senior year } & \multicolumn{2}{|l|}{2} \\
\hline
\end{tabular}


HOW:

\begin{tabular}{cc} 
HOW: & \\
\hline Individual & Group \\
\hline Initial recruitment meeting & Team presentations \\
Academic advising appointments & Workshops \\
Weekly meetings & Structured class \\
& Guest lecturers \\
\hline
\end{tabular}




\begin{tabular}{c} 
Appendix O \\
Statements Categorized by TWA Elements: Results of Study \\
*Italicized statements marked by $(\bullet)$ are statements that achieved group consensus with IQD \\
\hline TWA Element \\
$\begin{array}{ccc}\text { Importance Applicability Potential } \\
\text { Use }\end{array}$ \\
\hline
\end{tabular}

\section{Transferable Skills:}

Discussions about the following transferable skills: leadership, discipline, motivation, communication, hard $\mathrm{X}$ X work, sacrifice, prioritizing, being accountable, discipline, overcoming obstacles, positive thinking, and preparation Stressing transferable skills that student-athletes are developing through participation in their sport (because they often do not have the opportunity to gain professional experience in a summer job or internship due to the demands of their sport)

Discussions about asking the student-athletes what they believe are their transferable skills and filling in the gaps of what they might have left out Using challenging sporting experiences to discuss transferable communication skills of student-athletes and how they may apply to skills in future situations Discussions about transferable skills with student-athletes by an expert in the vocational field (i.e. Career Services) Discussions about transferable skills learned from sport and how they are applied towards academics or the workplace

\section{Post-retirement Environment:}

Assisting student-athletes with getting involved in activities, social groups, major clubs, etc. outside of athletics (because athletics too often become an identity and they should be well- rounded individuals with other avenues of social support)

Discussions with student-athletes including getting used to free time and lack of structure without sports

\section{Task Requirements of Non-Sporting Careers:}

Discussions with student-athletes including comparison of sporting environment to working environment (career to practice, boss to coach, etc.)

Encouraging hands-on work experience for student-athletes Having an identified staff member address career-related tasks for student-athletes

$\mathrm{X}$

X

X
X

X

X

X 


\section{Personal and Professional Values:}

Discussions with athletes including professionalism (punctuality, hard work, discipline, etc.)

Discussing values with student-athletes within the

framework of their decision-making process in academics and other aspects of their lives

Timing and Setting of Discussions:

Conducting discussions with student-athletes through structured organizational activities (e.g. Life Skills/Professional Development programs, 1st year study courses, etc.)

Discussing these topics with student-athletes all throughout their academic career 